\title{
THE EFFECTS OF CONSTRUCTIVE REALISM AND ATTACHMENT ORIENTATION ON THE ADJUSTMENT OF UNIVERSITY STUDENTS
}

\author{
A thesis submitted to \\ The Faculty of Graduate Studies and Research \\ in partial fulfillment of the requirements for the degree of \\ Doctor of Philosophy \\ by \\ Ersin Asliturk \\ Department of Psychology \\ Carleton University \\ April 2009 \\ (C2009 Ersin Asliturk
}


Library and

Archives Canada

Published Heritage

Branch

395 Wellington Street

Ottawa ON K1A 0N4

Canada
Bibliothèque et

Archives Canada

Direction du

Patrimoine de l'édition

395 , rue Wellington

Ottawa ON K1A 0N4

Canada

Your file Votre référence

ISBN: 978-0-494-52056-7

Our file Notre référence

ISBN: 978-0-494-52056-7

NOTICE:

The author has granted a nonexclusive license allowing Library and Archives Canada to reproduce, publish, archive, preserve, conserve, communicate to the public by telecommunication or on the Internet, loan, distribute and sell theses worldwide, for commercial or noncommercial purposes, in microform, paper, electronic and/or any other formats.

The author retains copyright ownership and moral rights in this thesis. Neither the thesis nor substantial extracts from it may be printed or otherwise reproduced without the author's permission.
AVIS:

L'auteur a accordé une licence non exclusive permettant à la Bibliothèque et Archives Canada de reproduire, publier, archiver, sauvegarder, conserver, transmettre au public par télécommunication ou par l'Internet, prêter, distribuer et vendre des thèses partout dans le monde, à des fins commerciales ou autres, sur support microforme, papier, électronique et/ou autres formats.

L'auteur conserve la propriété du droit d'auteur et des droits moraux qui protège cette thèse. $\mathrm{Ni}$ la thèse ni des extraits substantiels de celle-ci ne doivent être imprimés ou autrement reproduits sans son autorisation.
In compliance with the Canadian

Privacy A'ct some supporting forms may have been removed from this thesis.

While these forms may be included in the document page count, their removal does not represent any loss of content from the thesis.
Conformément à la loi canadienne sur la protection de la vie privée, quelques formulaires secondaires ont été enlevés de cette thèse.

Bien que ces formulaires aient inclus dans la pagination, il n'y aura aucun contenu manquant.

\section{Canadä}




\begin{abstract}
Adaptation to stressful transitions is considered from the perspective of Kellian constructivism and attachment theory. It was hypothesized that: (a) constructive realism (i.e., thinking about both negative and positive future possibilities) should be related with better adjustment during transition to university than positively biased or negatively biased thinking; (b) secure attachment style would buffer transitional stress and change to towards attachment insecurity would be predicted by an unrealistic orientation; (c) constructive realists would use different strategies to prepare for an anticipated stressor, including setting different expectancies of success.

In Study I, first year students at Carleton University $(\mathrm{N}=143)$ filled out the Orientation to University Scale (OUS) that was administered in mass testing $(\mathrm{N}=1294)$ to test the reliability and validity. Results indicated that the OUS has a good test-retest reliability, convergent validity (regarding to the measures of optimism, defensive pessimism and proactive coping), and discriminant validity (regarding to the measures of impression management and self-deception). Study II conducted in the Winter term $(\mathrm{N}=341)$ showed that: (a) realistic orientation can be more adaptive in terms of satisfaction with university than a negatively biased orientation when unexpected adversities strike, but realistic orientation is not significantly more adaptive than a positively biased orientation; (b) decreasing levels of attachment anxiety and attachment avoidance were associated with higher levels of satisfaction with university and satisfaction with life; and (c) change towards attachment insecurity was partly predicted by a negatively biased orientation to university. Study III $(\mathrm{N}=54)$ showed that: (a) positively oriented students tended to perceive higher levels of future performance than
\end{abstract}


realists and they did not alter their perception of past performance after a difficult experimental test; (b) positively oriented students who were instructed to imagine "only success" did not significantly reduce their positive mood after the test. 


\section{Acknowledgments}

It is challenging to adequately express my debt of gratitude to Chris Davis for his help over the years to an unusual graduate student. About two years ago, I was at the edge of leaving the project of "doing a $\mathrm{PhD}$ " partly because of my nonsignificant experimental results (about the effects of existence on attachment) and problems in data gathering, partly because of my ambivalent ideas and feelings about the filed of social and personality psychology (whether it is valuable information or "impeccable triviality"), and partly because of my shifting interests in psychology (towards history, theory and criticism). Clearly, what sustained my commitment to this project was Chris' great support. I think he always meant, as Zen teachers suggest: "Matters of great concern should be considered lightly... and matters of small concern should be considered seriously". I will remember this. Thanks Chris, for everything!

I would like to mention Fran Cherry and Tim Pychyl. With Fran, I was able to learn more about "great concerns". Beyond the academic projects, she has been a valuable friend for me. With Tim, I was able to learn more about the link between the small concerns and the great ones within the context of personality psychology. I think his passionate commitment to university education is memorable. I also want to thank to AnnMarie Churchill, Kim Matheson, Patrick Gaudreau and Steven Prus for their valuable contributions to this project. AnnMarie's ideas and thesis were very valuable for me.

I should thank to my wonderful friends, my family members, to Dow's Lake Park and to Japanese judo. Last, but certainly not least, a sturdy angel fish and two red-tailed sharks, our cat Fetis, and most importantly my girlfriend Berrak made my home more than a warm place during this project. I love you all! 
Table of Contents

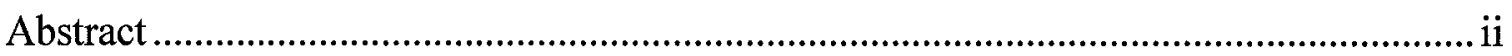

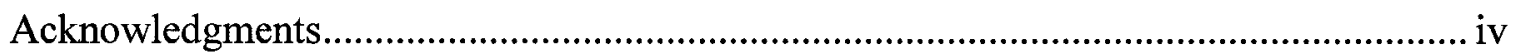

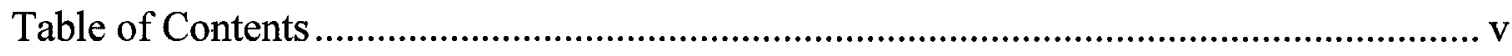

List of Figures .................................................................................................... vii

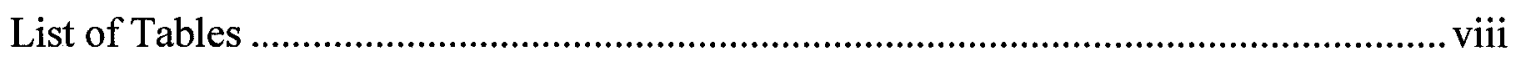

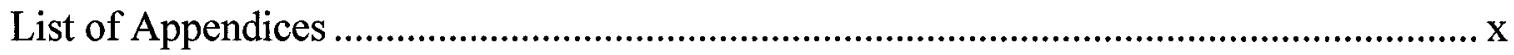

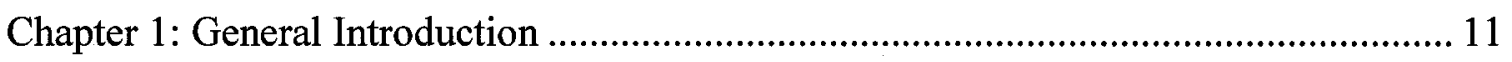

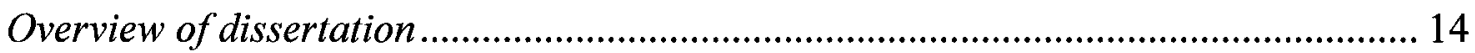

Chapter 2: Importance of Constructive Realism ...................................................... 16

Relevant research and conceptual connections.................................................... 19

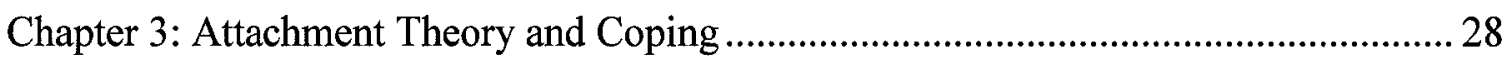

Chapter 4: Constructive Realism and Attachment Orientation....................................... 36

Chapter 5: First Year Students and Transition to University..................................... 41

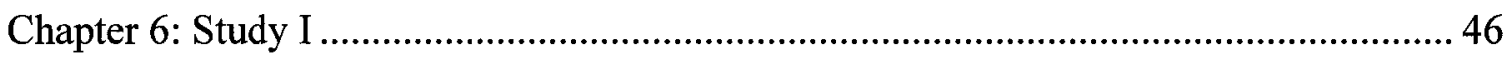

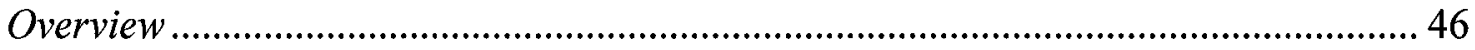

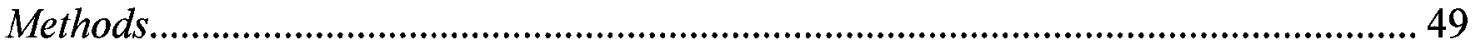

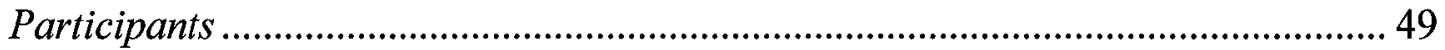

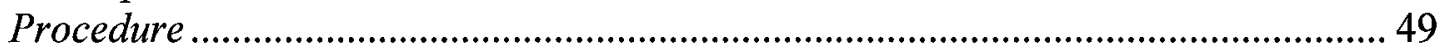

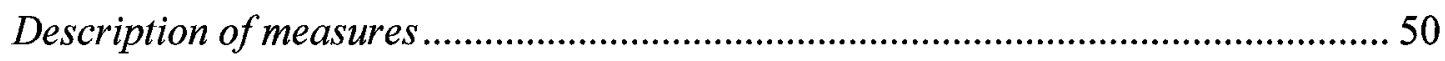

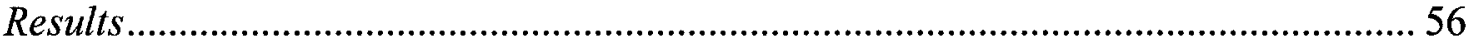

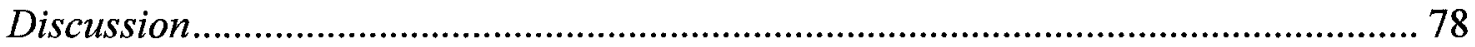

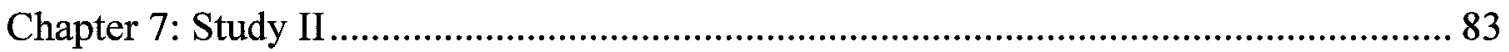

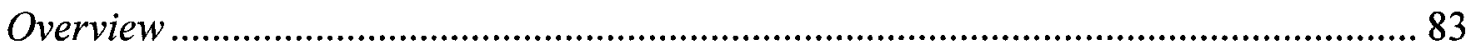

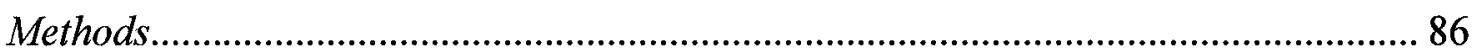

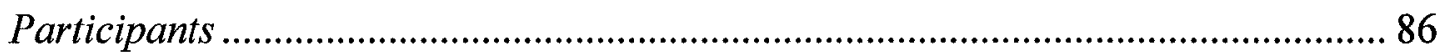

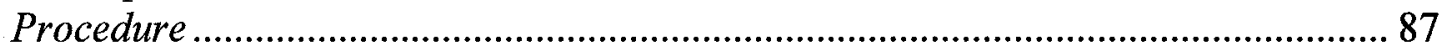

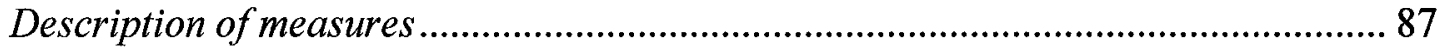

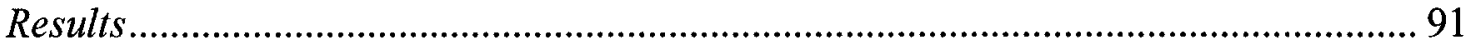


Discussion 123

Chapter 8: Study III 131

Overview 131

Method

Participants

Procedure

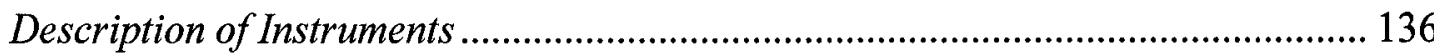

Results....

Discussion

Chapter 9: General Discussion and Conclusion.

Positively oriented students are doing well

The role of constructive realism in adjustment to university..................................... 147

The effects of attachment (in) security and the way it changes ................................... 151

Implications and directions for the future research ............................................... 153

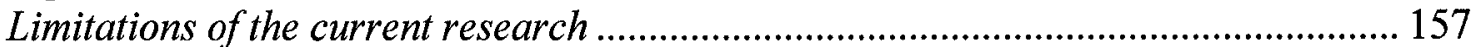

Conclusion 158

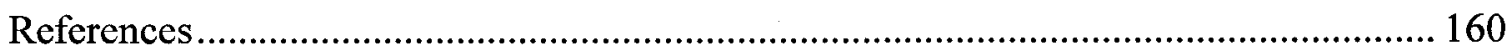




\section{List of Figures}

Figure 1. Dimensional view of attachment styles (from Fraley, 2005).

Figure 2. Impression management scores of the orientation groups

Figure 3. Self-deception scores of the orientation groups

Figure 4. Adjusted means for defensive pessimism scores of the orientation groups....... 71

Figure 5. Adjusted means for proactive coping scores of the orientation groups ........... 75

Figure 6. Adjusted means for optimism scores of the orientation groups 78

Figure 7. Satisfaction with university scores of orientation groups at low versus high

$$
\text { level of difficulty. }
$$

Figure 8. Adjusted Satisfaction with university scores of orientation groups with or without extra difficulty, after controlling for the effects of perceived social support

Figure 9. Adjusted Satisfaction with life scores of orientation groups. 107

Figure 10. Change in attachment-avoidance from Time1 to Time2

Figure 11. Change in attachment-anxiety from Time1 to Time2

Figure 12. Adjusted satisfaction with university scores of orientation groups 121

Figure 13. Estimated performance just before and just after the test.

Figure 14. Pretest and Posttest mood levels of realists and positively oriented students in success and success-fail conditions 142 


\section{List of Tables}

Table 1. Factor structure and items loadings of the OUS 52

Table 2. Cross-tabulation of orientation groups from Time1 to Time2..... 59

Table 3. Correlations

Table 4. The effect of positive and negative thoughts, and their interaction, on

impression management scores.

Table 5. The effect of positive and negative thoughts, and their interaction, on self-

deception scores.

Table 6. The effect of positive and negative thoughts, and their interaction, on defensive pessimism scores. 70

Table 7. The effect of positive and negative thoughts, and their interaction, on pro-active coping scores. 74

Table 8. The effect of positive and negative thoughts, and their interaction, on optimism scores

Table 9. The effects of difficulty ratings, positive thoughts and negative thoughts on satisfaction with university 96

Table 10. The effects of extra difficulties, positive thoughts and negative thoughts on satisfaction with university after controlling for the effects of perceived social support 100 Table 11. The effects of attachment variables on satisfaction with university scores .... 109 Table 12. The effects of attachment variables on satisfaction with life scores.

Table 13. Means and standard deviations of future orientation groups on attachment variables at Time 1

Table 14. Within-subjects effects on attachment variables by thinking variables 
Table 15. Between subjects effects on attachment variables by thinking variables

Table 16. The effects of positive and negative thinking on satisfaction with university

after controlling the effects of attachment variables

Table 17. Within subjects effects on estimated performance scores.

Table 18. Between subjects effects on estimated performance scores........

Table 19. Within subjects effects on mood scores (PA-NA)

Table 20. Between subjects effects on mood scores (PA-NA)

Table 21. Correlations. 


\section{List of Appendices}

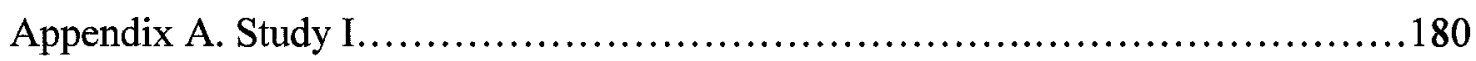

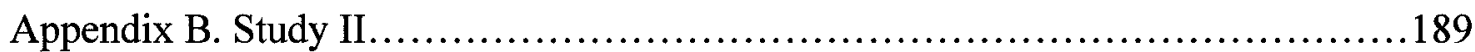

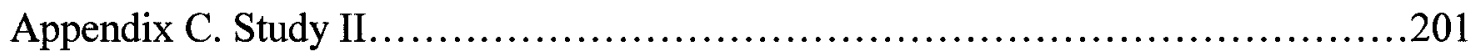




\section{Chapter 1: General Introduction}

This dissertation focuses on the adaptive value of constructive realism and having secure relationships during a significant life transition. Coming from a constructivist perspective, recent research on coping in life transitions suggests that having a balanced view of future events, such as acknowledging or thinking about both positive and negative possibilities, can be more adaptive than possessing a predominantly positive or negative view of future (Churchill, 2005). Representing a modern psychodynamic perspective, on the other hand, research on attachment theory indicates that a secure attachment orientation (i.e., low level of attachment-anxiety and attachment-avoidance) plays a buffering role during challenging life transitions (e.g., Mikulincer \& Florian, 1998; Mikulincer, Shaver \& Pereg, 2003). This dissertation is an investigation of the extent to which and the ways in which these two perspectives predict well-being and adjustment on the specific ground of the transition to university. More specifically, this dissertation will test the adaptive value of realistic thinking (i.e., balanced view of future events) and attachment security, and the interplay between these two.

In the past twenty years, a number of social and personality psychologists have promoted the idea that being optimistic about the self and future has health benefits for individuals (e.g., Aspinwall \& Taylor, 1992; Taylor \& Brown; 1994; Scheier, Carver, \& Bridges, 2001). Indeed, the adaptiveness of optimism and positive emotions have been well-supported with empirical evidence (e.g., Scheier, Carver, \& Bridges, 2001; Taylor \& Brown, 1988, 1994). A number of scholars, however, have taken issue with this position, arguing that unrealistic optimism or positively biased thinking might not be as adaptive during stressful life transitions as was previously suggested (Churchill, 2005; Colvin \& 
Block, 1994; Norem \& Chang, 2002; Oettingen \& Mayer, 2002; Peterson, 2000;

Scheneider, 2001). Pancer and colleagues (2000), for example, demonstrated that integratively complex thoughts can be adaptive when there is high level of perceived stress. Similarly, Ann Marie Churchill (2005) argued that psychologically constructing an adaptive view of social world necessarily requires one to think about the potential for both joy and tragedy in life. Those who give significant consideration to the possibility of both positive and negative outcomes are referred to as constructive realists, and some preliminary research suggests that they tend to cope well during stressful events (Churchill, 2005).

If one's view of future events is positively biased or cognitively simple, then one is apt to be unprepared and shocked should events not unfold as anticipated. On the other hand, to the extent that one possesses a broad set of constructs that incorporate the possibility of a variety of outcomes, then one ought to be better prepared should one experience a less than desired outcome. When faced with adversity, whereas optimistically or positively biased individuals might feel shocked, realistic individuals who have given sufficient thought to negative possible outcomes may be better prepared when these outcomes occur, and thus be more resilient.

This constructivist view of coping, however, is not the only perspective in social and personality psychology explaining why some people are overwhelmed during stressful life transition whereas others are not. Attachment theory, particularly, states that successful coping with stressful life events is influenced by the sense of security felt in one's close relationships. Coming from an evolutionary and psychodynamic perspective, attachment theorists argue that feeling a sense of security in the early stages of life (and 
in current close relationships) are critically important factors for understanding how people respond to stress (for reviews, Mikulincer \& Shaver, 2003, 2007; Shaver \& Mikulincer, 2005). The theory suggests that secure individuals (relative to those who are insecurely attached) tend to cope adaptively with stressful life transitions as they can more easily activate their psychological and social resources during stressful transitions, such as a positive sense of self, efficient social skills and supportive primary relationships.

The thesis examines coping with the transition to university from these two different frameworks. I examine the extent to which both perspectives predict successful coping with this stressful transition. I argue that both a realistic orientation to future and secure orientation in attachment relationships can buffer the stress during challenging transitions. I also argue from a constructivist perspective that attachment style is constructed in one's life history and it should be open to deconstruction or reconstruction during various attachment-relevant transitions. Although attachment theory has assumed that attachment style tends to be stable over life time, the relevant research indicates that the meaning and perceived quality of one's relationships can change during stressful transitions (e.g., Cozzarelli, Karafa, Collins \& Tagler, 2003; Davila, Burge \& Hammen, 1997; Davila \& Cobb, 2003). It is a question whether these changes can be explained and predicted by a realistic or unrealistic orientation to future, or more generally, from the perspective of a constructivist theory of stress and coping (e.g., Butt \& Parton, 2005; Gillies \& Neimeyer, 2006; Neimeyer \& Baldwin, 2003; Sewell, 2003). Hence, in this dissertation, I will explore the predictive power of two different theories and their interplay. 
This dissertation is important for two main reasons. First, although there has been some concern and criticism about the maladaptive nature of unrealistic optimism when the desired outcomes are not attained or difficulties occur, little evidence has been found for this "dilemma of unrealistic optimism" (Armor \& Taylor, 2002). Although some studies published recently help resolve this dilemma (Benyamini, 2005; Chang \& Sanna, 2003; Myers \& Steed, 1999), none of them are theoretically grounded. My approach to solve the dilemma of unrealistic optimism is based on a constructivist point of view. This dissertation is an attempt to further develop and provide evidence for this interpretation of the problem of unrealistic optimism. Second, although there is a large body of literature on adaptiveness of a secure attachment style in stressful conditions, there remains a question about how attachment-related processes interact with or are changed by one's future-related thought processes. Hence, contrasting and comparing the effects of anticipatory thoughts and attachment orientation on well-being might be fruitful for further theoretical developments to understand coping with stress during significant life transitions.

\section{Overview of dissertation}

This general introduction continues with an overview of research on realistic orientation with a particular reference to literature on optimism, pessimism and coping. Following the section on constructive realism, a summary of attachment theory and its relation to life transitions will be provided. Then, the conceptual connections between realistic orientation and attachment security will be reviewed. Finally, the literature on 
transition to university will be reviewed to show why first year university students represent an appropriate population to test the hypotheses of the research.

Following the introduction, I will present findings of an initial study designed to develop and validate a measure of realistic orientation to university. The relationship of realistic orientation to similar constructs such as optimism, pessimism and pro-active coping will be summarized. Following Study I, Study II will show how realistic orientation and attachment orientation are adaptive in the context of the transition to university. Study II will also examine how attachment orientation changes as a function of orientation to university. In Study III, I will present the results of an experiment designed to compare the effects of realistic orientation (i.e., balanced thinking) and optimistic orientation (i.e., positively biased thinking) on a particular stressor in a controlled setting. Following the empirical studies, a general discussion will follow with a particular emphasis on the adaptive value of realism and attachment security in life transitions. Finally limitations of the current studies and directions for future research are considered. 


\section{Chapter 2: Importance of Constructive Realism}

The concept of constructive realism in this dissertation refers to a balanced view of future events in the sense that one acknowledges or anticipates both positive and negative future possibilities (Churchill, 2005). People who are constructive realists have a tendency to think about both the potential benefits and risks of upcoming challenges in a balanced way. Drawing from Kelly's Personal Construct Theory (1955/1991), Churchill (2005) argued that this balanced way of thinking about anticipated stressful situations facilitates the accommodation of undesired experiences into one's personal understanding of the social world (i.e., one's personal construct system). From this constructivist perspective, the term "constructive" refers to the process of building up mental representations of the social environment. The process of constructing a social world is based on one's past experiences, but one's personal constructions can not perfectly reflect reality or predict future events. Therefore, "realism" is not about the representation of the world "as it really is," or "as it is going to be", rather it is used to refer to the potential for positive and negative experiences in specific contexts. This acknowledgment may help individuals to adaptively function during stressful times.

Personal constructs are bipolar dimensions (e.g., good-bad) by which people identify similarities and differences between events or make sense of their social world. Kelly (1955/1991) argued that humans have anticipations based on certain constructions of reality or personal constructs. For example, when a first year university student thinks about university life, initially she or he might think that the courses will be exciting (rather than boring); readings and assignments will be manageable (rather than difficult); there will be a lot friends and parties (rather than loneliness); and she/he will be really 
independent (rather than bounded with new regulations and responsibilities in life). The reality can be different and these biased thoughts can cause disappointment. According to a Kellian framework, people use personal constructs and they evaluate the elements in life (e.g., courses, friends and cars) according to these bipolar dimensions. The way a person constructs the social world, according to Kelly, gives a shape to her/his anticipations of future and these anticipations have an impact on her/his psychological reactions to future events. In his book, The Psychology of Personal Constructs, Kelly argued, as his the fundamental postulate, that "a person's processes are psychologically channelised by the way in which he anticipates events" (1955/1991, p. 32). Hence, the disappointment of this student is associated with the way she or he constructs the experience of being a first year university student. Similarly, a first-time expectant mother might think that her baby will be healthy, easy-to-care, and motherhood will feel wonderful. However, the baby can be difficult and motherhood can be very exhausting. Psychological reactions of this mother can be predicted by her biased and relatively simple anticipations (Churchill, 2005).

Many social and personality psychologists following George Kelly have argued that individuals function like "intuitive scientist". Just like scientists who have hypotheses based on theories, people have anticipations based on their constructs. They interpret their experience through the lens of their constructs. When overwhelming disconfirming evidence is presented, people may be forced to change their theories or constructs. These changes in one's constructs, however, can sometimes be costly emotionally and psychologically. 
Constructivist psychologists emphasize the importance of acknowledging negative future possibilities (Butt \& Parton, 2005; Neimeyer \& Baldwin, 2003; Sewell, 2003). Developing a constructivist model of trauma, Sewell (2003) named the inability to make sense of a traumatic experience (and inability to assimilate it into one's perceptual system) as constructive bankruptcy. According to Sewell, those individuals who do not give thought to the possibility of experiencing trauma in life may have to go through an emotionally painful period of destruction and deconstruction of their meaning system. Similarly, Klion and Pfenninger (1997) referred to the anticipatory failures of people who constructed a narrow or biased understanding of the social world. According to Klion and Pfenninger, faced with invalidating experiences, people may have to revise their perceptual system.

According to constructivist researchers, what makes an experience challenging or stressful is not only the direct effects or the objective characteristics of the events but also the subjective construction (or meaning) of these events. Constructivism emphasizes the personal meaning system as the main psychological response unit. When one's anticipations (based one's interpretations of social reality) do not help to make sense of the adversity, psychological disturbance is likely to appear (see e.g., Gillies \& Neimeyer, 2006). Although this might suggest that adverse experiences can only be understood from a subject-centered, idiographic approach, I would argue that the subjective aspect of these experiences can be quantified and therefore studied nomothetically. Because there are shared characteristics of stressful transitions and common anticipations among individuals, it is possible to compare one's anticipations against one's subsequent experiences. 


\section{Relevant research and conceptual connections}

The concept of constructive realism shares some similarity with the concepts of proactive coping, and constructive thinking. It is also conceptually related to optimism, pessimism, strategic optimism, defensive pessimism and positive and negative fantasies. Below I summarize similarities and differences between these concepts and constructive realism, and also their implications for a constructive approach to realism.

Aspinwall and Taylor (1997) conceptualize proactive coping as "efforts undertaken in advance of a potentially stressful event to prevent it or to modify its form before it occurs" (p. 417). There are important benefits to paying attention and recognizing potential stressors, such as actively preparing oneself for potential adversities. Using an internet-based survey, Aspinwall, Sechrist, and Jones (2005) showed that proactive coping was associated with greater worry and dispositional optimism, and greater efforts to acquire required information about the $\mathrm{Y} 2 \mathrm{~K}$, a computer bug that was thought to cause major problems as the year changed from 1999 to 2000 . Aspinwall et.al reported that proactive coping was positively related with precautious attitudes to minimize the impact of $\mathrm{Y} 2 \mathrm{~K}$ and negatively related with accommodative coping ("going with the flow" and accepting what might happen, see also Aspinwall, 2005 for a discussion). Individuals with a proactive coping style tend to engage in efforts to remove the potential future obstacles to reach their goals, build up their personal resources continuously, and tend to report personal growth (Schwarzer \& Taubert, 2002). Since thinking proactively requires one to carefully consider and plan for the possibility of undesired outcomes (i.e., prepare for the worst) while maintaining general optimistic 
expectations (i.e., expecting the best), it is reasonable to assume that constructive realists tend to be pro-active copers. Although available data do not yet indicate who is inclined to cope proactively, constructive realists may be more likely than others to be proactive copers.

Constructive thinking, as developed by Epstein and Meier (1989), refers to a broad coping variable. Constructive thinkers tend to successfully manage the problematic situations by actively attempting to remove the source of distress, they tend to alter their thinking in stressful situations, manage negative emotions successfully and act more efficiently than non-constructive thinkers. Epstein and Meier (1989) argue that constructive thinking is directly related to the intelligence of the experiential self, the self that is emotionally driven, automatic, preconscious and relatively stable, rather than the cognitive self that is logically driven, rational, conscious and rapidly changeable (see Epstein, 2003 for cognitive-experiential self-theory). The automatic emotional processes of constructive thinkers are thought to help them solve everyday problems with minimum cost and stress. Constructive thinkers tend to have successful work, love and social relationships and they report lower levels of psychological and physiological symptoms (Epstein \& Meier, 1989). It is argued that constructive thinkers are better able to revise their perceptual system to better adapt in various situations, and thus they can act more effectively with more positive emotions than non-constructive thinkers (Park, Moore, Turner \& Adler, 1997). Mikulincer, Shaver and Pereg (2003) argued that constructive thinking is the primary coping disposition of secure individuals (i.e., low level of attachment anxiety and attachment avoidance). Unlike constructive thinking, constructive realism refers to the conscious thought processes of the cognitive self, rather than 
experiential self; and constructive realism is specific to a particular context of future transition, rather than representing a general coping orientation in everyday life. Hence, our notion of constructive realism is more open to changes after significant life transitions than is Epstein's concept of constructive thinking.

Constructive realism might also be discussed with reference to the concepts of optimism-pessimism. Optimism is defined as a general tendency to expect that good things will happen in the future, and pessimism as the opposite (Scheier, Carver \& Bridges, 2001). Since optimism is defined as the "expectancies that pertain more or less to the individual's entire life space" (Scheier, Carver \& Bridges, 2001, p. 190), it is different than constructive realism in some ways. Unlike the trait concept of optimismpessimism, the concept of constructive realism is, first, open to change. Someone who has a positively biased view of a specific future transition, for example, can learn to think more realistically through acknowledging both negative and positive possibilities. Second, unlike dispositional optimism, our notion of realistic orientation is a contextspecific concept. Third, whereas optimism and pessimism are considered opposite ends of a single continuum, we think of positive and negative thoughts as orthogonal dimensions. Finally, the concept of optimism-pessimism is centered on outcome expectancies, whereas the concept of constructive realism is centered on consideration of possible future events. Although positive and negative thoughts might contribute to expectancies, frequently thinking about a positive or negative outcome does not imply that one necessarily expects that outcome to occur.

The concept of optimism has attracted considerable attention in positive psychology and health psychology, and positive effects of dispositional optimism on 
psychological well-being are well-known (Scheier, Carver, \& Bridges, 2001). In healthrelated contexts, for example, optimism is related with lower levels of postpartum depression and anxiety in women after the birth (Fontaine, \& Jones, 1997), better postabortion adjustment (Cozzarelli, 1993); greater subjective well-being after coronary heart surgery (Fitzgerald, Tennen, Affleck, \& Pransky, 1993), and cancer diagnosis (Carver et al., 1993), lower psychological distress among HIV positive and HIV negative gay and bisexual men (Taylor et al., 1992); and greater subjective well-being among caregivers of people with various diseases (Given et al., 1993; for a review see Scheier, Carver, Bridges, 2001).

It has also been shown in other contexts that higher levels of optimism among new college students at the beginning the semester predict better adjustment (Aspinwall \& Taylor, 1992). Scheier and Carver (1992) similarly found that optimism among first year college students is related with less stress, depression and loneliness at the end of the semester. Raikonen, Matthews, Flory, Owens and Gump (1999) found that optimism among middle aged adults is significantly related with lower negative mood, higher positive mood and lower level of perceived stressfulness of the negative events. Taylor and Brown (1994) note that optimism is positively correlated with feeling better, satisfactory relationships, higher level of motivation, and use of successful coping skills with and recovery from certain illnesses. These are a few of the studies focusing on optimism in different contexts.

Although a number of studies confirmed the connection between optimism and positive life outcomes, some other studies challenged this view. In the context of HIV infection, for example, Goodman, Chesney and Tipton (1995) showed that optimistic 
adolescents were less likely to seek information about HIV-testing and were less likely to go through the test than those who were dispositionally pessimistic. Perkins, Leserman, Murphy and Evans (1993) found that optimism among gay men was related with highrisk sexual behaviour. In another study with high school students, it was found that pessimism among adolescents about the risk of acquiring AIDS (i.e., perceiving high risk) was related with greater intention to change risky sexual behaviour (Gladis, Michela, Walter, \& Vaughan, 1992).

Tennen and Affleck (1987) argued that dispositional optimism might be very maladaptive when bad things happen, especially when optimism is combined with low sense of control (see also Norem \& Chang, 2001). Similarly, Chang and Sanna (2003) found a notable interaction, indicating that while a low level of accumulated life stress over the course of a year is associated with better physical and psychological well-being among optimists (relative to pessimists), higher level of accumulated life stress has more negative effects on optimists than pessimists. These studies suggest that optimism might have a downside.

Another line of research suggests that there are contextual (i.e., intrapersonal, interpersonal and cultural) meanings and specific definitions of optimism and pessimism. Julie Norem and her colleagues conceptualized and differentiated adaptive cognitive strategies of defensive pessimists from strategic optimists (Norem \& Cantor, 1986; Norem \& Chang, 2002). Defensive pessimists set unrealistically low expectations but use this fear of doing poorly as a motivation for pursuing their goals, and tend to perform as well as strategic optimists. Strategic optimists, on the other hand, set high expectations and avoid extensive reflection. In terms of cultural differences in optimism and 
pessimism, Chang (1996) showed that, for example, Asian-American college students are prone to be more pessimistic than Caucasian-American students. Since the adaptive nature of social selves is differently constructed across cultures, meanings associated with optimism and pessimism may also differ across cultures.

In another context, it was found that optimism and pessimism are correlated to a lesser extent in older adults than in young people (e.g., Mroczek, Spiro, Aldwin, Ozer, \& Bosse, 1993), suggesting that aging may be a factor in the construction of a balanced view of life. This research suggests that the structure of the construct may change with age. Whereas optimism and pessimism strongly negatively correlated among young people, they were less correlated among older people, suggesting that older adults can be both optimistic and pessimistic at the same time. These findings indicate that optimism and pessimism are complex and different constructs having different functions in different contexts (Norem \& Chang, 2001). A number of studies also confirmed the idea that optimism and pessimism do not represent end points of a single continuum and they can predict different health outcomes (e.g., Benyamini, 2005; Chang, Maydeau-Olivares, \& D'Zurilla, 1997; Marshall, Wortman, Kusulas, Hervig \& Vickers, 1992; RobinsonWhelen, Kim, MacCallum \& Kiecolt-Glaser; 1997).

Hence, this literature review suggests that there might be both advantages and disadvantages of optimistic and pessimistic thoughts and feelings. Positive effects of positive emotions and reflection, and negative effects of ruminative thinking are well reported (e.g., Frederickson, 2001; Nolen-Hoeksema, Parker, \& Larson, 1994; Trapnell \& Campbell, 1999). However, there is also an argument for the positive function of negative fantasies and negative function of positive fantasies. In an analysis of the effects of one's 
fantasies (i.e., one's thoughts and mental images of future) on effort and success, Oettingen and Mayer (2002) found that positive fantasies predicted less effort and low success among undergraduates anticipating an exam and graduates looking for a job relative to negative fantasies. Because positive fantasies can seduce a person to enjoy the present moment, they yield lower motivation to actively construct the desired future. On the other hand, Oettingen and Mayer argue,

Negative fantasies about a desired future depict potential problems and setbacks related to an improved future. Though negative in tone, they should fail to be linked to depression and passivity, because they pertain to a constructive road to a better future. These negative fantasies about a desired future, then, seem to have the reverse effects than ruminative thoughts about one's present depressive mood. (Oettingen \& Mayer, 2002, p.1210, emphasis added).

Hence, negative fantasies can orient people to the necessities of the here and now to get ready for the anticipated future. Although Oettingen and Mayer (2002) reported very high negative correlations between negative and positive fantasies and combined them into one index, their research highlights the importance of the quality and frequency of one's thinking and imagination.

Recently, Churchill (2005) found evidence for the orthogonal nature of positive and negative thinking, and showed that constructive realism, defined as a balanced view of both positive and negative future possibilities, can predict well-being over and above optimism-pessimism. In her study, women expecting their first baby were interviewed before and after birth. Whereas those who pre-partum thought predominantly about positive possibilities adjusted most successfully to the birth when the birth was as 
expected, they did not adjust well when the birth was not as expected. Realists, on the other hand, adjusted more successfully when the birth was more difficult. Therefore, it can be argued that a more balanced view of future possibilities might lead one to prepare for future events cognitively by reflecting on them and constructively by engaging in suitable efforts. In this sense, constructive realism may prepare the person for negative surprises and may prevent excessive cognitive and affective load when one confronts adversities. Within the context of the transition to university, I argue that a balanced, realistic construction of what university life will be like can be beneficial among freshman students for later adaptation.

At this point, an important question coming to mind is about the sources of realistic life orientation. It may be argued that temperament and socialization in a familial and cultural atmosphere are the main determinants of constructive realism, as is believed to be the case for optimism and pessimism (e.g., Chang, 2001; Zuckerman, 2001). If one's personal meaning system is constructed throughout one's life, then one's orientation to future should be largely influenced by one's personal life history. More particularly and according to attachment theory, one's early interactions with close others in life are strong determinants of one's meaning system, mental models and psychological mechanisms.

There is some evidence that, for example, people who are pessimistic tend to have more negative memories of childhood relationships and dysfunctional adult relationships than do optimists (Heinonen, Räikkönen, Keltikangas-Järvinen, \& Strandberg, 2004). I argue, based on the assumptions of attachment theory and research, that constructive realism should be associated with a positive sense of self and others, which signify a 
secure orientation in life and a valuable personal source in adaptation to stressful transitions. In the next section, I will review attachment theory and its relevance to adaptation and transition to university. 


\section{Chapter 3: Attachment Theory and Coping}

Attachment theory was developed by British psychoanalyst John Bowlby $(1969 / 1971,1973,1980)$ as a theory of personality development. He argued that attachment is a biological bond between two organisms and serves a survival function in evolutionary terms. Bowlby (1969/1971) observed that human infants are born with an innate psychobiological system (the attachment behavioural system) which facilitates a repertoire of behaviours, such as clinging and crying, designed to attract their caregivers (attachment figures). He argued that such behaviour is indicative of the organismic roots of the survival bond in human and other species (Bowlby, 1969/1971). The set-goal of the attachment system is the attainment of actual or perceived protection and security. Reaching this goal terminates the activation of the system and a sense of felt security emerges. According to Bowlby, the availability, responsiveness, sensitivity, and supportiveness of the attachment figures, and the quality of time spent together, are important preconditions for the formation of a sense of attachment security. To the extent that attachment figures are available and sensitive, this infant will come to perceive that the world is generally a safe place, trustable others are available when needed, and the self is valuable and has psychological and social resources to deal with stress (Bowlby, 1973, 1988). This positive sense of others and self facilitate the free exploration of the environment and non-attachment behaviours.

When the attachment figure is not physically or emotionally available or is not responsive and sensitive to the infant's proximity seeking cues, the set-goal of the attachment system is not attained. In this case, where the primary attachment strategy fails to alleviate the distress, infants use secondary attachment strategies, such as 
hyperactivation and deactivation of the attachment system (Bowlby, 1973, see also Mikulincer \& Shaver, 2003). Hyperactivation refers to compulsively intensifying proximity-seeking attempts to elicit care and support from the attachment figure. Deactivation refers to inhibition of proximity-seeking inclinations and suppressing the ideas about the potential threat or discomfort. According to theory, the attachment system remains active over the life course and these interactions have long-term effects on personality development though the development of attachment working models (Bowlby, 1973). These mental models are developed and stored in the memory system through the countless interactions with the attachment figure. Hence, developing within the first months of life, it is claimed that attachment plays a crucial role in the construction of cognitive schemas, mental representations or internal working models about the responsive value of others and the self as worthy of love and care (Bowlby 1969/1971). The persistent patterns of interaction with attachment figures lead to the development of the representative, chronically accessible, and solidified working models.

The most chronically accessible working model of a person, based on a particular pattern of relational expectations, behaviours and emotions, is called attachment style. Ainsworth and her colleagues observed three different attachment styles in children, which they labelled as secure attachment, anxious-ambivalent and anxious-avoidant attachment styles (Ainsworth, Blehar, Waters \& Wall, 1978). Hazan and Shaver (1987) used the same categories to describe attachment styles in adolescents and adults.

Later analyses indicated that a dimensional view of attachment orientations is more appropriate and these orientations are better explained within the two dimensions of attachment avoidance and attachment anxiety (Bartholomew \& Horowitz, 1991; 
Brennan, Clark \& Shaver, 1998). Attachment avoidance is described as insecurity with respect to the intentions of the others, maintenance of emotional distance from others, a tendency towards deactivation of attachment system, compulsive self-reliance, denying attachment needs, suppressing unpleasant thoughts and emotions and inhibiting any display of stress. The attachment anxiety dimension refers to perception of selfworthiness. People scoring high on this dimension tend to exhibit a strong desire for intimacy, hyperactivation of attachment system through minimizing distance from attachment targets, high level of fear of rejection, jealousy and inappropriate selfdisclosures. A combination of attachment anxiety (internal working model of self) and attachment avoidance (internal working model of others) dimensions yield four attachment styles: secure, preoccupied, dismissing-avoidant, and fearful-avoidant (see figure 1). It should be added here that one of the main differences between the tripartite conceptualization of attachment styles (Hazan \& Shaver, 1987) and the dimensional view (Brennan, Clark \& Shaver, 1998) is splitting anxious-avoidant style into dismissingavoidant and fearful-avoidant attachment styles. 


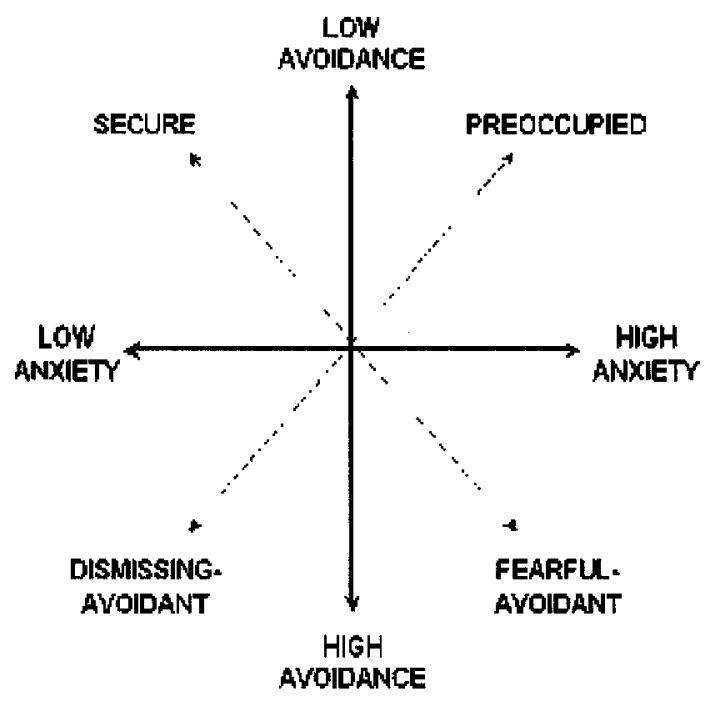

Figure 1. Dimensional view of attachment styles (from Fraley, 2005).

Recently, the issue of how stable attachment styles are over time has become an important concern. In the original attachment theory, it was generally accepted that "attachment representations are postulated to tend more toward assimilating, rather than accommodating to, later experiences" (Zhang \& Labouvie-Vief, 2004, p. 420). Although there is still a certain emphasis on the stability and continuity of attachment styles (e.g., Pietromonaco \& Barett, 2000), there is also considerable empirical evidence that the attachment styles are malleable to a certain extent (e.g., Collins \& Read, 1994; Cozzarelli, Karafa, Collins \& Tagler, 2003; Davila \& Cobb, 2003; Davila \& Sargent, 2003; Fraley, Waller \& Brennan, 2000; Zhang \& Labouvie-Vief, 2004).

Recent research shows that attachment styles may be altered by stable vulnerability factors (e.g., personality disturbance; Davila, Burge \& Hammen, 1997), negative events (e.g., parental divorce; Waters, Hamilton \& Weinfield, 2000), and relationship related 
life events (e.g., major conflicts; Cozzarelli et al., 2003). Although significant interpersonal life events may be associated with change in attachment style, it is important to note that the subjective construal of these events is critical. For example, in an 8-week daily diary study, Davila and Sargent (2003) showed that daily changes in felt attachment (i.e., change in the sense of attachment security) are associated with the subjective meanings that people assign to significant interpersonal life events, such as perception of interpersonal loss.

In general, insecure attachment styles (i.e., tendency to have anxiety with self and/or avoidance from others) are associated with maladaptive coping skills and difficulties in affect regulation (Lopez et. al 2001). On the other hand, a secure attachment style is positively correlated with a set of psychological variables such as sociability, capacity for status, dominance, social presence, self-acceptance, independence, good impression, communality, well-being, achievement and positive family climate (Diehl, Elnick, Bourbeau, Labouvie-Vief, 1998). Similar results were found in the contexts of personal traumas such as divorce (Birnbaum, Orr, Mikulincer \& Florian, 1997), abortion (Cozzarelli, Sumer, \& Major, 1998), and in extremely life-threatening contexts (Mikulincer, Horesh, Eilati \& Kotler, 1999). It is argued that positive stress management beliefs of secure individuals allow them "to open their cognitive structures to new, even threatening information, and then to flexibly adjust their strategies for dealing realistically with environmental demands" (Mikulincer \& Shaver, 2003, p. 79). These studies suggest that a secure attachment style is a valuable personal adaptation resource to buffer the anxiety aroused in stressful situations and facilitates a return to functioning in life (see Mikulincer \& Florian, 1998; Mikulincer, Shaver \& Pereg, 2003, for reviews). 
Attachment theory has been tested in various domains of life, including the context of academic adjustment and transition to university. Several studies reported a positive association between attachment security and academic achievement. For example, it was found that higher levels of attachment anxiety or avoidance are associated with difficulties in concentrating on academic tasks and maintaining attention (Aspelmeier \& Kerns, 2003), and associated with lower levels of self-efficacy in dealing with academic tasks (Mikulincer \& Shaver, 2007). In a two year longitudinal study, Miller, Notaro, and Zimmermann (2002) found that those adolescents with a stable secure attachment had more positive attitudes towards school and higher levels of academic self-efficacy than those with a stable insecure attachment style.

Secure attachment has also been found adaptive during the stressful period of transition to college. For example, Lapsey and Edgerton (2002) showed that adjustment to college is positively related with secure attachment style. Their data support the view that secure attachment with parents support separation-individuation in a healthy way, through protecting relationality and autonomy. Similarly, Lopez and Gormley (2002) showed evidence that stably secure first year students tend to report higher levels of selfconfidence and lower levels of depression, personal problems and self-splitting scores during the first year. In a longitudinal study of adjustment to college by Larose, Bernier, Tarabulsy (2005), insecure attachment orientation was found to be related with poor preparation for examinations, poor attention to academic tasks, increasing fears of academic failures and decreasing grades over time (i.e., from high school to college). Securely attached students, on the other hand, did not report a decreasing academic achievement, indicating that successful transition to university can be predicted by the 
quality of one's close relationships. In other studies, students with an insecure attachment style were found to report decreasing academic grades during the transition from high school to college (Bernier, Larose, Boivin \& Soucy, 2004).

The experience of the transition to university is often characterized by a separation from parental attachment figures and the assumption of adult relationships, with the student taking on increased responsibilities for his or her academic and social life. According to attachment theory, this separation activates the attachment system, and consistent with this many students report homesickness, a sense of loss, psychological distress and absent-mindedness (Bernier, Larose, \& Whipple, 2005). When students with a preoccupied attachment style have to leave home for college, they often report an increase in relationship problems with parents and family-related stress (Bernier, Larose, \& Whipple, 2005).

Given the poor adjustment to life in university among insecure students, one can argue from a constructivist perspective that the way insecure individuals imagine life in university might be unrealistic. Likewise, in the context of transition to parenthood, anxious-ambivalent (i.e. preoccupied) people tend to experience trouble in their relationships, mostly because of their unrealistic expectations about their relationships (Rholes, Simpson, Campbell \& Grich, 2001; Simpson, Rholes, Campbell, Tran \& Wilson, 2003). The association between ambivalence and unrealistic expectations from relationships is important in the sense that new university students with an insecure attachment style may possess a biased image of the first year experience in university, a frame of mind that predicts poor academic and social adjustment. 
Realism, attachment and transition to university 35

Reproduced with permission of the copyright owner. Further reproduction prohibited without permission. 


\section{Chapter 4: Constructive Realism and Attachment Orientation}

It is a question whether there is anything that constructive realism might add to adaptive capacity of attachment security. Particularly, I wonder whether a balanced view of potential future events might contribute to well-being of people over and above their attachment orientation, especially when they face adversities. Given the empirical evidence that attachment orientation can change over time or during stressful transitions, I also wonder whether this change can be explained by the way they construct future events (i.e., positively biased, negatively biased, or balanced).

According to constructivist approaches, people continuously test their personal constructs against the reality as they perceive it, and they sometimes have to deconstruct or reconstruct the way they perceive social reality. In her book Shattered Assumptions, Janoff-Bulman (1992) argues that traumatic events often shatter fundamental assumptions that we are worthy of love, people around us are trustable, and the world is a fairly safe place in which good things happen to good people. Traumatic events may expose as illusory one's view of the self and others, forcing people to reconstruct a meaningful and coherent self-view and worldview. For example, studying the impact of parental divorce on college students, Franklin, Janoff-Bulman and Roberts (1990) provided some evidence that parental divorce can negatively alter college students' optimism about a successful future marriage.

Stressful transitions in life might also influence the quality of one's attachment orientation through a reflective process in which the person may narrate relationshiprelated past and present in a more complex manner. Actually, critics of attachment theory have stated that the way people narrate their childhood memories and current experiences 
can be altered, and thus, the quality of their attachment orientation can change (e.g., Lewis, 1997, 2001). Changing life stories of past can also influence the way people perceive their current relationships. Defending this constructive nature of attachment orientation in life, a number of psychologists extended the trait-like (i.e., descriptive) nature of "attachment styles" towards a more narrative view that suggests a meaning or construct system of attachment relationships (Bretherton \& Munholland; 1999; Gillies \& Neimeyer, 2006, Lewis, 2001). For example, Bretherton and Munholland (1999) suggested that internal working models of individuals are subjective, because they represent a social reality from the perspective of a particular individual and with a reference to her or his "history of meaning or attribution making" (p. 99). Thus, an autobiographical reflection on attachment history can create more complex working models during adulthood and can alter the meaning of one's current and past attachment experiences.

Dixon and Duck (1993) also emphasized this dynamic, contextual and constructivist view of attachment orientation. They stated that attachment style is "a reification of a meaning system" (p. 202) or a belief system. This belief system about the self and one's relationships is not independent from what else the person knows about the world. Rather, it seems that attachment orientation is related to a larger class of psychological phenomena (Duck 1994), in which meaning of self and the social world are continuously reinterpreted or reconstructed as a whole.

Similar views of change were expressed in other streams of psychology. From an existentialist and humanistic perspective, for example, it could be argued that history of one's attachment relations can not be evaluated in isolation of present existence and 
purpose in life. Existentialist authors have stated that the narration of one's factual personal history and the quality of one's overall psychological processes are not independent from here and now (e.g., Cannon, 1999; May, 1958; Ruitenbeek, 1962). This perception, actually, can liberate someone from the historical determinants of everyday consciousness. In Self-Determination Theory, for example, researchers argued that individuals can actively monitor their affective and cognitive processes through mindfulness, and thus, the way one thinks about the self and others can be opened to new alternatives (Ryan, Brown, Creswell, 2007). This alteration can also be facilitated by adopting a deeper meaning and purpose in life, or choosing a future (e.g., Maddi, 1998). Rollo May (1958) has stated that "what an individual seeks to become determines what he remembers of his has been. In this sense the future determines the past" (p. 69, italics in original). Although people cannot select their environments in their childhood, according to this humanistic perspective, life is inevitably based on selections and decisions towards future in adulthood. Hence, object relationships in life (i.e., relationship with close others) on which attachment theory was developed is not the only determinant of psychological well-being. Debats (1999) showed that project relationships (i.e., future oriented goals or lifework), besides the attachment relationships, are also valuable sources of psychological well-being in young individuals' lives.

Hence, attachment orientation is open to reconstruction in many ways and a constructivist epistemology may explain why every particular interpretation of the self, others and the world can change in life. George Kelly, for example, wrote in describing his philosophy of constructive alternativism that "all of our present interpretations of the universe are subject to revision or replacement" (1955/1991, p.11). Since people do not 
have access to a completely accurate and universal system of constructs representing the future as it is going to be, being open to alternate one's current worldview with more complex worldviews would be useful in time.

In terms of the subjective construction of one's social world and complexity of one's anticipations of future events, one might expect that secure individuals should be more realistic than insecure ones. There is some evidence that insecure individuals tend to hold a more unrealistic image of interpersonal world than do secure individuals. Rholes et al. (2001), for instance, reported that highly ambivalent women perceive lower levels of social support from their husbands during transition to parenthood than do secure women (see also Simpson, et al., 2003).

There is also evidence that securely attached adults tend to expect, in general, that more good things will happen in future than bad things (i.e., dispositional optimism, Heinonen, et al., 2004). The optimism of secure individuals, however, does not necessarily indicate that securely attached people are also positively oriented in every transitional context. There are two main differences between dispositional optimism and positive thinking: First, thinking about or anticipating positive possibilities in future is not same with expecting in general that good things will happen. Second, one can be optimistic in general and also realistic in terms of having a balanced view of a specific transitional context. There is actually evidence that dispositional optimism is independent from, for example, health-related optimism (see e.g., Aspinwall \& Brunhart, 1996; Luo \& Isaacowitz, 2007). Hence, it is an empirical question whether secure individuals tend to be constructive realists or positive oriented. 
More specifically, it could be asked whether secure and realistic freshman who hold a complex view of what university holds in store for them can do better psychologically than those who are unrealistic in this regard. Can we explain the negative or positive changes in students' attachment orientation in terms of their anticipatory processes? I argue that a balanced view of future possibilities can lead to constructive and successful coping with transitional problems, and in turn, this realistic orientation can buffer the possible stress on attachment relationships. In other words, if an unrealistic orientation to future brings about ineffective coping during stressful times, then it might have a negative and destructive impact on one's attachment system, and thus it may negatively influence one's attachment security. Hence, I expect that an unrealistic orientation to future can lead to a significant increase in attachment insecurity during stressful times. 
Chapter 5: First Year Students and Transition to University

Extensive research indicates that attending university for the first time can be a very stressful experience for many young individuals. Most new university students report problems of adaptation such as homesickness (Fisher \& Hood, 1987), friendsickness (Paul \& Brier, 2001), lack of social support and feeling of loneliness (Pierce, Sarason, \& Sarason, 1991), depressive symptoms and psychological stress (e.g., Dyson \& Renk, 2006; Kerr, Johnson, Gans, Krumrine, 2004), health problems (Fisher, Murray \& Frazer, 1985), difficulties in managing a new balance between agency and relationality (Karp, Holmstrom, \& Gray, 1998) and difficulties in managing the routines of everyday life (Holmstrom, Karp, \& Gray, 2002).

In addition, students tend to report problems in managing their academic tasks. At Carleton University, for example, the Office of Institutional Research and Planning (2007a) reported that first year students find the academic aspect of university the most challenging aspect of their transition. To cope with these difficulties, many students start using drugs and alcohol (Sadava \& Park, 1993), and many drop out of university. At Carleton University in $1992,28 \%$ of the first year students did not continue to second year, and only $27 \%$ of the students graduated in 4 years. In $2005,12 \%$ of the first year students did not continue to second year, and only $41 \%$ of the students who enrolled in 2001 graduated in 4 years (Office of Institutional Research and Planning, 2007b).

Proposing a model of adjustment to university, Wintre and Yaffe (2000) argued that students' pre-entry characteristics and experiences such as gender, demographic factors, parental social support, autonomy and high school achievement would predict psychological well-being variables such as perceived stress, depressive symptomology, 
and self-esteem. Wintre and Bowers (2007) actually reported evidence indicating that these variables predict adjustment to university or degree completion.

Beyond the individual and personality differences among students, difficulties in adaptation during the transition to university have also been predicted from the biased images of freshman that have been building in the prior years. Earlier researchers in the field of education adopted the term "freshman myth", which refers to the naïve, idealized and unrealistic image of first year experience that is common among new university students (Stern, 1966 as cited in Jackson, Pancer, Pratt, \& Hunsberger, 2000). Three decades of research indicates that a considerable portion of new students hold an unrealistic image of the first year experience (e.g., Bank, Biddle \& Slavings, 1992; Keup, 2007; Krallman \& Holcomp, 1997; Martin \& Hanrahan, 2004; Smith \& Wertiblet, 2005). For example, reflecting on transition experience, an anonymous student from a Canadian university reported:

University life was full of surprises. It was not what I anticipated... I guess I had idealized university life as exploratory, and a place to discover yourself amidst other people who were doing likewise. What I found was class differences highlighted to the extreme, politics in the classroom, sexism everywhere, and a real fear of true self-exploration and positive change among individuals and by the institution itself (Jackson et al., 2000, p. 2100) However, there are alternative ways of anticipating university life and not every student shares the same experiences. Using a cluster analysis of student expectations, Jackson and colleagues (2000) showed that there are important individual differences among incoming students in the way that they think about their future university life. 
They found that an "optimistic" view of future might be more beneficial than a "fearful" or a "complacent" view. This finding is consistent with the line of research indicating the adaptive value of optimism (Armor \& Taylor, 2002; Aspinwall \& Taylor 1992; Scheier \& Carver, 1992) and positive construal of future life tasks (Zirkel \& Cantor 1990). In addition, Jackson et.al, (2000) also showed that a "prepared" view of university life, which combines optimistic expectations and acknowledgment of one's active role in coping, predicts adjustment to university better than any other view, including the "optimistic" one.

In another study, Pancer and colleagues (2000) showed that complex expectations (i.e., integrative complexity) do not directly predict adjustment to university during the first year, but they interact with perceived stress. Integratively complex thoughts can be adaptive when there is high level of perceived stress. When perceived stress is low, however, those with simple thoughts reported higher scores of academic, social and personal adaptation and positive attachment to university than those with complex ones. This is consistent with the constructivist perspective that a broad view of future possibilities can be adaptive when adversities occur (Churchill, 2005). In the present study, the potential interaction between one's expectations and the difficulties of the transition to university are considered.

The goals of the research presented in this thesis are: 1) to develop a contextspecific measure of the realistic orientation for university students; 2) to test whether students with a realistic orientation cope successfully with the transition to university, relative to students with other orientations; and 3) to assess whether realistic orientation 
to university can account for change in attachment styles over the course of the first year of university. These goals lead to a number of hypotheses:

1. It is predicted that possession of an orientation to university that incorporates both the negative and positive aspects of approaching the transition experience will lead to better adjustment to university and well-being than would possessing an orientation that is predominantly positive (or optimistic) or negative (or pessimistic), especially in the context of difficulties.

2. It was expected that secure attachment at the beginning of the term would predict subsequent adjustment to university and satisfaction with life, measured later in the term. Specifically, those who are low in attachment avoidance and attachment anxiety are expected to report higher level of satisfaction with university and satisfaction with life. It is also predicted that increase in attachment anxiety and attachment avoidance would be associated with decreasing levels of satisfaction with university and satisfaction with life.

3. It is predicted that change in attachment orientation could be predicted by orientation to university. I anticipated that while positively oriented students might be overwhelmed when adversity hits and would change towards attachment insecurity, realistic students would be less affected by the difficulties and would remain stable or change towards greater attachment security.

4. It was also predicted that a realistic orientation can predict adjustment to university and well-being over and above attachment variables.

In order to test the hypotheses of the research, three studies were conducted at Carleton University. In the first study, positive and negative expectations of the new 
university students were measured and the validity of the Orientation to University Scale (OUS) was tested against similar constructs. To test the main hypotheses, a second study was conducted towards the end of the academic year. In the third study, I tested the effect that realistic and optimistic thinking would have on coping in a controlled experiment. 


\section{Chapter 6: Study I}

\section{Overview}

The primary purpose of the first study was to develop a measure of realistic orientation applicable to students beginning their university education. Part of the process of developing the instrument is establishing its psychometric properties, including reliability and validity. Reliability can be assessed in terms of inter-item correlations (e.g., coefficient alpha), as well as temporally. In this study, I will assess both forms of reliability.

Hypothesis 1: The positive and negative subscales of the OUS would be significantly and positively correlated from Time1 to Time2.

Hypothesis 2: Realistic orientation would generally stay stable from Time1 to Time 2 and there would be change towards realistic orientation among positively and negatively oriented students in time.

Realistic orientation to university in this dissertation is operationalized as the frequency of thinking about both positive and negative future possibilities in transition to university. Based on Churchill's (2005) work, I define people who are realistic in their orientation to university as those who report thinking frequently about both positive and negative possibilities. In contrast, those who are positively oriented are defined as those who give frequent thought to positive possibilities but relatively little thought to negative possibilities. Negatively oriented persons are those who give frequent thought to negative possibilities, but relatively little thought to positive possibilities. Finally, those who are not future oriented (at least with respect to university) are those who report relatively few thoughts of positive or negative possibilities. 
To establish discriminant validity for my measure of the realistic orientation, I will compare those who are realistically oriented to those who are positively oriented and negatively oriented on measures of social desirability (impression management and selfdeception) to test whether scores on the instrument might contain such bias. I anticipate that realistically oriented and negatively oriented people will tend not to be influenced by impression management or self-deception, since they do acknowledge, perhaps against the current zeitgeist of thinking positively, thinking about negative possibilities. Positively oriented people, on the other hand, may be more inclined to report socially desirable response tendencies.

Hypothesis 3: Positively oriented students will be more likely to respond in a socially desirable way than negatively oriented or realistically oriented students. Convergent validity for the instrument will be assessed by testing whether those scoring as realistic differ in expected ways on conceptually related constructs from those scoring as positively oriented or negatively oriented. I expect that students who are realistically oriented will tend to score higher than those who are positively oriented on proactive coping and defensive pessimism. Relative to those who are realistic, positively oriented are presumed to pay little attention to the possibility of negative outcomes, and so should have little need to cope proactively or to worry about failure - the latter, a key aspect of defensive pessimism. However, I do not anticipate that those who are realistic in their orientation will differ from negatively oriented students on defensive pessimism. What discriminates negatively oriented people from realistically oriented people is the latter's focus on positive possibilities. Since defensive pessimism does not assess these positive possibilities, I anticipate no difference on this measure between these two 
groups. Realists should, however, score higher on proactive coping relative to negatively oriented persons. Because negatively oriented people do not, relative to realistically oriented people, anticipate positive outcomes, I anticipate more avoidant coping in this group.

Hypothesis 4: Realistic students and negatively oriented students will score higher on defensive pessimism than positively oriented students, but will not differ from each other.

Hypothesis 5: Realistic students will score higher on proactive coping than positively or negatively oriented students. Realistic students will score lower on avoidant coping relative to negatively oriented students.

Given past research by Churchill (2005), I anticipate that my measure of positive, negative, and realistic orientations will have generally weak correlations with optimism, indicating that the two concepts are not measuring the same thing. Nevertheless, I do anticipate that negative thinking will be correlated moderately with pessimistic thinking, as was found by Churchill (2005). Thus, negatively oriented and realistically oriented students will report somewhat lower optimism scores than positively oriented and not future oriented students.

Hypothesis 6: Negatively oriented and realistically oriented students will report somewhat lower optimism scores than positively oriented and not future oriented students. 


\section{Methods}

\section{Participants}

Participants were 143 first year university students at Carleton University recruited from a larger pool of 1294 Psychology 1001 students who had completed the questionnaire as part of mass testing in September 2007. Factor analyses reported below are based on the mass testing sample of 1294; other reliability and validity of data, however, are based on the subsample of 143 . Of the 143,113 were female (79\%). The mean of age was 19 years $(S D=3.16)$. Students completed the validity survey between January 15 and February 5, 2008, on average 4 months after completing the initial mass testing.

\section{Procedure}

Using the online recruitment system of the Psychology 1001/1002 Subject Pool, students were invited to participate in the mass testing at the beginning of the academic year (September 2007). Those who participated in this survey were granted 1 percentage increase in their course grade.

Students who had participated in the online mass testing at the beginning of the academic year were invited to participate in another online study titled "First Year Students' Coping with the Transition to University". The study was advertised on the web page of the online recruitment system of the Psychology Department in mid-January. Students participated by completing an online survey. The survey included the Orientation to University scale, the Life Orientation Test-Revised to assess optimism and pessimism, Proactive Coping Inventory to assess coping styles, satisfaction with 
university and subjective well-being measures, and a measure of social desirability. Those who finished this survey were granted 1 percentage increase in their Psychology 1001/1002 grade. The complete survey is provided in Appendix A.

\section{Description of measures}

Orientation to University Scale (OUS). Items for the OUS scale were generated based on my reading of the literature on the transition to university and my own knowledge of the expectations and assumptions of first year university students. I also enlisted the help of students in our lab who were temporally closer to the first year experience. The literature indicates that new students commonly report academic and social expectations such as "looking forward to learn more in depth things" and "looking forward to parties" (see Jackson et al., 2000; Keup, 2007; Smith \& Wertiblet, 2005). Items were designed to be general enough that they would be applicable to most new university students. Consistent with Churchill's (2005) description of constructive realism, the questions focus on the extent to which students report that they thought about the various issues (as opposed to assessing the extent to which students agree or disagree). Following the recommendations of the Prospectus Committee, the participants were asked, "When you think about yourself as a new student at Carleton University, how frequently do you think about each of these issues?" Nine of the statements concerned positive academic possibilities (e.g., "Getting good grades in my courses" and "Increasing my knowledge and skills") and seven were negative academic possibilities (e.g., "Thinking, 'am I disciplined enough to do well"” and "How difficult it will be to concentrate on various academic issues"). Seven of the statements reflected positive 
social possibilities (e.g., "Making and being with new friends" and "Going to parties"), and seven were negative social possibilities (e.g., "How I will handle being alone or the possibility of being isolated" and "The challenges of not having or making enough money"). Each item was rated on a seven point scale ranging from $1=$ 'never' to $7=$ 'very frequently'.

It was anticipated that the items making up the Orientation to University Scale would factor along four dimensions of thinking: Positive Academic, Negative Academic, Positive Social and Negative Social. A Principal Component Analysis was conducted on the 30 items of the OUS administered at mass testing $(N=1208)$. The scree plot of the eigenvalues suggested that the data best fit a four factor model (eigenvalues $>1.64$, representing $42.9 \%$ of the common variance). Following Varimax rotation, four factors were identified. The first factor included 11 items including all nine positive academic items and two positive social items, and is identified as the "positive thoughts subscale" (items are listed in Table 1). The second factor included the seven negative academic items as well as two negative social items, and is identified as the "negative thoughts subscale" (items listed in Table 1). The third factor contained five positive social items and three negative social items. This set of items is clearly social in content (see Table 1). The fourth factor contained two items, both concerning financial concerns. 
Table 1. Factor structure and items loadings of the OUS

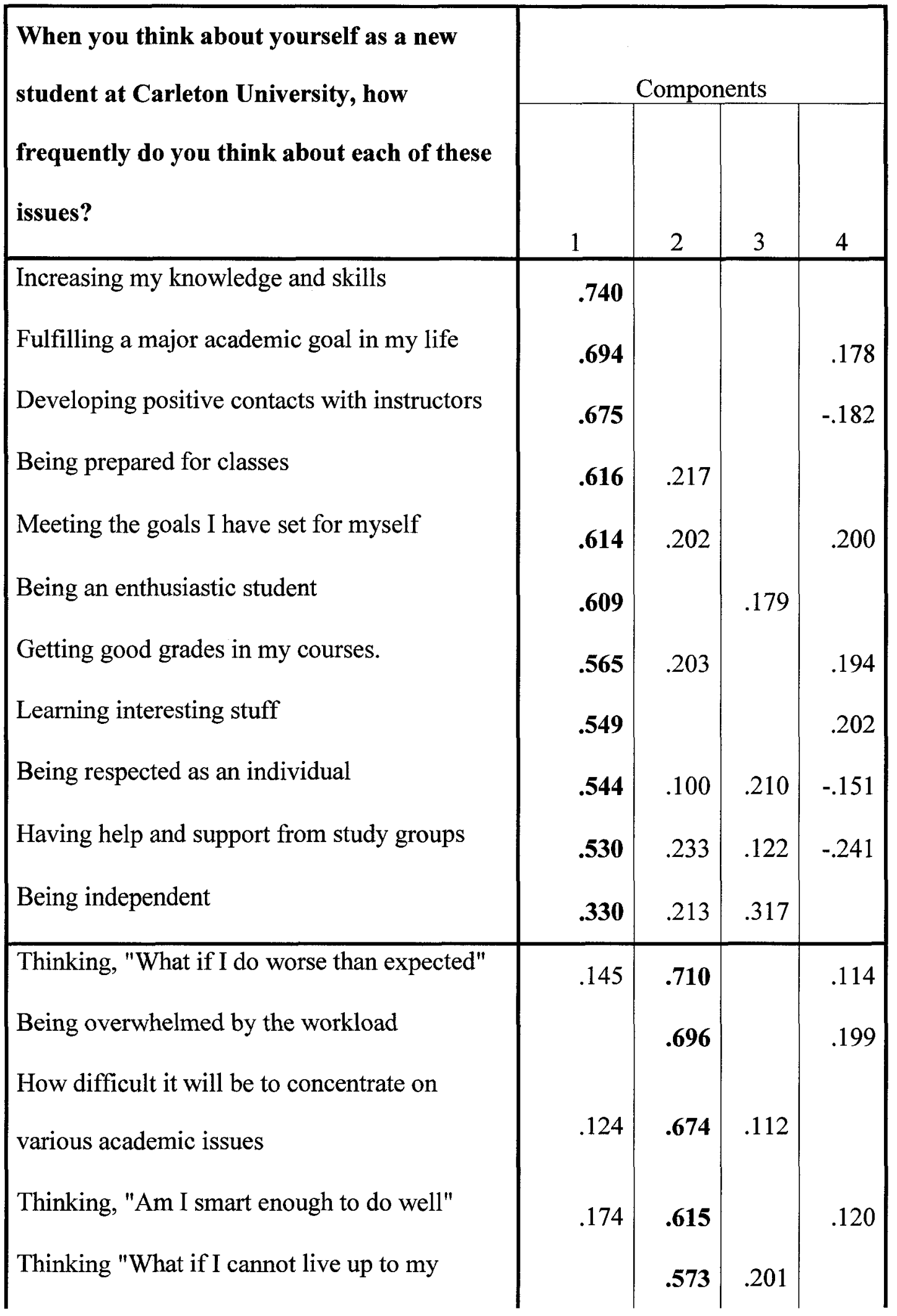




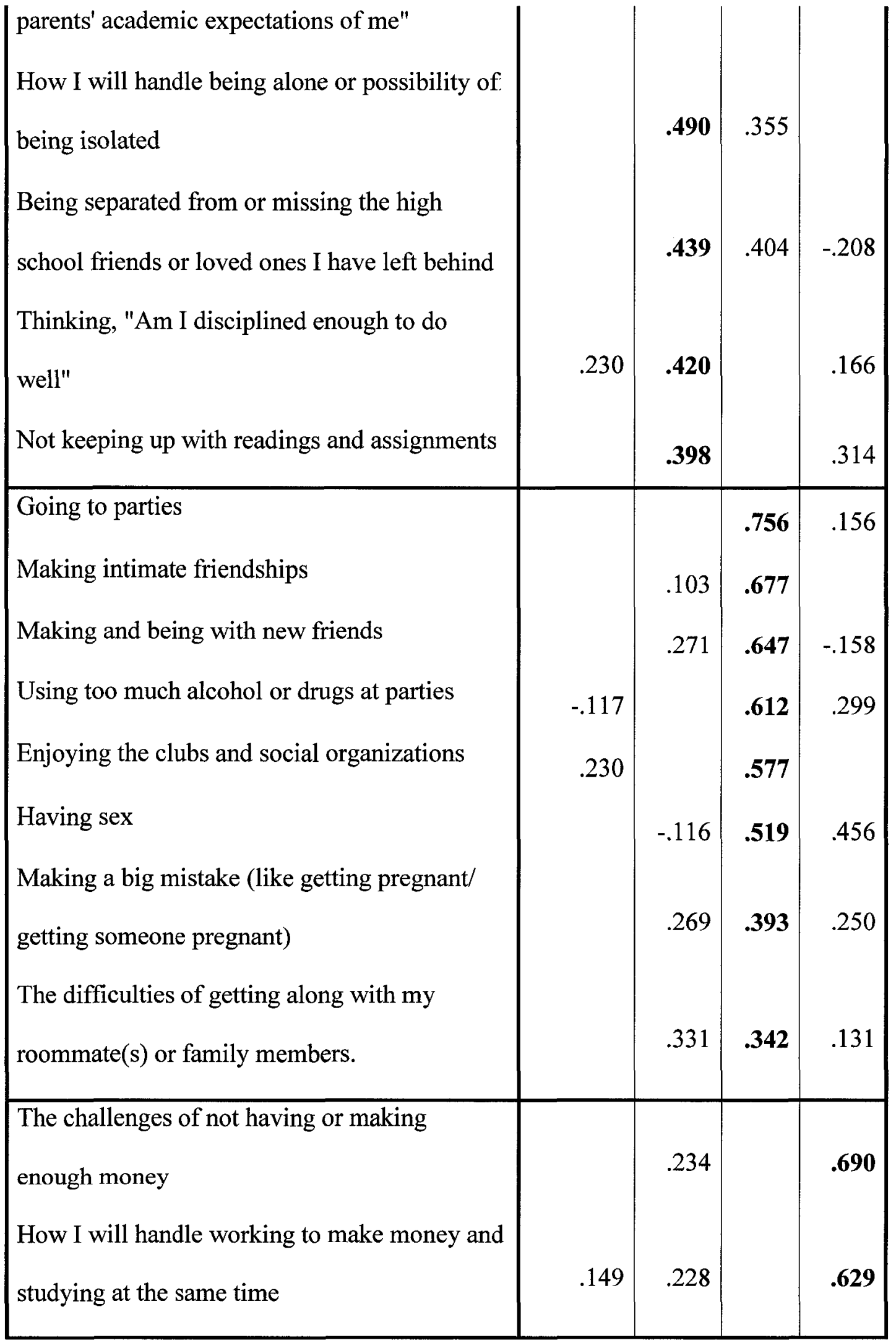


Response scale: $1=$ "never" to 7 "very frequently". $\mathrm{N}=1208$. Extraction Method: Principal Component Analysis. Rotation Method: Varimax with Kaiser Normalization. Loadings in bold indicate primary loadings. Item loadings $<|.10|$ are not printed.

A positive thoughts subscale score was calculated as an average of the 11 items loading predominantly on this dimension (each unit weighted), and a negative thoughts subscale score was calculated as an average of the 9 items loading on this dimension (each unit weighted). These variables were normally distributed with means of 5.17 (SD $=0.83)$ and $4.49(S D=1.07)$, respectively ${ }^{1}$. Cronbach's alpha for the 11 item Positive thoughts subscale was 0.82 and 0.77 for the 9 item Negative thoughts subscale. The two subscales were positively correlated $(r(1276)=0.31, p<.001)$.

The 30 item OUS was readministered at the January follow-up in the same form as it appeared at mass-testing. Mean scores of the Positive thoughts and Negative thoughts subscales were computed as reported above. Cronbach's alpha for the positive thoughts subscale was .82 and .79 for the negative thoughts subscale. Consistent with

${ }^{1}$ Means were $M=3.59(S D=1.07)$ and $M=4.46(S D=1.82)$ for social and financial dimensions, respectively. My focus in this dissertation is on the first two factors. But before dismissing the social and financial dimensions, it is important to show that they represent a relatively small proportion of the anticipatory thoughts of these students. To examine this, I calculated the percentage of the sum of thoughts (as measured by frequency rating of the 30 items of the full scale) of the items representing the four factors. Positive academic thoughts represented $43 \%$ of all thoughts (as measured by the instrument), negative academic thoughts represented 30\%, social thoughts represented $21 \%$ and financial thoughts represented $6 \%$. 
what was found in mass testing, the two subscales were correlated positively $(r(142)=$ $0.33, p<.01)$

The Balanced Inventory of Desirable Responding (BIDR). To assess the effects of the socially desirable responding, the BIDR was used. The BIDR (Paulhus, 1991) measures two components of socially desirable responding (i.e., self-deception and impression management- other-deception) with two 20 -item subscales, using a scale 1 "not true" to 7 "very true". Each subscale is made up of statements that are too good to be true (e.g. "I am a completely rational person", "I never swear"). After reverse scoring negatively worded statement, the self-deception and impression management scores are determined by summing the number of items on each subscale that the participant indicates a 6 or 7 on (i.e., very true). Cronbach's Alpha was .74 for self-deception subscale and .82 for impression management subscale. The two subscales were positively correlated $(r(141)=0.55, p<.01)$.

Defensive Pessimism Questionnaire (DPQ). The DPQ assesses defensive pessimism (Norem \& Cantor, 1986; Norem \& Illingworth, 2004). There are 12 items measuring defensive pessimism (e.g., "I carefully consider all possible outcomes", or "Considering what can go wrong helps me to prepare"). Items were rated from 1 (not at all true of me) to 7 (very true of me). Cronbach's alpha was 0.87 .

Proactive Coping and Avoidant Coping. Proactive coping refers to cognitive and behavioural strategies that lead people to pay attention and recognize potential stressors and to act in advance to prevent them. Avoidant coping, on the other hand, refers to the strategies that lead people to stay away from directly and actively solving present stressful events (Greenglass, Schwarzer \& Taubert, 1999). For the purposes of the current 
study, we have chosen 7 items to measure proactive coping and 3 items to measure avoidant coping from the Proactive Coping Inventory developed by Greenglass et.al, (1999). The measure of proactive coping contained items such as "Rather than acting impulsively, I usually think of various ways to solve a problem" and "In my mind I go through many different scenarios in order to prepare myself for different outcomes". The 3 item avoidant coping measure contained items such as "When I have a problem I like to sleep on it". Items were rated from 1 "not at all true" to 4 "completely true". Cronbach's alpha was 0.85 for proactive coping and was 0.77 for avoidance coping. The two measures were not correlated $(r(141)=-0.08, \mathrm{~ns})$.

The Life Orientation Test-Revised (LOT-R). To test for convergent validity of the OUS scale, scores at Time1 were correlated with dispositional optimism/pessimism (as measured by the LOT-R, Scheier, Carver, \& Bridges, 1994). The LOT-R is a 10-item questionnaire (of which 4 are filler items not used in the calculation of scores) that assesses people's generalized expectations about their future. Each item is rated on a 5point scale, where $1=$ "I strongly agree" and $5=$ "I strongly disagree". This instrument is the standard instrument in the field for assessing trait optimism and pessimism and has demonstrated validity and reliability in prior research (e.g., Scheier, Carver, \& Bridges, 1994). Cronbach's alpha for the six item scale was 0.85 .

\section{Results}

Hypothesis 1: Test-retest Reliability.

Mean scores on the positive thoughts subscale declined from Time 1 to Time 2 ( $M$ $=5.26$ to $M=4.99, t(137)=4.42, p<.001)$, as did scores on the negative thoughts 
subscale $(M=4.69$ to $M=4.52, t(137)=2.45, p<.02)$. Correlations of the positive and negative scores from mass testing to later in the term indicated that the temporal reliability of the scale was good. Positive thinking scores at the mass testing were positively correlated with positive thinking scores 4 months later $(r(142)=0.56, p<$ .01). Similarly, negative thinking scores at the mass testing were positively correlated with negative thinking 4 months later $(r(142)=0.69, p<.01)$.

\section{Hypothesis 2: Categorical stability.}

Because the realistic orientation is defined as the combination of frequent positive and frequent negative thoughts about an approaching stressful context, it is important to assess the reliability of those who score high on both subscales, as well as those who score as positively oriented (frequent positive, but infrequent negative) and negatively oriented (frequent negative, but infrequent positive). To assess the stability of scores among those who are deemed realists, positively oriented, and negatively oriented at mass testing, I categorized participants based on whether they were in the realistic orientation quadrant, positive orientation quadrant, negative orientation quadrant, and finally a quadrant of those scoring low on both positive and negative subscales (not academically oriented) based on their OUS scores at mass testing. To establish whether a participant was realistic, positively focused, negatively focused, or not academically oriented, I used a criterion of $+/-1 / 4$ of a standard deviation of the mean on each of the subscales. Splitting the sample at $+/-1 / 4$ standard deviation of the mean effectively divides the distribution of scores into thirds. Comparing the top and bottom thirds of the distribution (or those above $1 / 4$ standard deviation above the mean and those below $1 / 4$ standard deviation less than the mean) may eliminate one-third of the sample, but it 
avoids the problem of using median split (see MacCallum, Zhang, Preacher, \& Rucker, 2002). Thus, those who were deemed realistic were at least $1 / 4$ standard deviation above the mean on both the positive academic and negative academic subscales at the mass testing; those who were positively oriented with at least $1 / 4$ standard deviation above the mean on the positive academic subscale and at least $1 / 4$ standard deviation below the mean on the negative academic subscale at the mass testing, and so on. Using these criteria, of the 142 participants in Study 1, 36 were deemed realistic at the mass testing, 20 were positively oriented at mass testing, 10 were negatively oriented at mass testing, and 26 were deemed not future oriented at mass testing (in the sense that they did not think frequently about either positive or negative academic issues at mass testing). The remaining 51 participants were within $1 / 4$ standard deviation of the mean on at least one of the positive academic or negative academic subscales. To assess the extent to which members of each group shifted in their thinking about university over the 4 months, participants at Time 1 were categorized into one of the four groups based on their scores on the OUS at Time 2 . Table 2 below shows that more than $60 \%$ of those deemed realistic at Time 1 remained in this category at Time $2,50 \%$ of those coded as positively oriented remained in this category, $30 \%$ of those deemed negatively oriented at Time 1 remained in this category, and more than $60 \%$ of those deemed not future oriented remained in that category. Of those who shifted, the most common shifts were towards negatively oriented and towards realistically oriented. 
Table 2. Cross-tabulation of orientation groups from Time1 to Time2

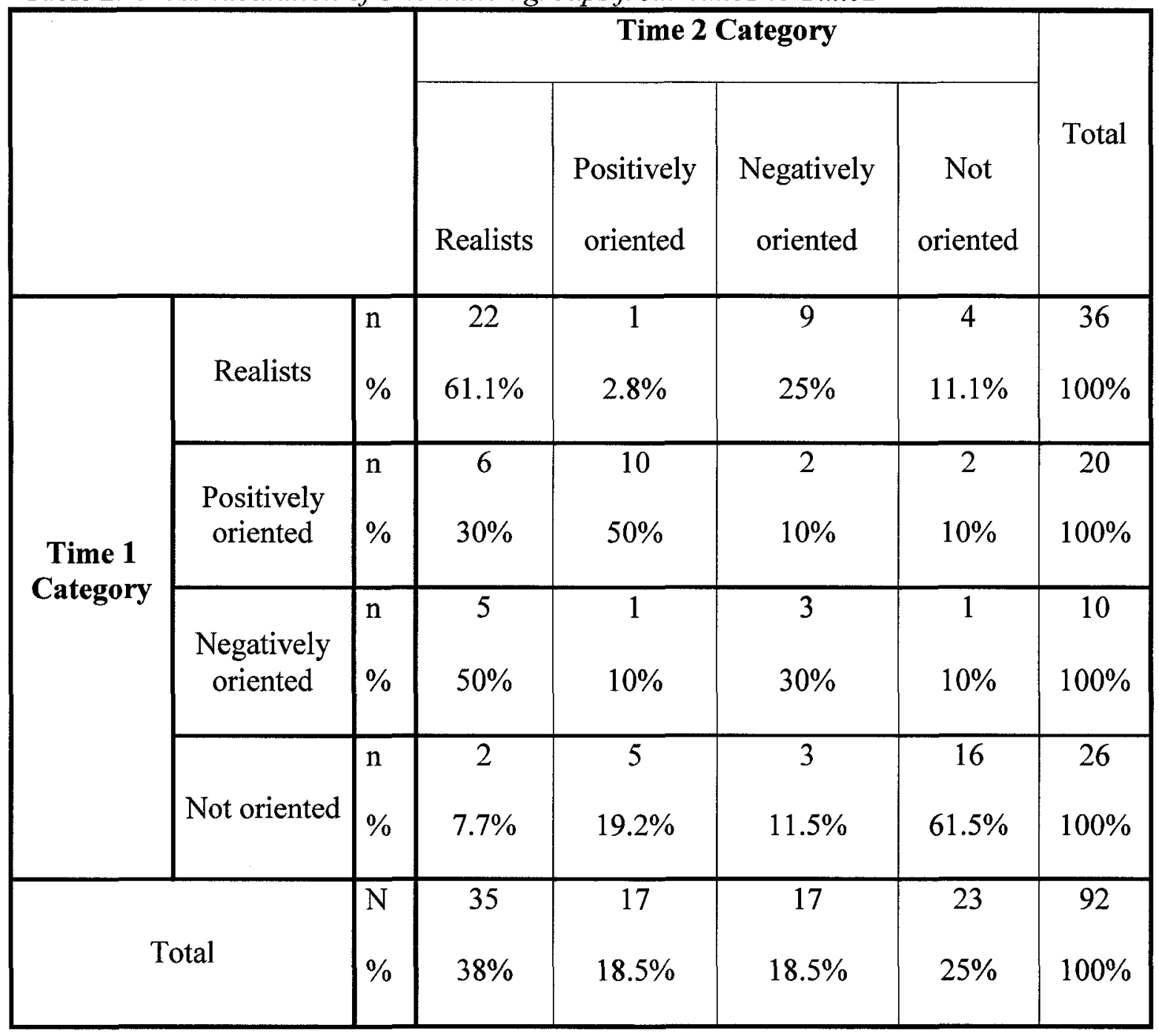

Table 3 provides a matrix of correlations showing the extent to which the frequency of positive and negative thoughts about university correlates with various measures, including impression management and self-deception. People scoring high on the positive thoughts subscale were somewhat more likely score higher on impression management $(r(142)=.17, p<.05)$, but were not more likely to score high on the selfdeception scale of the BIDR $(r=.01)$. However, those who scored low on negative 
thoughts subscale were particularly likely to score high on both impression management $(r(142)=-.37, p<.01)$ and self-deception $(r(142)=-.40, p<.01)$. 
Table 3. Correlations

\begin{tabular}{|c|c|c|c|c|c|c|c|}
\hline & $\begin{array}{l}\text { Positive } \\
\text { Thinking }\end{array}$ & $\begin{array}{l}\text { Negative } \\
\text { Thinking }\end{array}$ & $\begin{array}{c}\text { Self } \\
\text { Deception }\end{array}$ & $\begin{array}{c}\text { Impression } \\
\mathrm{M} .\end{array}$ & Optimism & $\begin{array}{c}\text { Defensive } \\
\text { Pess. }\end{array}$ & $\begin{array}{c}\text { Proactive } \\
\text { Coping }\end{array}$ \\
\hline $\begin{array}{l}\text { Positive } \\
\text { Thinking } \\
\text { Negative } \\
\text { Thinking } \\
\text { Self } \\
\text { Deception } \\
\text { Impression } \\
\text { M. } \\
\text { Optimism } \\
\text { Defensive } \\
\text { Pess. } \\
\text { Proactive } \\
\text { Coping } \\
\text { Avoidant } \\
\text { Coping }\end{array}$ & $\begin{array}{c}.01 \\
.17^{*} \\
-.09 \\
.29^{* *} \\
.26^{* *} \\
-.14\end{array}$ & $\begin{array}{l}-.40^{* *} \\
-.37^{* *} \\
-.45^{* *} \\
.52^{* *} \\
-.09 \\
-.04\end{array}$ & $\begin{array}{c}1 \\
.55^{* *} \\
.39^{* *} \\
-.21^{*}\end{array}$ & $\begin{array}{c}1 \\
.25^{* *} \\
-.15\end{array}$ & $\begin{array}{c}-.47^{* *} \\
.13\end{array}$ & $\begin{array}{l}.38 * * \\
-.06\end{array}$ & $\begin{array}{c}1 \\
-.08\end{array}$ \\
\hline
\end{tabular}

* Correlation is significant at the 0.05 level (2-tailed). 
Hypothesis 3:Influence of Social Desirability. It was hypothesized that positively oriented students would be more likely to respond in a socially desirable way than would negatively oriented or realistically oriented students. A pair of regression analyses were conducted to assess whether those who were positively oriented (low negative and high positive thoughts) differed from other groups on impression management and selfdeception. First, positive thoughts and negative thoughts (after centering), and then the two-way multiplicative interaction were entered in the regression equations. Results of the analysis on impression management are in Table 4. Consistent with the bivariate results, positive thinking $(\beta=.34, t(140)=4.35, p<.001)$ and negative thinking $(\beta=$ $.49, t(140)=-6.20, p<.001)$ significantly predicted impression management. The twoway interaction term was not found to be significant $(t(139)<1.0)$. Tolerance values were all above .80 , indicating that there were no problems with collinearity among independent variables. The two main effects suggest that frequent positive thoughts and frequent negative thoughts have opposing effects, implying that realists (those with frequent positive and frequent negative thoughts) are situated half.way between positively oriented and negatively oriented participants (see Figure 2).

To confirm this is in fact true, I also have categorized thinking variables using a criterion of $+/-1 / 4$ of a standard deviation of the mean and conducted a one-way ANOVA on impression management scores. There were significant differences among groups $(F$ $(3,88)=6.28, p=.001)$. Tukey's Post-hoc comparisons indicated that positive oriented students $(M=8.90 ; 95 \% C I: 6.94,10.86)$ scored significantly higher than realists $(M=$ $5.14 ; 95 \% C I: 4.00,6.28)$, negatively oriented $(M=4.40 ; 95 \% C I: 1.78,7.02)$ and than 
the not-oriented group $(M=5.19 ; 95 \% C I: 3.90,6.49)$. Other comparisons were nonsignificant.

Table 4. The effect of positive and negative thoughts, and their interaction, on impression management scores.

\begin{tabular}{|c|c|c|c|c|c|c|c|c|c|c|}
\hline \multirow{2}{*}{ Model } & \multicolumn{5}{|c|}{1} & \multicolumn{5}{|c|}{2} \\
\hline & b & $\mathrm{SE}$ & $\beta$ & $\mathrm{t}$ & Sig & b & $\mathrm{SE}$ & $\beta$ & $\mathrm{t}$ & Sig \\
\hline \multicolumn{11}{|l|}{ Positive } \\
\hline Thoughts & 1.75 & 0.40 & 0.34 & 4.35 & 0.00 & 1.78 & 0.42 & 0.35 & 4.27 & 0.00 \\
\hline \multicolumn{11}{|l|}{ Negative } \\
\hline Thoughts & -1.77 & 0.29 & -0.49 & -6.20 & 0.00 & -1.78 & 0.29 & -0.49 & -6.10 & 0.00 \\
\hline \multicolumn{11}{|l|}{ Positive* } \\
\hline Negative & & & & & & 0.08 & 0.31 & 0.02 & 0.26 & 0.79 \\
\hline$R^{2}$ Total & & & 0.24 & & & & & 0.24 & & \\
\hline
\end{tabular}


Figure 2. Impression management scores of the orientation groups

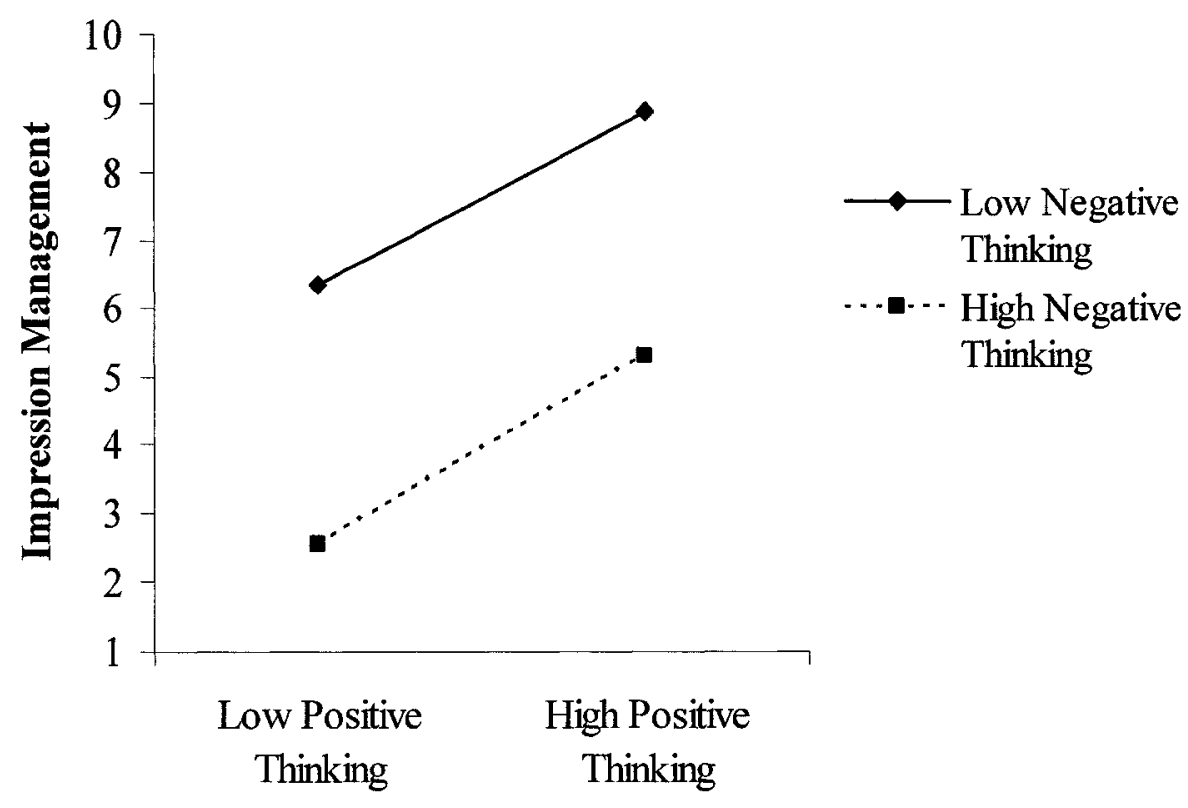


With regard to self-deception scores, we obtained a significant effect of positive thinking $(\beta=.17, t(140)=2.10, p<.05)$ and negative thinking $(\beta=-.46, t(140)=-5.62$, $p<.001)$. The two-way interaction term was not found to be significant $(t(139)<1.0$, see Table 5). The two main effects showed that frequent negative thoughts are strongly and negatively associated with self-deception and frequent positive thoughts are slightly and positively associated with self-deception (see Figure 3).

In order to specifically compare groups, I conducted a one-way ANOVA on selfdeception scores after categorizing thinking variables using a criterion of $+/-1 / 4$ of a standard deviation of the mean. There were significant differences among groups ( $F(3$, $88)=3.46, p<.05)$. Post-hoc comparisons indicated that positively oriented students $(M$ $=6.35 ; 95 \% C I: 4.71,7.99)$ scored marginally higher than realists $(M=3.97 ; 95 \% C I$ : $2.94,5.00 \mathrm{p}=.06)$ but not significantly higher than negatively oriented students $(M=$ $3.40 ; 95 \% C I: 1.71,5.09)$. Although there is a larger score difference between positively oriented and negatively oriented students than there is between positively oriented and realists, the small $\mathrm{n}$ for negatively oriented students meant that this group's standard error was large. It should be noted that there were only 10 students in the group of negatively oriented, compared to 36 realists, 20 positively oriented and 26 students in the notoriented group. 
Table 5. The effect of positive and negative thoughts, and their interaction, on selfdeception scores.

\begin{tabular}{|c|c|c|c|c|c|c|c|c|c|c|}
\hline \multirow{2}{*}{ Model } & \multicolumn{5}{|c|}{1} & \multicolumn{5}{|c|}{2} \\
\hline & $b$ & $S E$ & $\beta$ & $t$ & Sig & $b$ & $S E$ & $\beta$ & $t$ & Sig \\
\hline $\begin{array}{l}\text { Positive } \\
\text { Thoughts }\end{array}$ & 0.79 & 0.37 & 0.17 & 2.10 & 0.04 & 0.81 & 0.39 & 0.18 & 2.09 & 0.04 \\
\hline $\begin{array}{l}\text { Negative } \\
\text { Thoughts }\end{array}$ & -1.49 & 0.27 & -0.46 & -5.62 & 0.00 & -1.50 & 0.27 & -0.46 & -5.53 & 0.00 \\
\hline $\begin{array}{l}\text { Positive* } \\
\text { Negative }\end{array}$ & & & & & & 0.07 & 0.29 & 0.02 & 0.25 & 0.81 \\
\hline$R^{2}$ Total & & & 0.18 & & & & & 0.18 & & \\
\hline
\end{tabular}


Figure 3. Self-deception scores of the orientation groups

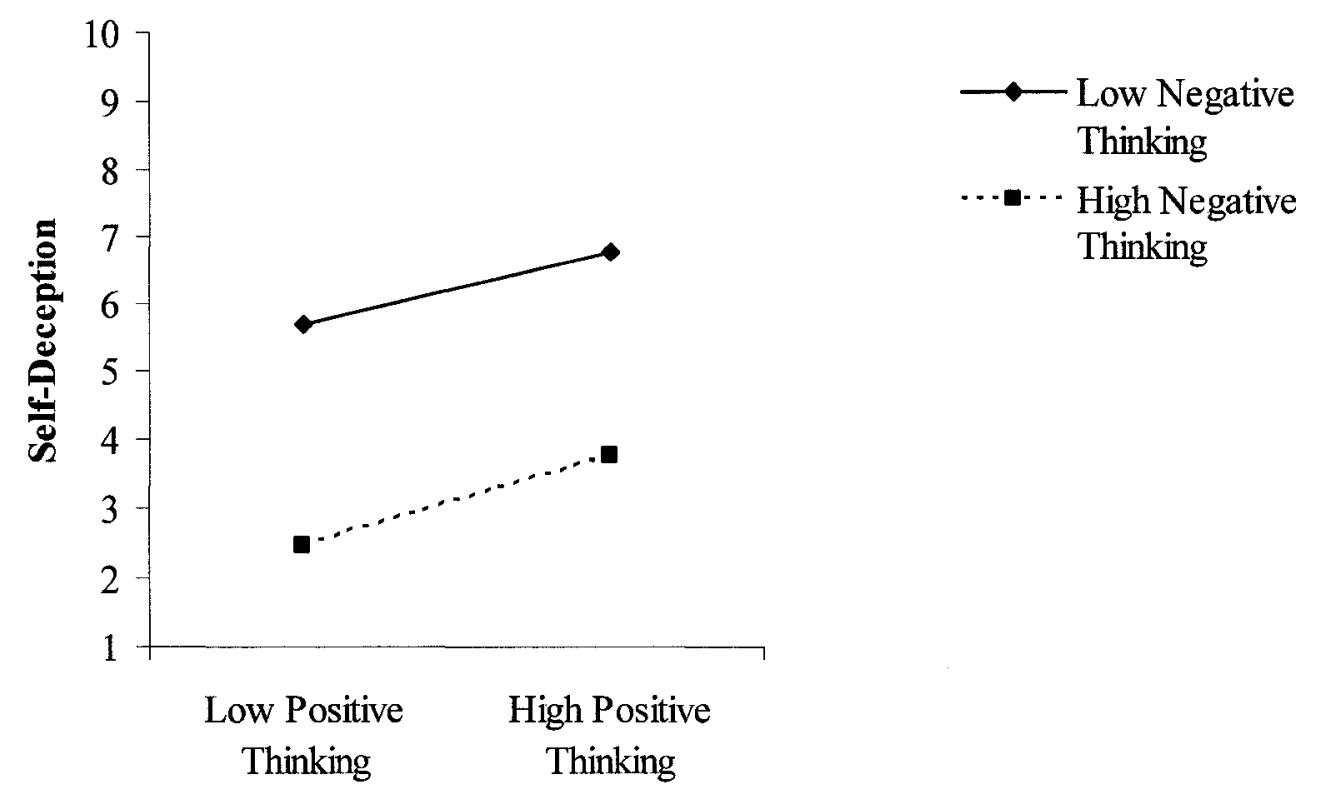


Hypothesis 4: Defensive Pessimism and Orientations to University. As anticipated, negative thinking was significantly and positively related to defensive pessimism, $r(142)=.52, p<.01$. Surprisingly, positive thinking was also positively correlated with defensive pessimism, $r(142)=.29, p<.01$. However, since positive and negative thinking are positively related, this latter correlation may be attributable to the covariance among positive and negative thinking. To take into account this covariance, and to test whether realistically oriented subjects differed from positively and negatively oriented subjects on defensive pessimism, a multiple regression was conducted where defensive pessimism was predicted from positive thinking score, negative thinking score, and the multiplicative interaction of positive and negative thoughts (after centering). In this regression analysis, I obtained a nonsignificant effect of positive thinking $(\beta=.11 ; t$ $(140)=1.63, p=0.11)$ and a significant effect of negative thinking $(\beta=.48, t(140)=$ $6.25, p<.001)$. The two-way interaction term was not found to be significant $(\beta=-.06 ; t$ $(139)=-0.79, \mathrm{~ns})$. This regression was repeated controlling for the effects of impression management and self-deception scores. The pattern of the results was same: I obtained a nonsignificant effect of positive thinking $(\beta=.12, t(138)=1.51, p=.13)$ and a significant effect of negative thinking $(\beta=.47, t(138)=5.28, p<.001)$ and a nonsignificant two-way interaction $(\beta=-.06 ; t(137)=-0.78$, ns, see Table 6 and Figure 4). Consistent with Hypothesis 4, this suggests that realists and negatively oriented participants score higher on defensive pessimism than positively oriented participants and not-oriented participants.

To confirm this interpretation, I conducted a one-way ANCOVA on defensive pessimism using the four groups defined as at least $+/-1 / 4$ of a standard deviation on both 
variables. The analysis controlled for the effects of social desirability. There were significant differences among groups $(F(3,86)=5.23, p=.01)$. Post-hoc comparisons indicated that realists $(M=4.95 ; 95 \% C I: 4.62,5.28)$ scored significantly higher than positively oriented $(M=4.17 ; 95 \% C l: 3.71,4.65)$ and not-oriented group $(M=3.96$; $95 \%$ CI: $3.59,4.38)$. Negatively oriented students, however, did not significantly differ from the other groups, due to large standard error of mean $(M=4.60 ; 95 \% C I: 3.95,5.20)$. 
Table 6. The effect of positive and negative thoughts, and their interaction, on defensive pessimism scores

\begin{tabular}{|c|c|c|c|c|c|c|c|c|c|c|}
\hline \multirow{2}{*}{ Model } & \multicolumn{5}{|c|}{1} & \multicolumn{5}{|c|}{2} \\
\hline & $\mathrm{b}$ & $\mathrm{SE}$ & $\bar{\beta}$ & $\mathrm{t}$ & Sig & $\mathrm{b}$ & $\mathrm{SE}$ & $\beta$ & $\mathrm{t}$ & Sig \\
\hline $\begin{array}{l}\text { Self- } \\
\text { Deception }\end{array}$ & -0.01 & 0.03 & -0.03 & -0.37 & 0.71 & -0.01 & 0.03 & -0.03 & -0.36 & 0.72 \\
\hline $\begin{array}{l}\text { Impression } \\
\text { Manag. }\end{array}$ & 0.00 & 0.02 & 0.02 & 0.20 & 0.84 & 0.01 & 0.02 & 0.02 & 0.21 & 0.83 \\
\hline $\begin{array}{l}\text { Positive } \\
\text { Thoughts }\end{array}$ & 0.17 & 0.11 & 0.12 & 1.51 & 0.13 & 0.15 & 0.12 & 0.11 & 1.27 & 0.20 \\
\hline $\begin{array}{l}\text { Negative } \\
\text { Thoughts }\end{array}$ & 0.46 & 0.09 & 0.47 & 5.28 & 0.00 & 0.48 & 0.09 & 0.48 & 5.32 & 0.00 \\
\hline $\begin{array}{l}\text { Positive* } \\
\text { Negative }\end{array}$ & & & & & & -0.06 & 0.08 & -0.06 & -0.78 & 0.44 \\
\hline$R^{2}$ Total & & & 0.29 & & & & & 0.29 & & \\
\hline
\end{tabular}


Figure 4. Adjusted means for defensive pessimism scores of the orientation groups

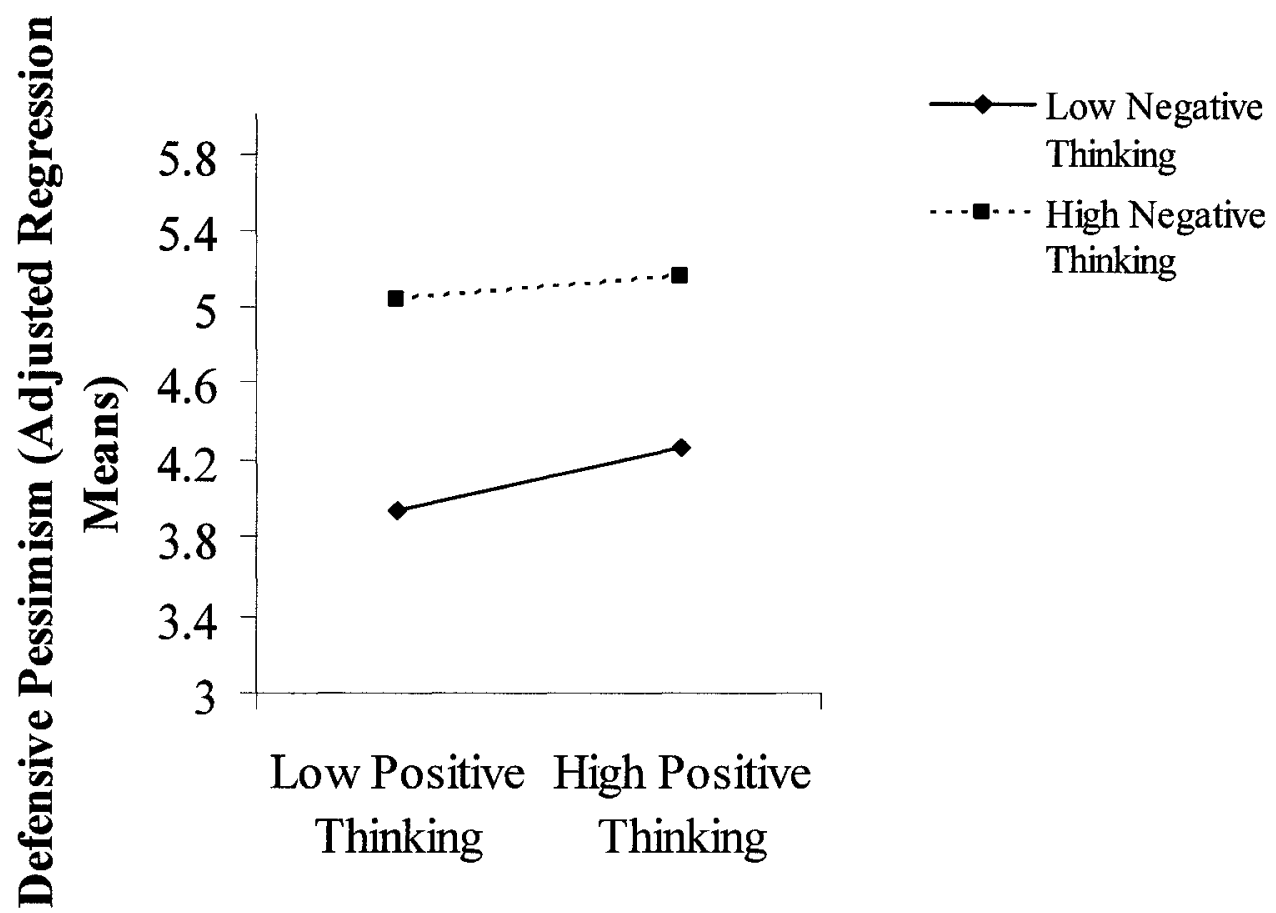




\section{Hypothesis 5: Proactive and avoidant coping}

Table 3 reports that the positive thoughts subscale was positively correlated with proactive coping $(r(142)=0.26, p<.01)$ but not significantly related to avoidant coping $(r(142)=-.14, p>.05)$. Frequency of negative thoughts, on the other hand, was not significantly correlated with either proactive coping or avoidant coping $(r \mathrm{~s}=-.09,-.04$, respectively). Regression analyses were conducted to assess whether realists differed from positively and negatively oriented students on both proactive coping and avoidant coping. With regard to proactive coping, we obtained a significant effect of positive thinking $(\beta=.34, t(140)=3.95, p<0.01)$, a significant effect of negative thinking $(\beta=$ $.21, t(140)=-2.48, p<.05)$ and a nonsignificant two-way interaction $(t(139)=-1.1, \mathrm{~ns})$. After controlling for the effects of impression management and self-deception scores, we obtained a significant effect of positive thinking $(\beta=.27, t(138)=3.10, p<.001)$, a nonsignificant effect of negative thinking $(t(138)=-0.64, \mathrm{~ns})$, and a nonsignificant twoway interaction $(t(137)=-1.25$, ns, see Table 7$)$. This suggests that positively oriented and realistically oriented students do not differ from each other on pro-active coping, but both differ from negatively oriented and not-future oriented group (Figure 5).

This result was tentatively confirmed with a one-way ANCOVA conducted on pro-active coping scores after controlling the effects of social desirability and categorizing thinking variables using a criterion of $+/-1 / 4$ of a standard deviation of the mean. There were marginally significant differences among groups $(F(3,86)=2.29, p=$ $.08)$. Given that test was marginal, I used .10 as a criterion for post-hoc contrasts. These comparisons of the adjusted means indicated that realists $(M=2.91 ; 95 \%$ CI: $2.74,3.09)$ and positively oriented students $(M=2.93 ; 95 \% C I: 2.68,3.19)$ differed (at $p<.10)$ from 
the not-oriented group ( $M=2.60 ; 95 \% C I: 2.39,2.82)$, but not from the negatively oriented students ( $M=2.64 ; 95 \%$ CI: $2.30,2.98)$. As stated before, the small $\mathrm{n}$ for negatively oriented group results with a large standard error. 
Table 7. The effect of positive and negative thoughts, and their interaction, on pro-active coping scores.

\begin{tabular}{|c|c|c|c|c|c|c|c|c|c|c|}
\hline \multirow{2}{*}{ Model } & \multicolumn{5}{|c|}{1} & \multicolumn{5}{|c|}{2} \\
\hline & $\mathrm{b}$ & $\mathrm{SE}$ & $\beta$ & $\mathrm{t}$ & Sig & $\mathrm{b}$ & SE & $\beta$ & $\mathrm{t}$ & $\mathrm{Sig}$ \\
\hline $\begin{array}{l}\text { Self- } \\
\text { Deception }\end{array}$ & 0.04 & 0.02 & 0.27 & 2.85 & 0.01 & 0.04 & 0.02 & 0.27 & 2.87 & 0.00 \\
\hline $\begin{array}{l}\text { Impression } \\
\text { Manag. }\end{array}$ & 0.01 & 0.01 & 0.05 & 0.53 & 0.60 & 0.01 & 0.01 & 0.05 & 0.55 & 0.58 \\
\hline $\begin{array}{l}\text { Positive } \\
\text { Thoughts }\end{array}$ & 0.21 & 0.07 & 0.27 & 3.10 & 0.00 & 0.19 & 0.07 & 0.24 & 2.71 & 0.01 \\
\hline $\begin{array}{l}\text { Negative } \\
\text { Thoughts }\end{array}$ & -0.03 & 0.05 & -0.06 & -0.64 & 0.52 & -0.02 & 0.05 & -0.04 & -0.40 & 0.69 \\
\hline $\begin{array}{l}\text { Positive* } \\
\text { Negative }\end{array}$ & & & & & & -0.06 & 0.05 & -0.10 & -1.25 & 0.21 \\
\hline$R^{2}$ Total & & & 0.18 & & & & & 0.19 & & \\
\hline
\end{tabular}


Figure 5. Adjusted means for proactive coping scores of the orientation groups

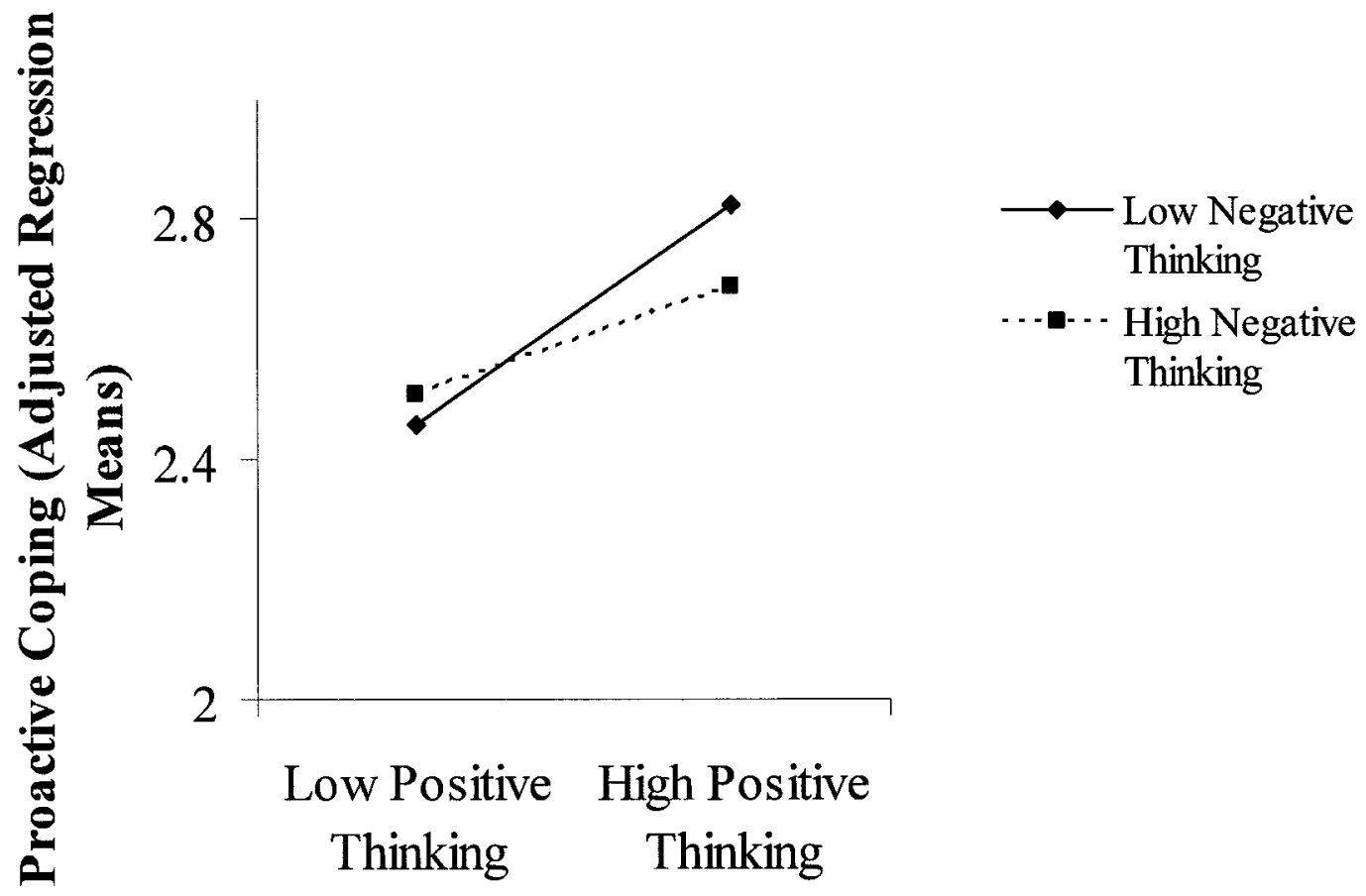


The analysis on avoidant coping did not yield significant effects of positive and negative thinking or an interaction effect (all $t \mathrm{~s}<|1.45|$, ns). Controlling for the effects of social desirability did not change the results.

\section{Hypothesis 6: Optimism}

At the bivariate level, the frequency of positive thoughts was not correlated significantly with optimism, $r(142)=-.09$. The frequency of negative thoughts, however, was significantly and negatively correlated with optimism, $r(142)=-.45, p<.01$ (see Table 3). To assess whether realists different from the other groups on optimism, a multiple regression was conducted. In this regression, I obtained a nonsignificant effect of positive thinking $(t(140)<1.0, \mathrm{~ns})$ and a significant effect of negative thinking $(\beta=$ $.48, t(140)=-5.98, p<.001)$. The two-way interaction term was not found to be significant $(t(139)=1.09, \mathrm{~ns})$. Those scoring low on negative thoughts (positively oriented and those not future oriented) were more optimistic than those scoring high on negative thoughts (negatively oriented students and realists). After controlling for the effects of impression management and self-deception scores, the pattern of the results was same. I obtained a nonsignificant effect of positive thinking $(t(138)=0.59, \mathrm{~ns})$ and a significant effect of negative thinking $(\beta=-.38, t(138)=-4.20, p<.001)$ and a nonsignificant two-way interaction $(t(137)=1.06 \text {, ns, see Table } 8 \text { and Figure } 6)^{2}$.

\footnotetext{
${ }^{2}$ This result was confirmed with a one-way ANCOVA conducted on optimism scores after categorizing thinking variables using a criterion of $+/-1 / 4$ of a standard deviation of the mean. There were significant differences among groups $(F(3,86)=5.61, p=.001$. Post-hoc comparisons of the estimated marginal means indicated that positively oriented
} 
Table 8. The effect of positive and negative thoughts, and their interaction, on optimism scores

\begin{tabular}{|c|c|c|c|c|c|c|c|c|c|c|}
\hline \multirow{2}{*}{ Model } & \multicolumn{5}{|c|}{1} & \multicolumn{5}{|c|}{2} \\
\hline & $\mathrm{b}$ & $\overline{\mathrm{SE}}$ & $\beta$ & $t$ & Sig & $\mathrm{b}$ & $\mathrm{SE}$ & $\beta$ & $t$ & $\mathrm{Sig}$ \\
\hline \multicolumn{11}{|l|}{ Self- } \\
\hline Deception & 0.07 & 0.02 & 0.26 & 2.89 & 0.00 & 0.07 & 0.02 & 0.26 & 2.88 & 0.00 \\
\hline \multicolumn{11}{|l|}{ Impression } \\
\hline Manag. & -0.01 & 0.02 & -0.04 & -0.48 & 0.63 & -0.01 & 0.02 & -0.05 & -0.49 & 0.62 \\
\hline \multicolumn{11}{|l|}{ Positive } \\
\hline Thoughts & 0.06 & 0.10 & 0.05 & 0.59 & 0.56 & 0.08 & 0.10 & 0.07 & 0.83 & 0.41 \\
\hline \multicolumn{11}{|l|}{ Negative } \\
\hline Thoughts & -0.31 & 0.07 & -0.38 & -4.20 & 0.00 & -0.33 & 0.08 & -0.40 & -4.33 & 0.00 \\
\hline \multicolumn{11}{|l|}{ Positive* } \\
\hline Negative & & & & & & 0.07 & 0.07 & 0.08 & 1.06 & 0.29 \\
\hline$R^{2}$ Total & & & 0.26 & & & & & 0.27 & & \\
\hline
\end{tabular}

students $(M=3.94 ; 95 \% C I: 3.61,4.27)$ and the not-oriented group $(M=3.55 ; 95 \% C I$ : $3.28,3.83)$ scored significantly higher than realists $(M=3.19 ; 95 \% C I: 2.96,3.42)$ and than negatively oriented students $(M=3.04 ; 95 \% C I: 2.60,3.47)$. Other comparisons were nonsignificant. 
Figure 6. Adjusted means for optimism scores of the orientation groups

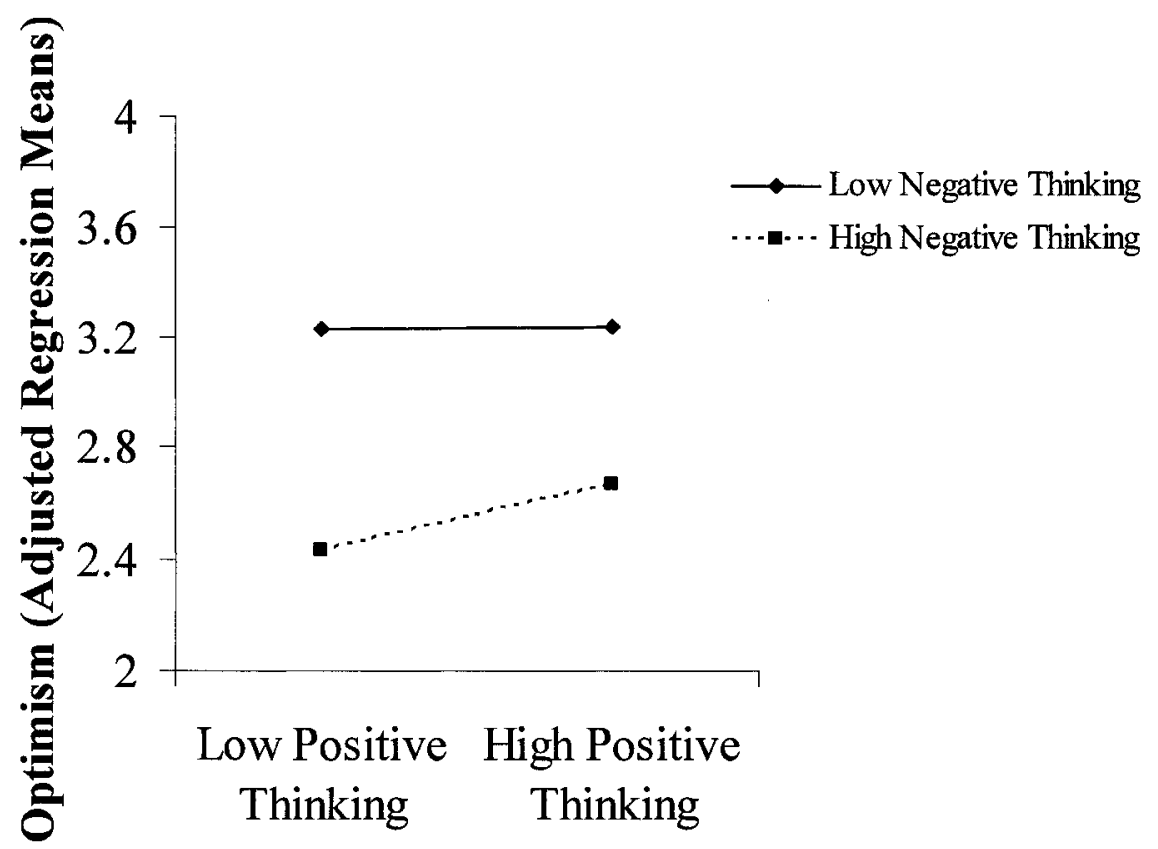

Discussion

This study was designed to develop a measure of realistic orientation to transition to university, and to assess its reliability and validity. Based on the relevant literature indicating the salience of academic and social dimensions of students expectations, it was hypothesized that four orthogonal latent factors would emerge tapping into positive academic, negative academic, positive social and negative social aspects of transition to university. The results partially supported this structure.

As expected, the results of the factor analysis indicated that items reflecting the frequency of thinking about positive and negative academic possibilities loaded separately on the first two factors. There were, however, some commonalities with the social aspects of university experience. Two social positive items also loaded clearly on 
the positive academic factor ("being respected as an individual"; "being independent"). These items highlighted a commonality between academic achievement and a concern for individuation (Jackson et al., 2000; Keup, 2007; Smith \& Wertiblet, 2005; Zirkel \& Cantor 1990). In addition, the negative aspect of academic experience was related to the thoughts or concerns about loneliness and homesickness (e.g., "how I will handle being alone or possibility of being isolated"; "being separated from or missing the high school friends or loved ones I have left behind"). This might be the potential feelings of homesickness and the need for one's close relationships when the academic tasks are potentially challenging.

Contrary to our expectations, the social aspect of university experience was not found to be separated as positive and negative. Rather social thoughts composed a single factor indicating social concerns of new students (e.g., "going to parties"; "having sex"; "making a big mistake (like getting pregnant/ getting someone pregnant)". One reason for this could be the nature of one's excitements. Although going to parties and having sex might be emotionally very rewarding to think about, these positive thoughts also seem to be associated with the anxiety aroused by the unwanted possibilities. Hence, it seems that thinking about some experiences about transition to university might have both an incentive and deterring value simultaneously. Finally, an apparent negative thought about transition to university was financial concerns. Although we expected that financial concerns would be correlated with social concerns, students seem to differentiate them from each other. Because of the potential conceptual problems that could arise using incoherent items loaded together, I decided not use the social aspects of thinking in the rest of the analyses. 
Based on the first two dimensions (i.e., "positive academic" and "negative academic"), the analyses indicated that the OUS has good test-retest reliability. With an interval of 6 months, test-retest correlations in the range of .5 to .6 are within the range of most personality trait measures for young adults. Meta reviews in the literature indicate that most studies find a test-retest coefficient of .50 to .70 over 6 months for major personality traits among young adults (Caspi, Roberts, \& Shiner, 2005; Fraley \& Roberts 2004; Schuerger, Zarrella \& Hotz, 1989). Given that one would expect that orientations would shift somewhat as one becomes more familiar with the university environment, the observed test-retest correlations of .56 for positive thoughts and .69 for negative thoughts is reasonable. The categorical analysis of university orientation from Time1 to Time2 also indicates that realistic orientation is generally stable. However, I did find a tendency for positively oriented and negatively oriented students to shift towards realistic orientation (see Table 2). Realists don't become positively oriented; if anything they change towards negative orientation. This result shows that tendencies to think about future possibilities, especially a realistic orientation, might be fairly stable over periods of 4 months, indicating the potential significance of underlying personality traits, such as optimism, defensive pessimism and proactive coping.

The analyses with impression management (i.e., other deception) and selfdeception indicated that positively oriented students are the most vulnerable group to social desirability. Research shows that optimistic people tend to score high on social desirability and narcissism relative to pessimistic people (Farwell, Wohlwend-Lloyd, 1998; Schweizer, Beck-Seyffer, Schneider, 1999). Hence, not thinking about (or denying) negative possibilities might be related with self-defence and defensive positive emotions. 
Oettingen and Mayer (2002) argued that exclusively positive imagination might bring about positive feelings here and now, however, this mindset might also be costly in the long run. Although some researchers argue that defensive tendencies such as narcissism can be healthy when they are associated with high self-esteem (Sedikides, Rudich, Gregg, Kumashiro, \& Rusbult, 2004), it might be fruitful to test the consequences of this mindset in a stressful context.

The validational analyses confirm Churchill's (2005) results showing that positive thinking is not correlated with LOT-R optimism, but negative thinking is inversely related to optimism. This finding implies that positively oriented students do not necessarily expect in general that good things will happen rather than bad things. Likewise, it can be said that optimists expect the best, but do not necessarily think a lot about a positive future. Compared to the other groups, however, positively oriented students are like optimists insofar as they tend not to think about negative possibilities. Those who are pessimistic, however, do think a lot about negative possibilities, as is evident from the strong correlation of negative thinking and optimism. Actually, the positive correlations between defensive pessimism and negative thinking confirm the view that realists and negatively oriented students might be more ready for potential negative future experiences than the other groups. Realists, unlike negatively oriented students, might have the motivational advantages of positive thinking on the one hand, and preparative advantages of negative thinking on the other hand (Oettingen \& Mayer, 2002).

I expected that students with a realistic orientation would score higher on proactive coping than positively oriented students. I found, however, that their scores are 
at the same level (after taking into account differences between realists and positive thoughts on social desirability). Surprisingly, positively oriented students reported that they are proactive copers, comparable to those deemed to be realistically oriented. Given that positively oriented students report that they do not give much thought to negative possibilities (at least in an academic context), it is puzzling that they would endorse proactive coping items like "Rather than acting impulsively, I usually think of various ways to solve a problem" and "In my mind I go through many different scenarios in order to prepare myself for different outcomes". One reason might be the nature of the proactive coping style questions that are too general to reflect the differences among orientation groups that were formed by the frequency of future-related academic thoughts. It will be important for future research to examine the relations of proactive coping to positive and realistic orientations in a more specific context. This is an issue to which I will return in Studies 2 and 3.

I also expected that realistically oriented students would score higher on avoidant coping than positively oriented students. However, I did not find any differences between orientation groups. Positive and negative thoughts are not related with items like "When I have a problem I usually let it sit on the 'back burner' for a while". Similar to the proactive coping style measure, avoidant coping style is a broad measure of coping. Some students might be more avoidant, for example, in the context of school work than others, however, a general measure of avoidant coping may not differentiate them. 


\section{Chapter 7: Study II}

\section{Overview}

The main purpose of the second study was to test the adaptive function of a realistic orientation, measured in September, as it plays out over the academic year. Spending about two terms at Carleton University, many students experienced a wide range of difficulties. In this study, I examine whether students who are realistically oriented will cope more successfully with these difficulties during their transition to university relative to students who are more positively oriented or negatively oriented.

I have argued that constructive realism should be assessed with reference to a particular context. That is, rather than assessing a general tendency to think realistically in a variety of contexts, I have argued for an assessment approach that focuses on what one is thinking in a particular context - in this case, the transition to university. If one assesses orientations in a contextual fashion, then it also makes sense to assess outcomes of interest contextually. For instance, one possible reason why I found in Study 1 that realistically oriented and positively oriented students did not differ on proactive and avoidant coping may be owing to the fact that coping was assessed as a general coping style. Therefore, in the present study, I will use as my main outcome measure a scale assessing satisfaction with university, as opposed to the more general satisfaction with life scale. I will, however, include a measure of general life satisfaction for the sake of comparison. I anticipate that although satisfaction with university and satisfaction with life scores will be correlated positively across participants, the effect of a realistic orientation will be more evident with the former measure. 
Hypothesis 1: I hypothesize that students who possess a realistic orientation in September will report greater satisfaction with university relative to those who are positively oriented or negatively oriented, especially when there are difficulties during the transition. I also will test whether this same effect holds for satisfaction with life.

As noted in the general introduction (Chapter 3), I am also interested in investigating the role that attachment orientation plays in one's satisfaction during the transition to university. Given that the attachment system is assessed at a broader level (i.e., it is not context-specific), I expect that the effect of attachment style will be evident at the contextual level (satisfaction with university) and at the general level (satisfaction with life). With respect to the adaptive function of attachment orientation, I expect that secure attachment, as a valuable personal resource, will predict adjustment to university and satisfaction with life. Specifically, those who are low in attachment avoidance and attachment anxiety are expected to report higher levels of satisfaction with university and satisfaction with life. I anticipate that increasing levels of attachment anxiety and attachment avoidance from Time 1 to Time 2 would be associated with decreasing levels of satisfaction with university and satisfaction with life.

Hypothesis 2: It is hypothesized that a secure attachment orientation and change towards attachment security would positively predict satisfaction with university and satisfaction with life.

It is also predicted that change in one's attachment orientation can be predicted by one's orientation to future. If a positively biased or negatively biased future orientation brings about ineffective coping during stressful times, then it might have a negative 
impact on one's attachment relationships. I anticipate that while positively or negatively oriented students might be overwhelmed during transition and would change towards attachment insecurity, realistic students would be less affected by the transition stress and would remain stable or change towards greater attachment security.

Hypothesis 3: It is hypothesized that relative to students who are realistically oriented, students who are positively oriented and students who are negatively oriented are likely to shift in their attachment orientation towards increased attachment anxiety and attachment avoidance.

As I reported in the introduction section of this dissertation (Chapter 3), past research indicates that attachment-anxiety and attachment-avoidance are powerful predictors of well-being. Given the significance of the literature indicating positive outcomes of attachment security, I assess whether a balanced view of potential future events (i.e., being realistic in one's orientation to university) might contribute to the university satisfaction of students over and above their attachment orientation, especially when they face with adversities. Since positive and negative anticipatory thoughts are context-specific variables, I also assess whether a realistic orientation to university predicts satisfaction with university over and above broad measures of attachment security. That is, Hypothesis 5 assesses whether a realistic orientation has incremental validity in the prediction of satisfaction with university and satisfaction with university over and above attachment security. As stated in Hypothesis 1, I will also include a measure of general life satisfaction for the sake of comparison.

Hypothesis 4: Students who are realistic in their orientation (relative to those who are positively oriented or negatively oriented) will report greater satisfaction with 
university, even after controlling for the effects of attachment orientation as measured in Time1 and Time2.

Prior research indicates that social support is an important predictor of well-being (e.g., Davis, Morris \& Kraus, 1998). Therefore, I will control the possible effects of perceived social support on outcome variables. I will also include a measure of perceived stress to observe the construct validity of the measure targeting transitional difficulties.

\section{Methods}

\section{Participants}

Participants were 341 first year university students at Carleton University who were enrolled the introductory psychology course. There were 242 (71\%) female and 99 (29\%) male students. The age mean was 19 years $(S D=3.53)$. There were 7 students who were older than 3 standard deviations from the mean whose ages were later adjusted to 30 years (approximately +3.0 SD). These 340 students were among the 1294 Psychology 1001 students who had filled out the mass testing survey at the beginning of the academic year (26.4\%). Single, unattached students represented $58 \%$ of the sample. About $4 \%$ of the students were in common law relationships, $2 \%$ were married, less than $1 \%$ were separated, divorced or widowed, and $36 \%$ were in a romantic relationship. Those students who did not have a prior university or college experience represented $75 \%$ of the sample 3 . Students completed the questionnaire between mid January and the end of March 2008, the time of the year that students tend to report higher levels of dissatisfaction. After their

\footnotetext{
${ }^{3}$ It is not clear what prior college or university experience involved as I did not ask students to describe their prior experience.
} 
Christmas holiday, students refocus their course work with the beginning of the Winter term. The effects of weather changes with increasing academic responsibilities may have a certain influence on both academic and life satisfaction of university students. Forty one students from the Study 1 participated in Study 2.

\section{Procedure}

Students who had participated in mass testing at the beginning of the academic year were invited to participate in a second online study titled as "A Study of Understanding Transition to University". The study was advertised in the Winter term (mid January 2008) on the web page of the online recruitment system of the psychology department. Those who finished this survey were granted 0.5 percentage increase in their course grade. The complete survey is provided in Appendix B.

\section{Description of measures}

Demographics. Students were asked to report their gender, age, relationship status and prior university experience at the beginning of the survey.

Satisfaction with University. Satisfaction with university was measured with the modified version of the Academic Major Satisfaction Scale (AMSS; Nauta, 2007). The unidimensional AMSS has 6 items (e.g., "I often wish I hadn't gone to this major", "I wish I was happier with my choice of an academic major"). Each item is rated on a 5point scale from "Strongly disagree" to "Strongly agree". I modified the instrument by replacing "major" with "university". Cronbach's alpha was 0.91 . This measure was positively correlated with Satisfaction with Life (described below; $r(340)=0.27, p$ 
$<.01$ ), although the somewhat modest correlation suggests that Satisfaction with University and Satisfaction with Life represent fairly distinct constructs. Test-retest correlation of satisfaction with university with 41 participants from the first study was $\operatorname{good}(r(41)=0.86, p<.001)^{4}$

Satisfaction with Life. To measure one's overall life satisfaction, the Satisfaction with Life Scale was used (SWLS; Diener, Emmons, Larsen, \& Griffin, 1985; Pavot, Diener, Colvin, \& Sandvik, 1991). This scale has five items (e.g., "In most ways my life is close to my ideal"') which are rated using a 7 point Likert type scale from "Strongly disagree" to "Strongly agree". Cronbach's Alpha was 0.87 .

Relationships Structures (RS) Questionnaire. The RS is a brief measure of adult attachment dimensions containing 10 Likert-type items assessing attachment-related anxiety (4 items) and avoidance (6 items) in two factors (Fraley et al., 2006). The scale is developed to measure attachment to different targets such as parents and romantic partners. Sample items include ("I worry that this person won't care about me as much as I care about him or her" and "I don't fully trust this person"). Participants were instructed to answer the questions with respect to someone to whom they feel closest (e.g., dating or marital partner, mother or father, or the best friend). The Cronbach's alpha was 0.88 for anxiety subscale, and 0.82 for avoidance subscale. The correlation between the two subscales was $r=0.43, p<.01$. This measure was also administered in the mass testing (Time1) and alpha coefficients for anxiety and avoidance were 0.88 and 0.82 , respectively $(r=0.35, p<.01)$. Attachment anxiety in Time1 was positively correlated

\footnotetext{
${ }^{4}$ As a part of Colleen Rainey's honours thesis, satisfaction with university was also measured in Study 1, but was not discussed.
} 
with attachment anxiety in Time2 $(r(337)=0.50, p<.01)$. Similarly, attachment avoidance in Time1 was positively correlated with attachment avoidance in Time2 ( $r$ $(337)=0.52, p<.01)$. Paired t-tests of the mean differences indicated that there were no significant changes in overall means from Time1 to Time2 on attachment anxiety and attachment avoidance $(t \mathrm{~s}<|1.0|)$.

Multidimensional Scale of Perceived Social Support (MSPSS). Social support was measured by the Multidimensional Scale of.Perceived Social Support. This questionnaire consists of 12 items measuring support from family, friends and significant others separately. Each factor contains 4 items, sample items include "I get the emotional help and support I need from my family" and "I have a special person who is a real source of comfort to me" (Zimet, Dahlem, Zimet, \& Farley, 1988). For the current research, social support was calculated globally by computing the mean of the 12 items (Cronbach Alpha $=0.91)$.

Perceived Stress Scale (PSS). Stress was assessed with the Perceived Stress Scale. This questionnaire consists of 10 items of which 4 are positively formulated (e.g., "In the last month, how often have you felt that things are going your way?") and 6 are negatively formulated (e.g., "In the last month, how often have you felt that you were unable to control the important things in your life?"). The PSS can be used for the assessment of nonspecific, appraised stress during the last month (Cohen, Kamarck, Mermelstein, 1983). Current alpha coefficient was $0.90(M=2.92, S D=0.68)$.

Difficulties in Transition to University Scale (DITS). To measure the level of difficulty experienced by students, I constructed an index of difficulties based on items used to assess their orientation to university. The 15 items for this scale map onto the 
negative OUS items that referred to challenges of first year experience (i.e., academic and social). For instance, whereas students were asked in September how frequently they thought about getting good grades in their courses, and how frequently they thought about how they would handle being alone, now they were asked how difficult it has been to get good grades in their courses or managing loneliness. I asked, a) whether the difficulty occurred (answered yes or no), and, if yes, b) the extent to which this aspect of the transition has been difficult. A four point response scale was used which ranged from "not at all" (1) to "very" (4).

The index of difficulties was composed of the number of difficulties experienced and perceived difficulty ratings. Number of difficulties was calculated by summing all the occurred difficulties (i.e., possible range 0 to 15 ; actual range 0 to $15, M=7.33, S D=$ 3.41). Perceived difficulty ratings were calculated by summing all the ratings of the reported difficulties (possible range 0 to 60 ; actual range 0 to $54, M=20.85, S D=11.13$ ). The alpha for the 15 item perceived difficulty scale was 0.80 . Mean difficulty rating per difficulty was $M=2.77(S D=0.43)$.

In addition to the 15 item difficulties scale, participants were provided 5 additional blank lines to report other difficulties experienced but not reflected in previous items. About $40 \%(n=135)$ of the students reported at least one extra difficulty. Students reported a wide range of difficulties that were mostly personal in nature, including "dealing with loss of a loved one", "a big break-up", "getting enough sleep", "being raped", "transportation", "erectile dysfunction"," personal problems" and "trying to figure out myself'. Number of difficulties was calculated by summing the extra difficulties (possible range 0 to 5 ; actual range 0 to $5, M=2.08, S D=1.39$ ). Perceived 
difficulty ratings were calculated by summing the ratings of the extra difficulties (possible range 1 to 20 ; actual range 1 to $20, M=6.71, S D=4.50$ ). Mean difficulty rating per difficulty was $M=3.29(S D=0.70)$. Because extra difficulties had higher severity ratings than the 15 item difficulties scale $(t(131)=8.31, p<.001)$, I treated extra difficulties as a separate variable. The two indices of difficulty ratings were positively correlated $(r(135)=0.25, p<.01)$. Number of difficulties and perceived difficulty ratings were moderately and positively correlated with perceived stress $(r(340)=0.44, p$ $<.01, r(340)=0.50, p<.01$, respectively)

\section{Results}

Demographics. To find out the degree to which demographic factors correlated with the main outcome (and also validity and control) measures (i.e., satisfaction with life, satisfaction with university, perceived stress, perceived social support), a series of analyses were conducted with age, gender, relationship status and prior experience. Age was slightly and negatively correlated with satisfaction with life $(r(337)=-0.11, p<$ $.05)$, but not with other measures. Gender, relationship status and prior college experience were found to be significant predictors of a number of dependent variables. Female students reported higher stress $(F(1,339)=22.68, p<.001)$, and social support $(F(1$, $339)=10.70, p<.01)$ than did male students. Single students reported lower levels of social support $(F(1,335)=15.41, p<.001)$ and satisfaction with life $(F(1,335)=3.08$, $p=.08$ ) than did students who were in a relationship. The time interval between beginning of the term and date of the survey completion was not significantly correlated 
with the outcome measures. Gender, relationship status and prior college experience were not significantly correlated with the rest of the dependent variables.

Group differences. Analyses were conducted to determine the extent to which demographic factors covaried with orientation to university. For these analyses, Realists were defined as at least $+/-1 / 4 \mathrm{SD}$ above the mean on positive thoughts and negative thoughts at mass testing. Positively oriented students were defined as those who were at least $1 / 4$ standard deviation above the mean on positive thoughts and at least $1 / 4$ standard deviation below the mean on negative thoughts at the mass testing, and so on. There were 81 realists (34\%), 46 positively oriented (19\%), 41 negatively oriented students (17\%), 70 not-oriented (29\%) students in groups. The differences between four orientation groups were tested on age (17-30), gender, prior college experiences (i.e., having an experience or not) and relationship status (i.e., being in a romantic, married, common-law relationship or not). There were significant differences among groups in age $(F(3,232)=$ $8.33, p<.001)$. Post-hoc comparisons indicated that positively oriented students $(M=$ $20.6 ; S E=.42)$ were significantly older than realists $(M=18.76 ; S E=.42)$, negatively oriented students $M=18.80 ; S E=.49)$ and the not-oriented group $(M=18.77 ; S E=.43)$. The groups differed in proportion who were female $\left(\chi^{2}(3,238)=18.94, p<.001\right)$. Eighty-four percent of the realists, $72 \%$ of positively oriented, $78 \%$ of negatively oriented students and $53 \%$ of not-oriented group were female. There was a significant difference among groups in their prior college experience $\left(\chi^{2}(3,236)=9.29, p=.03\right)$. Twenty-one percent of the realists, $44 \%$ of positively oriented, $23 \%$ of negatively oriented students and $22 \%$ percent of not-oriented group reported a prior college experience. Relationship 
status differed marginally between groups $\left(\chi^{2}(3,236)=6.22, p=.10\right)$. Forty percent of the realists, $59 \%$ of positively oriented, $35 \%$ of negatively oriented students and $40 \%$ percent of not-oriented group reported to be in a relationship.

There were significant differences among groups in the number of difficulties reported $(F(3,236)=5.23, p<.01)$. Post-hoc comparisons indicated that negatively oriented students $(M=9.63 ; S E=.76)$ reported significantly higher levels of difficulties than positively oriented $(M=7.63 ; S E=.56)$, and than the not-oriented group $(M=7.10$; $S E=.44)$. Realists were not significantly different from other groups $(M=8.78 ; S E=$ .36). There were also significant differences among groups in perceived difficulty ratings $(F(3,236)=6.00, p<.01)$. Post-hoc comparisons indicated that negatively oriented students $(M=28.75 ; S E=2.22)$ reported significantly higher levels of perceived difficulties than positively oriented students $(M=21.30 ; S E=1.79)$, and than the notoriented group $(M=19.84 ; S E=1.35)$. Realists $(M=25.55 ; S E=1.28)$ rated difficulties significantly higher than the not-oriented group. The table of correlation coefficients can be seen in Appendix B.

Hypothesis 1: Realistic orientation and adjustment to university. To test the hypothesis that realistically orientated students would adjust to university more easily than positively or negatively oriented students when transition to university is perceived to be relatively difficult, I have regressed perceived difficulty, positive thoughts and negative thoughts on satisfaction with university. First, difficulty ratings, positive thoughts and negative thoughts (after centering) were entered in the regression equation. Second, the two-way multiplicative interactions were calculated and entered in the 
equation. Finally, the three-way interaction term was entered into the equation. Results of the analysis are in Table 9. Difficulty ratings $(\beta=-.24, t(332)=-4.4, p<.01)$, positive thinking $(\beta=.18, t(332)=3.30, p<.001)$ and negative thinking $(\beta=-.12, t(332)=$ $2.16, p<.05)$ predicted satisfaction with university significantly. None of the two-way interaction terms were found to be significant (all $t$ s $(332)<1.4)$. The analysis also indicated that the three way interaction term was not significant $(t(332)<1.0$, see Figure 7). All the Tolerance values were above .80 , indicating that there were no problems with collinearity. The positive and negative thoughts main effects indicate that positively oriented students reported highest levels of satisfaction with university, followed by realistically oriented and not oriented students, followed by negatively oriented students ${ }^{5}$.

${ }^{5}$ To confirm this interpretation, I conducted a 2 (high versus low level of difficulty) X 4 (Realists or Positively oriented or Negatively oriented or Not-oriented group) ANOVA on satisfaction with university scores after categorizing thinking variables using a criterion of $+/-1 / 4$ of a standard deviation of the mean and controlling for perceived social support. There was a main effect of difficulties $(F(1,229)=16.83, p<.001)$, a main effect of orientation groups $(F(3,229)=5.71, p=.001)$, and a nonsignificant interaction effect $(F(3,229)<1.00)$. Collapsing over difficulties, post-hoc comparisons of orientation groups indicated that negatively oriented students $(M=3.67 ; 95 \% C I: 3.41$, 3.93) scored significantly lower than positively oriented students $(M=4.47 ; 95 \% C I$ : $4.23,4.71)$ than realists $(M=4.20 ; 95 \% C I: 4.02,4.38)$, and than not-oriented group $(M=$ 4.14; 95\% CI: 3.94, 4.34). The other comparisons were nonsignificant. However, the means for realists and not-oriented group were beyond the $95 \%$ confidence interval of positively oriented group, suggesting a trend. 
For all groups, greater difficulties were associated with less satisfaction with university.

When we add social support as a control variable, the results did not change significantly.

Similarly, covarying the effects of prior college experience, age and gender did not significantly change results. 
Table 9. The effects of difficulty ratings, positive thoughts and negative thoughts on satisfaction with university

\begin{tabular}{|c|c|c|c|c|c|c|c|c|c|c|c|c|c|c|c|}
\hline \multirow{2}{*}{ Model } & \multicolumn{5}{|c|}{$\overline{1}$} & \multicolumn{5}{|c|}{2} & \multicolumn{5}{|c|}{3} \\
\hline & $\mathrm{b}$ & $\mathrm{SE}$ & $\bar{\beta}$ & $t$ & Sig & $\mathrm{b}$ & SE & $\beta$ & $\mathrm{t}$ & Sig & $\mathrm{b}$ & $\mathrm{SE}$ & $\beta$ & $\mathrm{t}$ & Sig \\
\hline Difficulty & -0.02 & 0.00 & -0.24 & -4.40 & 0.00 & -0.02 & 0.00 & -0.24 & -4.32 & 0.00 & -0.02 & 0.00 & -0.24 & -4.19 & 0.00 \\
\hline $\begin{array}{l}\text { Positive } \\
\text { Thoughts }\end{array}$ & 0.20 & 0.06 & 0.18 & 3.30 & 0.00 & 0.25 & 0.13 & 0.22 & 1.91 & 0.06 & 0.25 & 0.13 & 0.22 & 1.87 & 0.06 \\
\hline $\begin{array}{l}\text { Negative } \\
\text { Thoughts }\end{array}$ & -0.11 & 0.05 & -0.12 & -2.16 & 0.03 & -0.08 & 0.09 & -0.09 & -0.88 & 0.38 & -0.08 & 0.09 & -0.09 & -0.87 & 0.39 \\
\hline $\begin{array}{l}\text { Negative * } \\
\text { Positive }\end{array}$ & & & & & & 0.00 & 0.01 & -0.03 & -0.27 & 0.79 & 0.00 & 0.01 & -0.03 & -0.26 & 0.80 \\
\hline $\begin{array}{l}\text { Difficulty * } \\
\text { Positive }\end{array}$ & & & & & & 0.00 & 0.00 & -0.05 & -0.43 & 0.67 & 0.00 & 0.00 & -0.04 & -0.42 & 0.68 \\
\hline $\begin{array}{l}\text { Difficulty * } \\
\text { Negative }\end{array}$ & & & & & & 0.06 & 0.05 & 0.07 & 1.36 & 0.18 & 0.06 & 0.09 & 0.07 & 0.62 & 0.54 \\
\hline $\begin{array}{l}\text { Difficulty * } \\
\text { Negative * } \\
\text { Positive }\end{array}$ & & & & & & & & & & & 0.00 & 0.00 & 0.01 & 0.07 & 0.94 \\
\hline$R^{2}$ Total & & & 0.11 & & & & & 0.12 & & & & & 0.12 & & \\
\hline
\end{tabular}




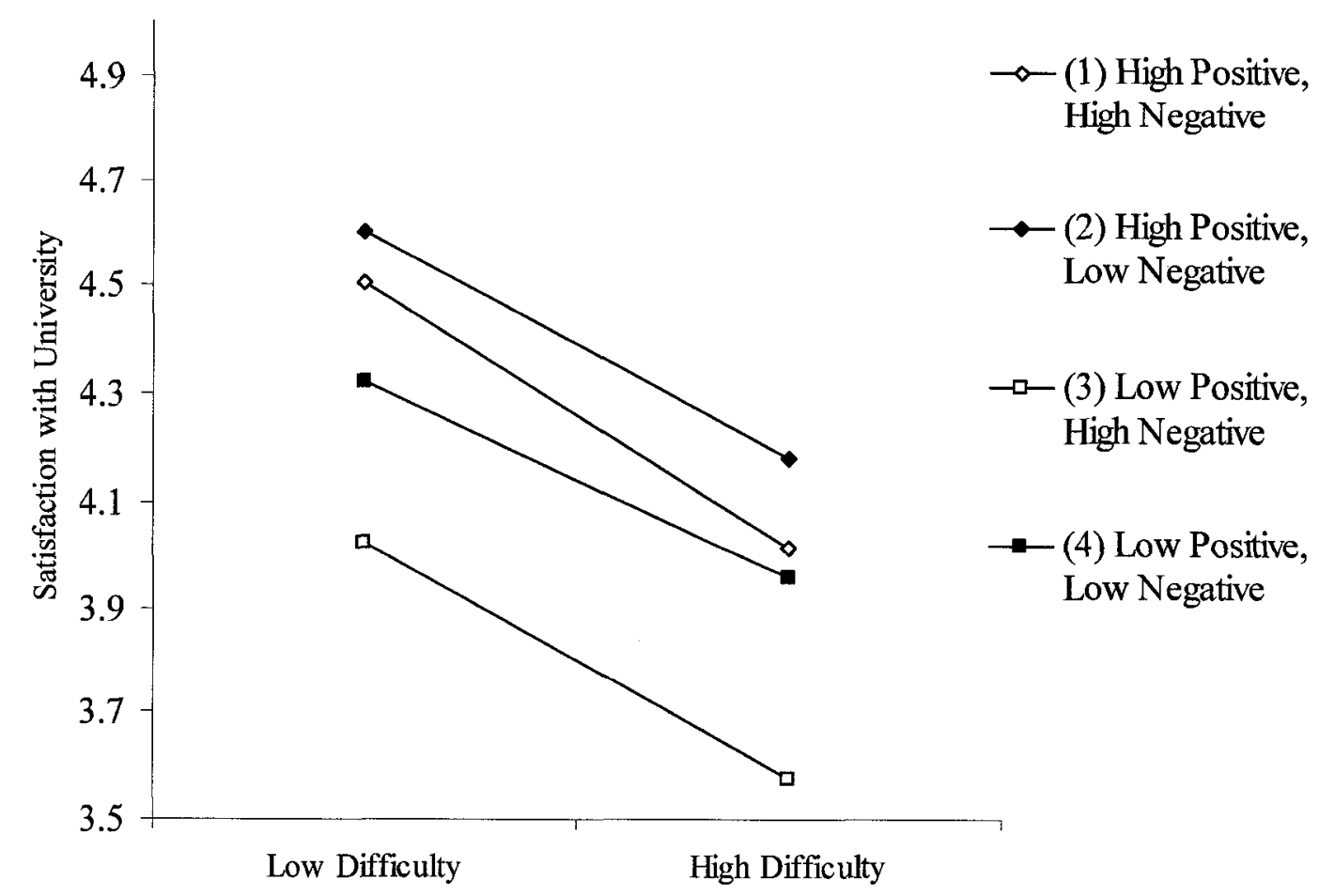

Figure 7. Satisfaction with university scores of orientation groups at low versus high level of difficulty 
Since overall scores of difficulties that students experienced did not interact with the OUS variables, I wondered whether having or not having extra difficulties can make a difference in the analysis. Extra difficulties tended to be more personal rather than academic or social; hence they might reflect idiosyncratic, emotionally significant and challenging difficulties. To test this idea, first, I dichotomized students into two groups: those who reported at least one extra difficulty which was "very difficult" $(n=103)$, and those who did not report any extra difficulty or who had extra difficulties that were not "very difficult" ( $n=237)$. Logistic regression with positive and negative thinking variables and their interaction indicated that there were no significant group differences on reporting or not reporting an extra difficulty $\left(\chi^{2}(3,340)=1.57, p=.67\right)$.

Before conducting the regression analysis, I also tested whether perceived social support would make a difference in the analysis. To test whether perceived social support interacts with thinking variables, I regressed perceived social support, positive thoughts, negative thoughts, the two-way multiplicative interactions and the three-way interaction term on satisfaction with university scores. Results showed that social support predicted satisfaction with university $(\beta=.17, t(338)=3.26, p<.01)$, but did not interact with positive thinking or negative thinking variables at any level of interaction (all $t \mathrm{~s}<\mid 1.14$, ns).

Given that social support only had a main effect on satisfaction with university, I have statistically controlled for it and tested the effects of future orientation when extra difficulties occur: Perceived social support (as a control variable), the dichotomous extra difficulty variable, positive thoughts, negative thoughts (after centering), the two-way multiplicative interactions and the three-way interaction term were regressed on 
satisfaction with university. Presence of an extra difficulty did not predict satisfaction with university $(\beta=-.07, t(332)=-1.34, p=.18)$. Positive thinking $(\beta=.19, t(332)=$ $3.44, p<.01)$ and negative thinking $(\beta=-.19, t(332)=-3.49, p<.01)$ were significant predictors. Extra difficulties interacted marginally with negative thinking $(\beta=.10, t(332)$ $=1.80, p=.07)$, and the analysis indicated that the three way interaction term was significant $(\beta=.16, t(332)=2.0, p<.05$, Table 10). 
Table 10. The effects of extra difficulties, positive thoughts and negative thoughts on satisfaction with university after controlling for the effects of perceived social support

\begin{tabular}{|c|c|c|c|c|c|c|c|c|c|c|c|c|c|c|c|}
\hline \multirow{2}{*}{ Model } & \multicolumn{5}{|c|}{1} & \multicolumn{5}{|c|}{2} & \multicolumn{5}{|c|}{3} \\
\hline & $b$ & $\mathrm{SE}$ & $\beta$ & $\mathrm{t}$ & Sig & $b$ & $\mathrm{SE}$ & $\beta$ & $\mathrm{t}$ & Sig & $b$ & $\mathrm{SE}$ & $\beta$ & $\mathrm{t}$ & Sig \\
\hline $\begin{array}{l}\text { Social } \\
\text { Support }\end{array}$ & 0.16 & 0.05 & 0.19 & 3.48 & 0.00 & 0.16 & 0.05 & 0.18 & 3.40 & 0.00 & 0.17 & 0.05 & 0.19 & 3.63 & 0.00 \\
\hline $\begin{array}{l}\text { Extra } \\
\text { Difficulty }\end{array}$ & -0.14 & 0.10 & -0.07 & -1.34 & 0.18 & -0.15 & 0.10 & -0.08 & -1.46 & 0.15 & -0.20 & 0.11 & -0.10 & -1.92 & 0.06 \\
\hline $\begin{array}{l}\text { Positive } \\
\text { Thoughts }\end{array}$ & 0.21 & 0.06 & 0.19 & 3.44 & 0.00 & 0.19 & 0.08 & 0.16 & 2.47 & 0.01 & 0.18 & 0.07 & 0.16 & 2.45 & 0.01 \\
\hline $\begin{array}{l}\text { Negative } \\
\text { Thoughts }\end{array}$ & -0.16 & 0.05 & -0.19 & -3.49 & 0.00 & -0.18 & 0.06 & -0.21 & -3.25 & 0.00 & -0.17 & 0.06 & -0.19 & -2.97 & 0.00 \\
\hline $\begin{array}{l}\text { Negative * } \\
\text { Positive }\end{array}$ & & & & & & 0.14 & 0.13 & 0.07 & 1.07 & 0.29 & 0.21 & 0.14 & 0.11 & 1.52 & 0.13 \\
\hline $\begin{array}{l}\text { Difficulty * } \\
\text { Positive }\end{array}$ & & & & & & 0.03 & 0.10 & 0.02 & 0.25 & 0.80 & 0.01 & 0.10 & 0.01 & 0.09 & 0.92 \\
\hline $\begin{array}{l}\text { Difficulty * } \\
\text { Negative }\end{array}$ & & & & & & 0.09 & 0.05 & 0.10 & 1.80 & 0.07 & -0.01 & 0.07 & -0.01 & -0.11 & 0.91 \\
\hline $\begin{array}{l}\text { Difficulty * } \\
\text { Negative * } \\
\text { Positive }\end{array}$ & & & & & & & & & & & 0.19 & 0.10 & 0.16 & 2.00 & 0.05 \\
\hline$R^{2}$ Total & & & 0.09 & & & & & 0.10 & & & & & 0.11 & & \\
\hline
\end{tabular}


Follow-up analyses at two levels of extra difficulties indicated that there was not a significant interaction effect of positive and negative thoughts when there are no extra difficulties $(\beta=-.01, t(232)=-.17, \mathrm{~ns})$. I did, however, obtain main effects for Positive thinking $(\beta=.16, t(232)=2.40, p<.01)$ and negative thinking $(\beta=-.20, t(232)=-3.11, p$ $<.01)$ among those reporting no extra difficulties. The two main effects suggest that positively oriented students reported the most satisfaction with university, followed by realistically oriented students and not-oriented students, who report more satisfaction than negatively oriented students (see Figure 8). The follow-up analyses, however, indicated that only positively oriented students significantly differed from the other groups. I conducted a 2 (having or not having an extra difficulty) X 4 (Realists or Positively oriented or Negatively oriented or Not-oriented group) ANCOVA on satisfaction with university scores after categorizing thinking variables using a criterion of $+/-1 / 4$ of a standard deviation of the mean and controlling for perceived social support. After saving the error term $\left(M S_{e}=.72\right)$ and conducting a one-way ANCOVA (at the level of no extra difficulties, $F(3,160)=4.22, p<.01)$, post-hoc comparisons of the orientation groups indicated that positively oriented students $(M=4.68 ; 95 \% C I: 4.34,5.01)$ scored significantly higher than realists $(M=4.08 ; 95 \% C I: 3.85,4.31, p<.05)$, negatively oriented students $(M=3.92 ; 95 \% C I: 3.62,4.22, p<.01)$, and the not-oriented group ( $M$ $=4.18 ; 95 \% C I: 3.96,4.40, p<.05)$. The other comparisons were nonsignificant $($ all $\mathfrak{q}<$ 2.99 , and $p>.10$ with harmonic sample size $n=36.84$ ).

When there were extra difficulties, however, positive thinking $(\beta=.36, t(98)=$ $3.26, p<.01)$ and negative thinking $(\beta=-.17, t(98)=-1.68, p=.10)$ predicted satisfaction with university (at least marginally). In addition, there was a significant 
interaction effect of positive and negative thoughts $(\beta=.26, t(98)=2.48, p=.02$, see Figure 8). Simple slope analyses at high levels of positive thinking indicated that there was no significant relationship between negative thinking and satisfaction with university $(\beta=.10, t(58)<1.00)$, indicating that there was not a significant difference between realists and positively oriented. At low levels of positive thinking, however, there was a significant and negative relationship between negative thinking and satisfaction with university scores $(\beta=-.38, t(39)=-2.53, p=.02)$, such that negatively oriented students scored significantly lower on satisfaction to university than did the not-oriented group.

Because I am also interested in comparing realists with negatively oriented students, I conducted simple slope analyses for those scoring high on negative thinking (as well, for the sake of completeness, as those scoring low on negative thinking). There was a significant and positive relationship between positive thinking and satisfaction with university at high levels of negative thinking $(\beta=.40, t(56)=3.28, p<.01)$, indicating that realists were significantly more satisfied with university than were negatively oriented students. At low levels of negative thinking, there was not a significant relationship between positive thinking and satisfaction with university scores $(\beta=.04, t$ $(41)<1.00)$, indicating that there was not a significant difference between positively oriented and not-oriented group.

These findings indicate that under conditions of extra difficulties, realists were as satisfied with university as were positively oriented students, and were more satisfied with university than were negatively oriented students. However, when no extra difficulties were reported, positively oriented students were more satisfied with university 
than were realistically oriented students. Covarying the effects of prior college experience, age and gender did not significantly change results. 


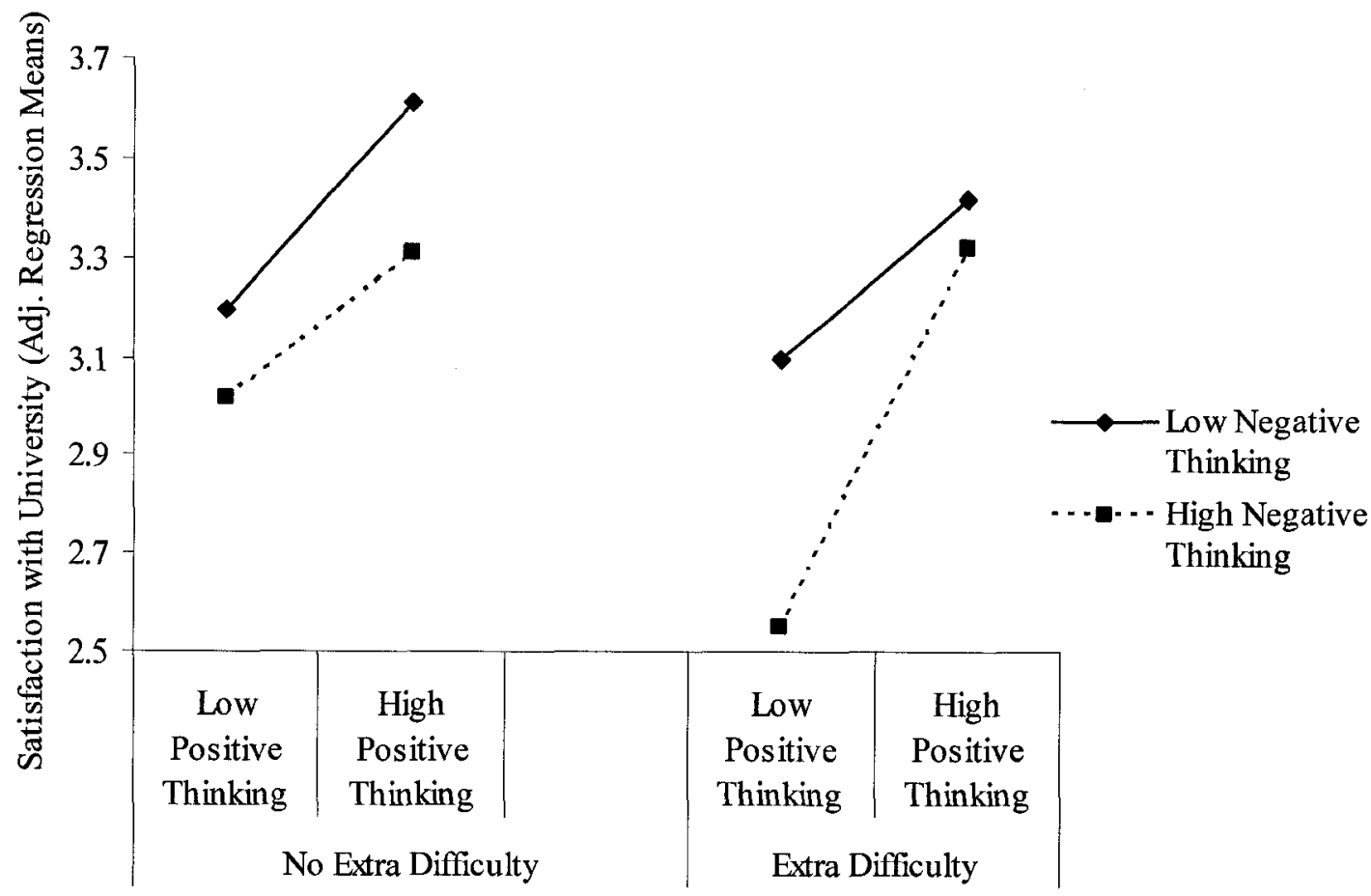

Figure 8. Adjusted Satisfaction with university scores of orientation groups with or without extra difficulty, after controlling for the effects of perceived social support 
I also ran parallel analyses to observe the effect of orientation and difficulties using life satisfaction as the dependent variable. I regressed positive thinking, negative thinking, extra difficulties, the two-way interaction terms and the three-way interaction term on satisfaction with life scores. I also controlled for the main effect of social support and also a marginal interaction of social support and extra difficulties $(\beta=.10, t(333)=$ $1.76, p=.08)$. Results showed that there was a marginally significant effect of positive thoughts $(\beta=.09, t(332)=1.72, p=.09)$, a significant effect of negative thoughts $(\beta=$ $.29, t(332)=-5.87, p<.001)$ and a significant effect of extra difficulties $(\beta=-.17, t(332)$ $=-3.62, p<.001)$. All other effects were nonsignificant and controlling the effects of prior college experience, age and gender did not significantly change the pattern results.

Because of the significant effect of negative thinking, realists and negatively oriented students seemed to be less satisfied with life than were positively oriented and the not-oriented group (see Figure 9). However, considering the marginal effect of positive thinking, it was important to follow this analysis with an ANCOVA in order to specifically compare orientation groups: I have categorized thinking variables using a criterion of $+/-1 / 4$ of a standard deviation of the mean and conducted a 2 (having or not having an extra difficulty) X 4 (Realists versus Positively oriented versus Negatively oriented versus Not-oriented group) ANCOVA on satisfaction with life scores, after controlling the effects of perceived social support and the marginal interaction of social support and extra difficulties. The main effect of the extra difficulties was significant $(F$ $(1,228)=6.23, p<.05)$. The effect of orientation groups was significant $(F(3,228)=$ $3.87, p=.01)$ and the two-way interaction was not significant $(F(3,228)<1.00)$. 
Collapsing over extra difficulties, post-hoc comparisons of groups indicated that negatively oriented students $(M=4.30 ; 95 \% C I: 3.90,4.69)$ reported marginally lower levels of satisfaction with university than positively oriented ( $M=4.96 ; 95 \% C I: 4.64$, 5.27), and significantly lower levels of satisfaction with university than not-oriented group ( $M=5.05 ; 95 \% C I: 4.71,5.38)$. Realists did not significantly differ from the other groups $(M=4.59 ; 95 \% C I: 4.34,4.84)$ and other comparisons were nonsignificant. 


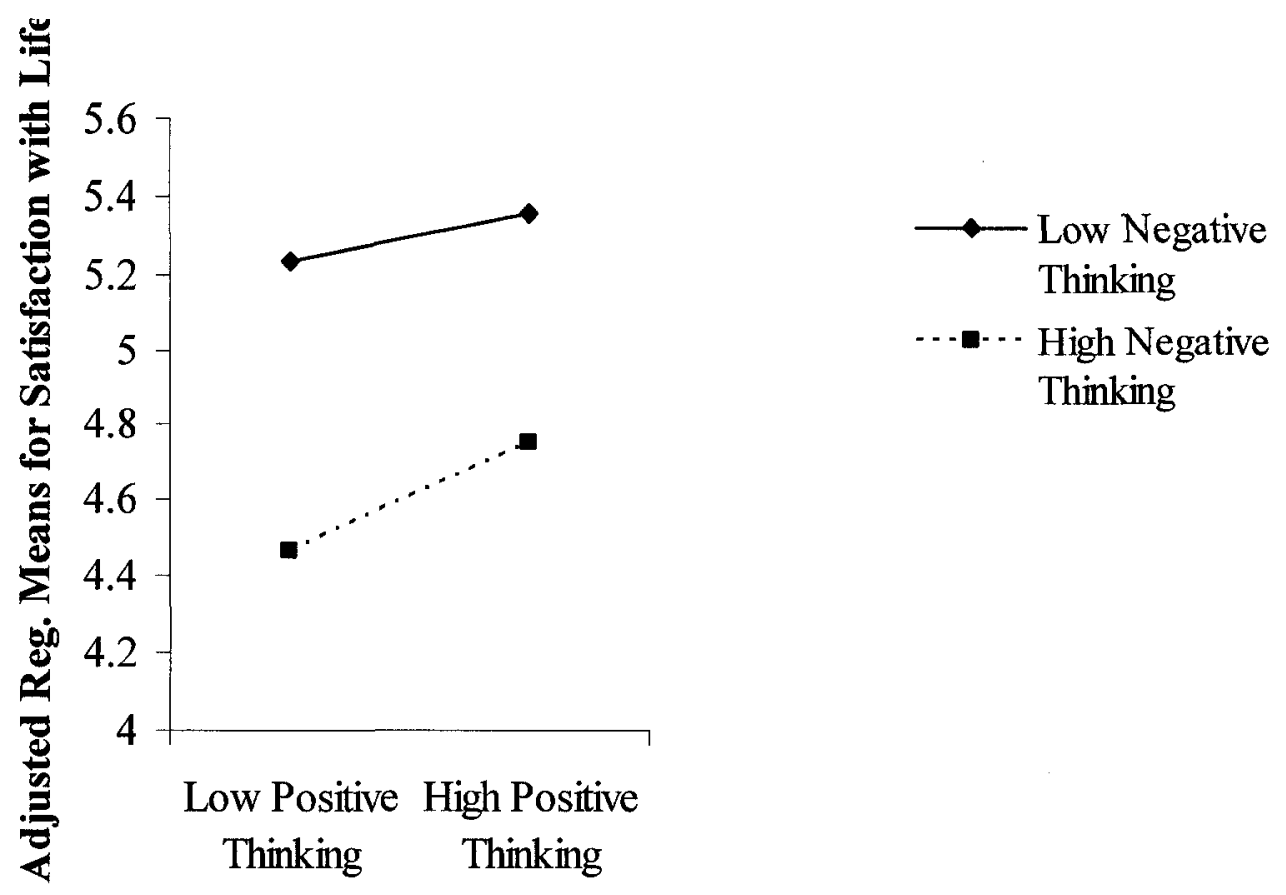

Figure 9. Adjusted Satisfaction with life scores of orientation groups. 
Hypothesis 3: Attachment orientation and adjustment to university. It was expected that secure attachment (low levels of attachment-anxiety and attachmentavoidance) at the beginning of the academic year - and change towards secure attachment - would predict satisfaction with university and satisfaction with life. Before testing this, I examined the stability of attachment anxiety and attachment avoidance Time1 to Time2. Attachment anxiety in Time1 was positively correlated with attachment anxiety in Time2 $(r(337)=0.50, p<.01)$. Similarly, attachment avoidance in Time1 was positively correlated with attachment avoidance in Time2 $(r(337)=0.52, p<.01)$. Paired t-tests of the mean differences indicated that there were not significant changes in overall means from Time1 to Time2 on attachment anxiety and attachment avoidance (all $t \mathrm{~s}<|1.0|$ ).

To test the hypothesis, first Time1 attachment variables and then Time2 variables were entered into hierarchical regression equations to predict satisfaction with university and satisfaction with life. With respect to satisfaction with university, attachment-anxiety at Time1 $(\beta=-.14, t(334)=-2.49, p<.05)$ significantly predicted satisfaction with university, but not attachment-avoidance $(\beta=-.02, t(334)<1.0$, see Table 11). That is, those students at Time1 reporting less attachment anxiety tended to report greater satisfaction with university at Time2. To assess whether change in attachment predicted satisfaction with university, Time2 attachment anxiety and attachment avoidance were added to the regression equation. Table 11 shows that Time2 attachment-anxiety $(\beta=-$ $.12, t(332)=-1.83, p=.07)$ and attachment-avoidance scores $(\beta=-.17, t(332)=-2.54, p$ $=.01)$ were (marginally) significant predictors of satisfaction with university $\left(R^{2}\right.$ change $=$ $.05, R^{2}$ total $\left.=.07\right)$. Students reporting decreasing anxiety and decreasing attachment avoidance reported better satisfaction with university. 
Table 11. The effects of attachment variables on satisfaction with university scores

\begin{tabular}{|c|c|c|c|c|c|c|c|c|c|c|}
\hline \multirow{2}{*}{ Model } & \multicolumn{5}{|c|}{1} & \multicolumn{5}{|c|}{2} \\
\hline & b & SE & $\beta$ & $\mathrm{t}$ & Sig & $\mathrm{b}$ & SE & $\beta$ & $t$ & Sig \\
\hline $\begin{array}{l}\text { Attachment } \\
\text { Anxiety Time1 }\end{array}$ & -0.09 & 0.03 & -0.14 & -2.49 & 0.01 & -0.04 & 0.04 & -0.06 & -1.01 & 0.31 \\
\hline $\begin{array}{l}\text { Attachment } \\
\text { Avoidance Time1 }\end{array}$ & -0.02 & 0.05 & -0.02 & -0.35 & 0.73 & 0.05 & 0.06 & 0.06 & 0.96 & 0.34 \\
\hline $\begin{array}{l}\text { Attachment } \\
\text { Anxiety Time2 }\end{array}$ & & & & & & -0.07 & 0.04 & -0.12 & -1.83 & 0.07 \\
\hline $\begin{array}{l}\text { Attachment } \\
\text { Avoidance Time2 }\end{array}$ & & & & & & -0.14 & 0.06 & -0.17 & -2.54 & 0.01 \\
\hline$R^{2}$ Total & & & 0.02 & & & & & 0.07 & & \\
\hline
\end{tabular}


With respect to satisfaction with life, attachment-anxiety in Time1 $(\beta=-.25, t$ $(334)=-4.48, p<.01)$ and attachment avoidance in Time1 $(\beta=-.13, t(334)=-2.43, p<$ .05 , see Table 12) significantly predicted satisfaction with life. That is, those students at Time1 reporting less attachment-anxiety and attachment-avoidance tended to report greater satisfaction with life at Time2. Adding attachment-anxiety and attachmentavoidance at Time 2 to the equation yielded significant effects for both. Time2 attachment-anxiety $(\beta=-.15, t(332)=-2.38, p<.05)$ and attachment-avoidance $(\beta=-$ $.15, t(332)=-2.38, p<.05)$ were significant predictors of satisfaction with life $\left(R^{2}\right.$ change $=$ $.05, R^{2}$ total $\left.=.15\right)$. Students reporting decreasing anxiety and decreasing attachment avoidance reported better adjustment to life in general.

Table 12. The effects of attachment variables on satisfaction with life scores

\begin{tabular}{|c|c|c|c|c|c|c|c|c|c|c|}
\hline \multirow{2}{*}{ Model } & \multicolumn{5}{|c|}{1} & \multicolumn{5}{|c|}{2} \\
\hline & b & SE & $\beta$ & $\mathrm{t}$ & Sig & $\mathrm{b}$ & SE & $\beta$ & $t$ & Sig \\
\hline $\begin{array}{l}\text { Attachment } \\
\text { Anxiety Time1 }\end{array}$ & -0.19 & 0.04 & -0.25 & -4.48 & 0.00 & -0.12 & 0.05 & -0.16 & -2.56 & 0.01 \\
\hline $\begin{array}{l}\text { Attachment } \\
\text { Avoidance Time1 }\end{array}$ & -0.15 & 0.06 & -0.13 & -2.43 & 0.02 & -0.07 & 0.07 & -0.06 & -0.98 & 0.33 \\
\hline $\begin{array}{l}\text { Attachment } \\
\text { Anxiety Time2 }\end{array}$ & & & & & & -0.16 & 0.07 & -0.15 & -2.38 & 0.02 \\
\hline $\begin{array}{l}\text { Attachment } \\
\text { Avoidance Time2 }\end{array}$ & & & & & & -0.12 & 0.05 & -0.15 & -2.38 & 0.02 \\
\hline$R^{2}$ Total & & & 0.10 & & & & & 0.15 & & \\
\hline
\end{tabular}


Hypothesis 4: Change in attachment security as a function of orientation to university. In this phase of the analyses, I tested the idea that change in attachment anxiety and avoidance could be predicted as a function of orientation to university. Particularly, it was hypothesized that positively and negatively oriented students would be more likely than realistic students to change towards attachment insecurity. Before conducting these analyses, however, it is important to assess the extent to which each group (realists, positively oriented, negatively oriented, not-oriented) has room to shift. If one group is near the ceiling or floor on attachment-anxiety or attachment-avoidance, their ability to shift towards security (or insecurity) will be constrained. To assess this possibility, I formed orientation groups using a criterion of $+/-1 / 4$ of a standard deviation of the mean on thinking variables and tabulated their attachment-anxiety and attachmentavoidance scores. Considering the range on the attachment style measure ( 1 to 7 , where 1 represents low anxiety or low avoidance), means at Time1 indicate that negatively oriented students $(M=2.95 ; 95 \% C I: 2.38,3.51)$ had more room to change towards lower levels of attachment-anxiety, than realists $(M=2.13 ; 95 \% C I: 1.78,2.49)$, positively oriented $(M=1.94 ; 95 \% C I: 1.57,2.32)$ and than not-oriented group $(M=2.03 ; 95 \% C I$ : $1.74,2.31 ; F(3,230)=4.36, p<0.01)$. With respect to attachment avoidance, all groups seemed to have comparable rooms to change towards higher or lower levels of attachment avoidance $(F(3,230)=1.23, \mathrm{~ns})$. For all groups, there was ample room for participants to become less securely attached (see Table 13). 
Table 13. Means and standard deviations of future orientation groups on attachment variables at Time 1

\begin{tabular}{|c|c|c|c|c|c|}
\hline & \multicolumn{2}{|c|}{$\begin{array}{c}\text { Time1 } \\
\text { Attachment-anxiety }\end{array}$} & \multicolumn{2}{|c|}{$\begin{array}{c}\text { Time1 } \\
\text { Attachment-avoidance }\end{array}$} \\
\hline & & $M$ & $S D$ & $M$ & $S D$ \\
\hline \multirow{4}{*}{$\begin{array}{c}\text { Future } \\
\text { Orientation }\end{array}$} & Realists & 2.13 & 1.61 & 1.91 & 1.02 \\
\hline & $\begin{array}{l}\text { Positively } \\
\text { oriented }\end{array}$ & 1.94 & 1.25 & 2.00 & 1.19 \\
\hline & $\begin{array}{l}\text { Negatively } \\
\text { oriented }\end{array}$ & 2.95 & 1.78 & 2.15 & 0.82 \\
\hline & Not-oriented & 2.03 & 1.16 & 2.21 & 1.06 \\
\hline
\end{tabular}

To specifically test the hypothesis that change in attachment anxiety and avoidance could be predicted as a function of orientation to university, a 2 (high vs. low positive thinking) X 2 (high vs. low negative thinking) X 2 (Time1 vs. Time2) mixed model MANOVA was conducted on attachment-anxiety and attachment-avoidance scores.

The multivariate within subjects test indicated that the effect of Time was not significant $(F(2,230)=1.31, p=.27)$, but there was a significant interaction effect of Time and positive thinking $(F(2,230)=4.36, p<.05)$. The interaction of Time and negative thinking and the three-way interaction term were not significant $(F \mathrm{~s}(2,230)=1$, ns).

Follow-up univariate tests on the significant interaction indicated that the interaction of Time and positive thinking was significant for attachment-avoidance scores $(F(1,230)=8.00, p<.01)$, but not on attachment anxiety scores $(F(1,230)<1.0$, see 
Table 14). There was an increase in attachment-avoidance scores (from $M=2.15, S E=.10$ to $M=2.42, S E=.10, t(131)=-2.26, p<.05)$ among students who were low in positive thinking at mass testing (i.e., negatively oriented and not-oriented group, see Figure 10), whereas there was no change over time (from $M=1.96, S E=.09$ to $M=1.86, S E=.10, t$ $(143)=0.95, \mathrm{~ns})$ in the attachment-avoidance scores of students who scored high in positive thinking at mass testing (i.e., realists and positively oriented). 
Table 14. Within-subjects effects on attachment variables by thinking variables

\begin{tabular}{|ll|c|c|c|c|}
\hline \multicolumn{1}{|c|}{ Source } & Measure & $d f$ & $M S$ & $F$ & Sig. \\
\hline Time & Anxiety & 1 & .929 & .878 & .350 \\
Time * Positive & Avoidance & 1 & .431 & .769 & .381 \\
Thinking & Anxiety & 1 & .065 & .062 & .804 \\
Time* Negative & Anoidance & 1 & 4.480 & 8.002 & .005 \\
Thinking & Avoidance & 1 & .391 & .698 & .404 \\
Time* & Anxiety & 1 & .716 & .677 & .411 \\
Positive*Negative & Avoidance & 1 & .385 & .688 & .408 \\
& Anxiety & 230 & 1.057 & & \\
Error (Time) & Avoidance & 230 & .560 & & \\
& & & & & \\
\hline
\end{tabular}




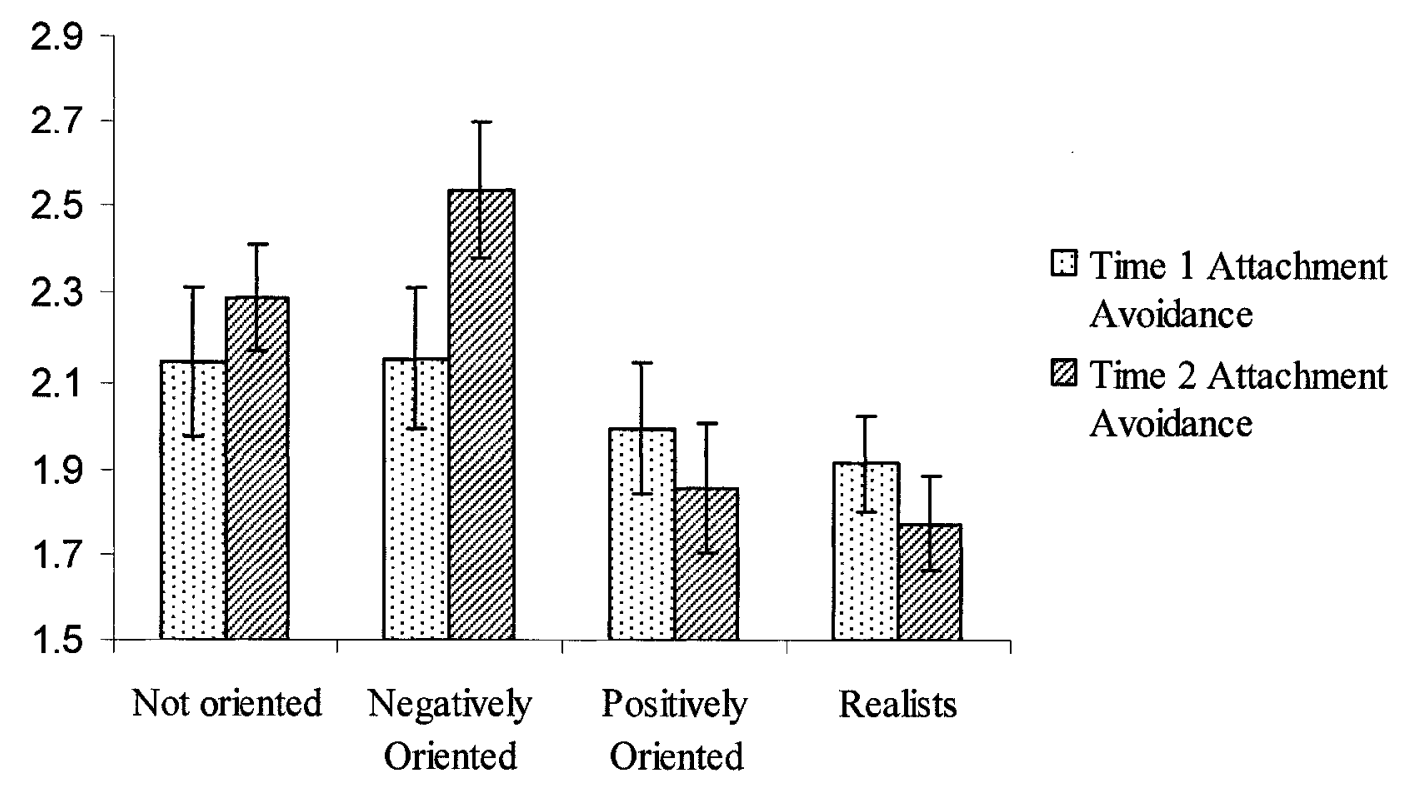

Figure 10. Change in attachment-avoidance from Time1 to Time2

The multivariate between subjects test indicated that there were main effects of positive thinking $(F(2,229)=6.83, p<.01)$ and negative thinking $(F(2,229)=4.72, p$ $=.01)$, but no significant interaction effect $(F(2,229)=1.44, p=.24)$.

Univariate tests of the significant between subjects effects indicated that the main effect of positive thinking was significant both on attachment-anxiety $(F(1,230)=8.09$, $p<.01)$ and on attachment-avoidance scores $(F(1,230)=11.43, p=.001$, see Table 15). Those students who scored high on positive thinking (i.e., realists and positively oriented) reported lower levels attachment-anxiety $(M=1.98, S E=0.11)$ and attachment avoidance $(M=1.89, S E=0.08)$ than did those students who scored low on positive thinking (i.e., negatively oriented and not-oriented group, $M=2.45, S E=0.12$ for anxiety and $M=$ 2.28, $S E=0.09$ for avoidance, see Figure 10 and Figure 11). The main effect of negative 
thinking was significant on attachment-anxiety $(F(1,230)=8.12, p<.01)$, but not on attachment-avoidance scores $(F(1,230)<1.0$, see Table 15$)$. There was also a marginal interaction effect of negative and positive thinking variables on attachment-anxiety scores $(F(1,230)=2.88, p=.09)$. Using the error term of the between subjects effects, the simple main effect of positive thinking at high level of negative thinking was found to be significant $(F(1,120)=10.39, p<.001)$, indicating that negatively oriented students $(M$ $=2.83 ; S E=.21)$ reported more attachment-anxiety than did realists $(M=2.08 ; S E=.15)$. However, the simple main effect of positive thinking at low level negative thinking was not significant $(F(1,110)<1.0)$, indicating the difference between positively oriented students and the not-oriented group was not significant in terms of attachment-anxiety. ${ }^{6}$

${ }^{6}$ These results were supported by follow-up analyses: I have categorized thinking variables using a criterion of $+1-1 / 4$ of a standard deviation of the mean and conducted a 2 (Time) X 4 (Realists versus Positively oriented versus Negatively oriented versus Notoriented group) ANOVA on attachment-anxiety and attachment-avoidance scores. With respect to attachment-avoidance, the effect of time was not significant $(F(1,232)<1.00)$ and the interaction of time and orientation was significant $(F(3,232)=2.94, p<.05)$. There were significant differences between orientation groups $(F(3,230)=4.82, p<$ .01). Collapsing over Time, post-hoc comparisons of groups indicated that Realists $(M=$ $1.84 ; 95 \%$ CI: $1.65,2.04)$ scored significantly lower level of attachment avoidance than negatively oriented students $(M=2.35 ; 95 \% C I: 2.07,2.62)$ and than the not-oriented group $(M=2.29 ; 95 \% C I: 2.08,2.50)$. Positively oriented students did not significantly differ from any other group $(M=1.93 ; 95 \% C I: 1.66,2.19)$. With respect to attachmentanxiety, within subjects effects were nonsignificant $(F \mathbf{s}<1.00)$. There were significant 
Table 15. Between subjects effects on attachment variables by thinking variables

\begin{tabular}{|cc|c|c|c|c|}
\hline Source & Measure & $d f$ & $M S$ & $F$ & Sig. \\
\hline Positive & Anxiety & 1 & 24.327 & 8.088 & .005 \\
Thinking & Avoidance & 1 & 17.138 & 11.428 & .001 \\
Negative & Anxiety & 1 & 24.429 & 8.122 & .005 \\
Thinking & Avoidance & 1 & .061 & .041 & .840 \\
Positive & & & & & \\
Thinking & Anxiety & 1 & 8.654 & 2.877 & .091 \\
Negative & & & & & \\
Thinking & Avoidance & 1 & 1.219 & .813 & .368 \\
Error & Anxiety & 230 & 3.008 & & \\
& Avoidance & 230 & 1.500 & & \\
\hline
\end{tabular}

differences between orientation groups $(F(3,230)=5.10, p<.01)$. Collapsing over Time, post-hoc comparisons of groups indicated that negatively oriented students $(M=$ $2.83 ; 95 \% C I: 2.46,3.21)$ scored significantly higher than realists $(M=2.08 ; 95 \% C I$ : $1.81,2.34)$ positively oriented $(M=1.88 ; 95 \% C I: 1.52,2.24)$ and than not-oriented group $(M=2.08 ; 95 \% C I: 1.78,2.37)$. Other comparisons were nonsignificant. 


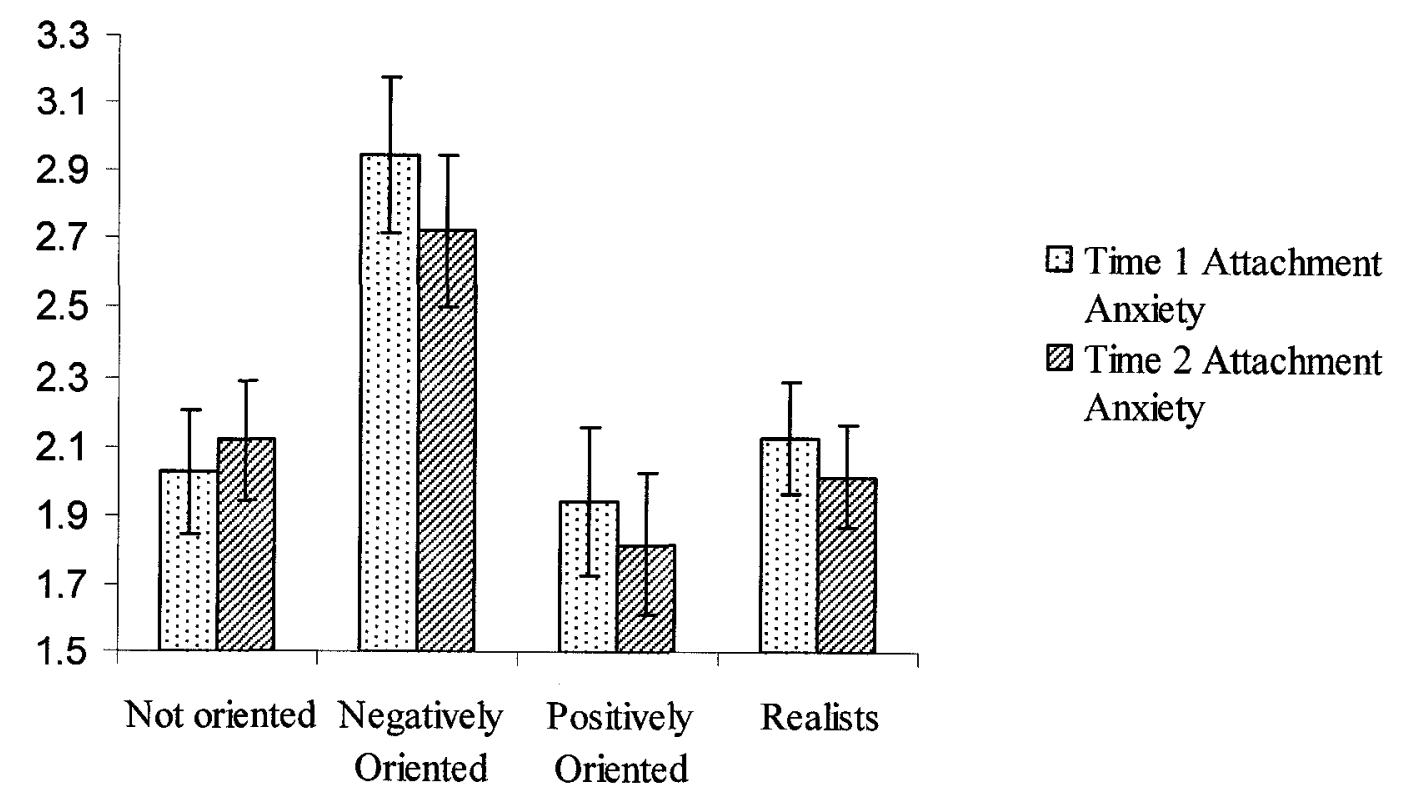

Figure 11. Change in attachment-anxiety from Time1 to Time2 
Hypothesis 5: Predicting satisfaction with university and satisfaction with life by the OUS over and above attachment dimensions. I tested whether frequency of positive and negative thinking would predict satisfaction with university and satisfaction with life over and above attachment orientation. In other words, Hypothesis 5 assesses whether realistic orientation has incremental validity in the prediction of satisfaction with university and satisfaction with life over and above attachment security. To test these hypotheses, parallel hierarchical regressions were conducted on the dependent variables of satisfaction with university and satisfaction with life. In these models, Time1 and Time2 attachment variables were first entered into the equations followed by positive and negative thinking variables, and finally the interaction of thinking variables.

With respect to satisfaction with university, we found that positive thinking $(\beta=$ $.18, t(330)=3.32, p<.01)$ and negative thinking $(\beta=-.17, t(330)=-3.11, p<.01)$ significantly predicted satisfaction with university over and above attachment variables $\left(R^{2}\right.$ change $=.04$, see Table 16). In addition, the interaction term of the thinking variables was marginally significant $\left(\beta=.09, t(329)=1.66, p=.10, R^{2}\right.$ change $\left.=.007\right)$. Simple slope analyses at high levels of negative thinking indicated that there was a significant and positive relationship between positive thinking and satisfaction with university $(\beta=.26, t$ $(143)=3.26, p=.001)$, indicating that there was a significant difference between realists and negatively oriented students such that realists reported greater satisfaction with university. At low levels of negative thinking, I also found a significant positive relationship between positive thinking and satisfaction with university $(\beta=.24, t(133)=$ $2.78, p<.01$ ), indicating that there was a significant difference between positively oriented students and not-oriented group. 
Simple slope analyses at high level of positive thinking indicated that the difference between realists and positively oriented students was not significant $(\beta=-.10, t$ $(167)=-1.27, n s)$. The analysis at low level positive thinking indicated that the difference between negatively oriented students and the not-oriented group was significant $(\beta=-.17$, $t(158)=-2.16, p=.03)$. The plotting of the regression means indicates that realists and positively oriented students report higher levels of satisfaction with university than did not-oriented group and negatively oriented students (see Figure 12).

Controlling the effects of perceived social support, prior college experience, age and gender did not significantly change the pattern of results. Results derived after entering extra difficulties as an independent variable yielded the same previous result with a significant three way interaction $(\beta=.16, t(313)=2.24, p=.03)$ : Realists and positively oriented students scored comparably in the presence of extra difficulties, and negatively oriented students seemed to be the least satisfied group. 
Table 16. The effects of positive and negative thinking on satisfaction with university after controlling the effects of attachment variables

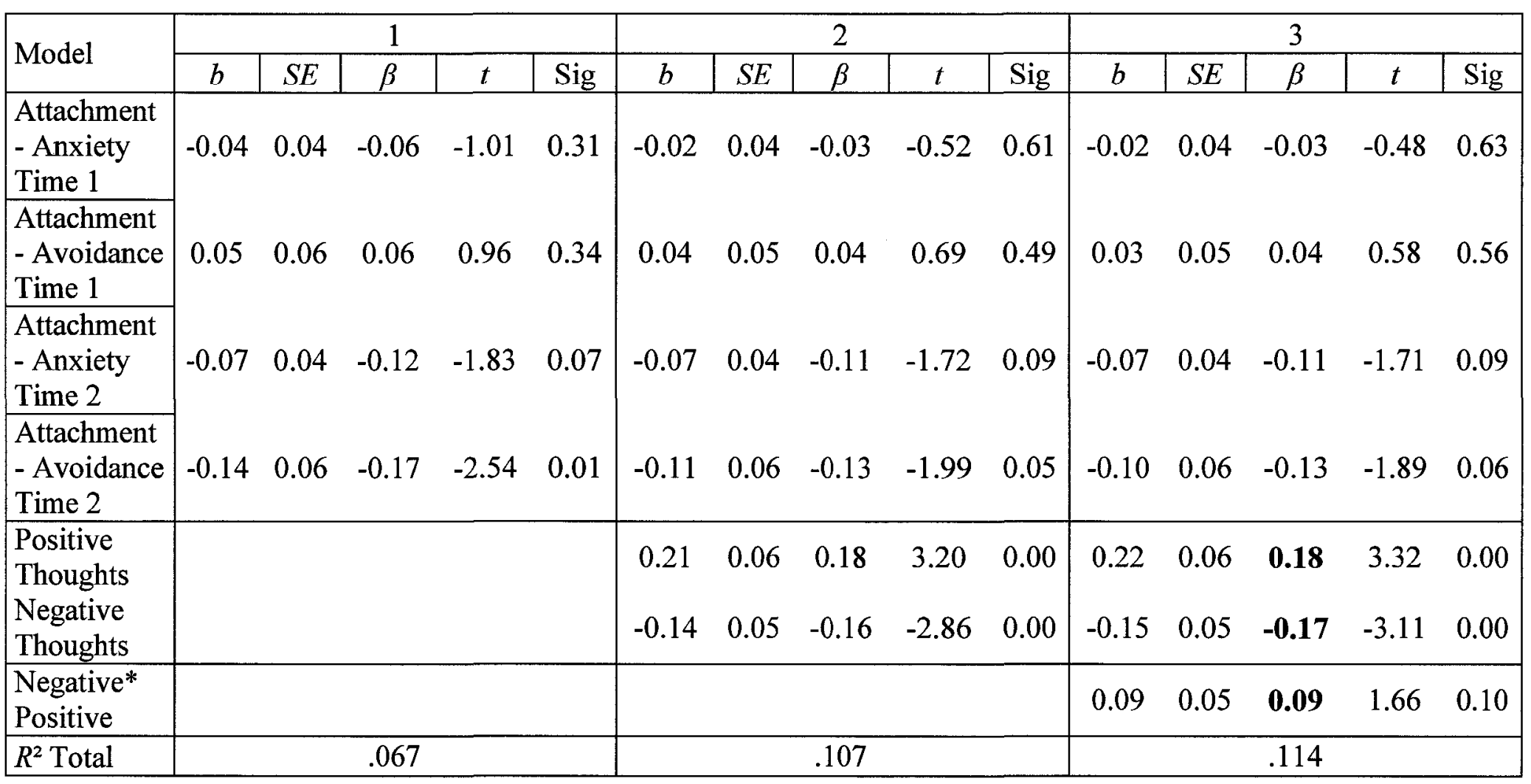


Figure 12. Adjusted satisfaction with university scores of orientation groups

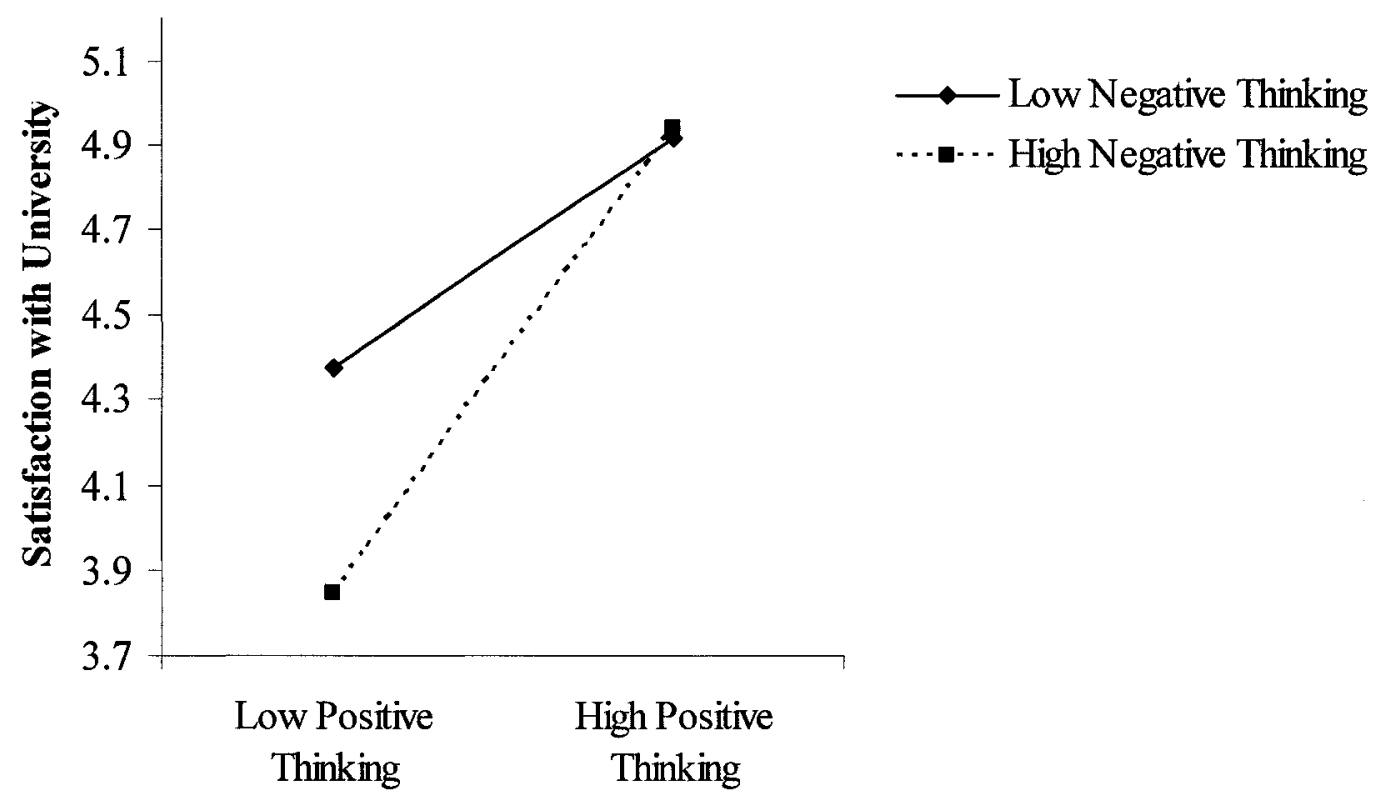

With respect to satisfaction with life, I found that negative thinking significantly predicted satisfaction with university over and above attachment variables $(\beta=-.26, t=$ $(330)=-4.85, p<.001)$. However, positive thinking $(\beta=.08, t=(330)=1.56, p<.12)$ and the interaction term were not significant $(\beta=.07, t=(329)=1.43, p=.16)$. Because, the effect of positive thinking was close to marginal, I also conducted a one-way ANCOVA on satisfaction with life in order to specifically compare orientation groups (using the four groups defined as at least $+/-1 / 4$ standard deviation on both variables). The analysis controlled for the effects of Time1 and Time 2 attachment variables. There were significant differences among groups $(F(3,226)=3.09, p<.05)$. Post-hoc comparisons indicated that negatively oriented students $(M=4.49 ; 95 \% C I: 4.13,4.84)$ 
scored significantly lower than not-oriented group $(M=5.10 ; 95 \%$ CI: $4.83,5.37)$.

Positively oriented ( $M=4.97 ; 95 \% C I: 4.64,5.30)$ and realistically oriented students ( $M$ $=4.70 ; 95 \% C I: 4.46,4.95)$ did not significantly differ from any other group.

\section{Discussion}

This second study was designed to test the idea that, first, a realistic orientation to university would be adaptive especially when difficulties occur during the transition to university life. Second, it was expected that a secure attachment orientation would buffer the stress of the transition. Third, I expected that any change in attachment orientation would be predicted by the presence or absence of a realistic orientation. Fourth, it was hypothesized that realism would predict adjustment to university over and above one's attachment orientation. I found partial support for each of these hypotheses.

Realistic orientation. Overall, the results showed that students with a realistic orientation were more satisfied with university than were negatively oriented students but not more than the positively oriented students. Although the difference between positively oriented students and realists were nonsignificant, the initial analysis conducted with overall difficulty ratings indicated that positively oriented students seemed to be more satisfied with university than were realists and negatively oriented students, regardless of the level of difficulties they reported.

I argued that the adaptive value of negative thinking can be best observed in a stressful context. The results suggest that although academic and social difficulties contribute to less satisfaction with university, the possession of a realistic orientation does not appear to protect students from the feelings of dissatisfaction. The reason why there 
was no protective effect of realistic orientation when difficulties occur might be the nature of difficulties. The occurrence and perception of difficulties experienced during the transition to university might be under one's control and dependent on one's selfefficacy beliefs and active efforts as suggested by Taylor and Brown (1994). In other contexts, such as transition to parenthood, the occurrence of difficulties such as a difficult childbirth might be out of one's control despite one's prior sense of control and optimistic expectations. Thus difficulties in the transition to parenthood might be uncorrelated with one's psychological preparation, as observed by Churchill (2005). In the context of the transition to university, however, it might be hard to detect such a sense of surprise or disappointment. Negative future thoughts, in this research, were positively correlated with the difficulty ratings. Hence, although students reported a number of difficulties, it seems that they were not unanticipated adversities. Students who had thought about potential negative difficulties actually experienced more difficulties than those who had not given much thought to the possibility of such difficulties. As a result, we did not obtain a significant interaction of future thoughts and difficulties in predicting satisfaction with university.

The analysis conducted with extra difficulties, however, confirmed the idea that surprising difficulties can be more challenging for negatively orientated students than for realistic students. Extra difficulties are more idiosyncratic and thus they seem to be emotionally more significant for the first year students than academic or social difficulties. Thus, extra difficulties might better represent the unexpected or surprising aspects of the transition to university than academic and social difficulties. When extra difficulties occur, I observed the protective capacity of a realistic orientation relative to 
other groups. Whereas negatively oriented students appear to have been affected negatively by extra difficulties, those who were realistic appear to be more resilient. It is important to note that although realistically oriented students tend to be more satisfied with university than negatively oriented students, the positively oriented students tend to be most satisfied. The difference between positively oriented students and those who are realistic shrinks to a nonsignificant level when there are extra difficulties, but it is not the case that realistically oriented students are more satisfied with university than positively oriented students.

The pattern of results was different when the dependent variable was satisfaction with life. With satisfaction with life as the dependent variable, I found that thought variables did not interact with extra difficulties. Positively oriented students were more satisfied than negatively oriented students and the difference between positively oriented and realists was not statistically significant. The unexpected result in these findings is likely owing to the predominantly academic content of the OUS. Results were meaningful when I matched the domain of the independent variable with the domain of the dependent variable. Similarly, because of the social nature of both attachment orientation and satisfaction with life, I found more meaningful results in analysing their relationships than were found in analysing the effects of attachment orientation on satisfaction with university (see below). Future research should focus on the extent of convergence between the domain of the realistic orientation and its effects on the domainspecific and domain-general experiences.

Attachment orientation. Another important aspect of this research was to test the idea that a secure attachment orientation would be psychologically supportive for first 
year students. As predicted, I found that decreasing levels (from Time 1 to Time 2) of attachment anxiety and attachment avoidance are significant predictors of satisfaction with university, and especially satisfaction with life. This is consistent with previous research conducted with university students (e.g., Bernier et al., 2004; Bernier et al., 2005; Larose, et al., 2005; Lapsey \& Edgerton, 2002; Lopez \& Gormley, 2002). In addition, as students' attachment security increased, they felt more satisfied with their university and with their life in general. It seems that those students who can meaningfully activate their attachment systems tend to be more satisfied than the others who become more avoidant or anxious in their relationships.

I also hypothesized that orientation to university can predict positive and negative changes in attachment security. As expected, there was some observed change in attachment orientation during the year that might be explained by university orientation. My analyses indicate that those with a positive orientation and those with a realistic orientation to university were most likely to maintain attachment security over the school year. Negatively oriented students and those who were not future oriented were more likely to shift towards increased attachment avoidance. With respect to attachment anxiety, all the groups stayed stable; however the negatively oriented students were the most vulnerable group to attachment anxiety. The change in attachment avoidance is consistent with the previous research indicating that attachment orientation might meaningfully change in the context of stressful life events and transitions (e.g., Cozzarelli et al., 2003; Waters, Hamilton \& Weinfield, 2000).

It is important to note that positively oriented students were as secure as realistically oriented students and were robust against change in attachment insecurity. 
Although I expected that positively oriented students would report significantly lower levels of attachment security than realists, it was found that they reported maintaining attachment security, as did realists. These results show that future-related positive and negative thinking are associated with attachment orientation and may be important predictors of change or stability in one's attachment orientation. The way individuals construct their future and anticipate future events may also have an effect on the way they perceive their close relationships in stressful times.

A final hypothesis related to both attachment and future orientation constructs was that a realistic orientation to university would predict greater satisfaction with university, even after controlling for the effects of attachment orientation as measured in Timel and Time2. Because attachment variables are powerful predictors of well-being, it was important to test whether contextual future-related thoughts can predict satisfaction with university over and above the quality of one's attachment orientation. Results showed that realists and positively oriented students were more satisfied with university than negatively oriented students, even after controlling the effects of attachment orientation. However, when satisfaction with life was a concern, only negative thinking predicted satisfaction with life over and above attachment variables, indicating that the contextspecific future-related thoughts can best predict context-specific dependent variables.

In sum, although the results do not support the hypothesis that students with a realistic orientation will cope with transition to university more effectively than positively oriented students, I was able show that realistically oriented students coped better than negatively oriented students, and coped as well positively oriented students under conditions of unanticipated stressors. In addition, these effects are not due to difference in 
attachment style. Indeed, I was able show that orientation to future partially explained shifts away from secure attachment.

Limitations of the study. Although Study 2 was generally successful insofar as it shows that negative thinking and positive thinking can be important predictors of adjustment to university and they predict change in attachment orientation, some limitations need to be acknowledged and addressed.

The first limit of the current study was the exclusively academic nature of the OUS. Since, the principal component analysis did not yield a discriminated pattern of positive social and negative social thoughts, I only used positive academic and negative academic thoughts as the dimensions of the OUS. Hence, the meaningful outcomes of the analyses conducted with the OUS were mostly associated with satisfaction with university scores. Developing a comprehensive measure of orientation to university, including social and personal aspects, will be important for future studies.

Second, it should be noted that the Timel data were gathered in SeptemberOctober 2007, about up to one month after first year students arrived at university. Students had already started to adapt to university environment, many of them had participated in university orientation programs and courses had started. It should be remembered, however, that realistic orientation was stable from September to January, and any change between August and September should be a change towards a more realistic orientation. Hence, despite the possibility that quality and frequency of future thoughts might have already changed and overly optimistic or overly pessimistic tendencies might have levelled in September, I was able to observe a pattern of result that 
was close to what I had expected. I predict that measuring orientation to university just before students start first year could result with stronger and more meaningful results.

Third, it is important to note that the effects of future orientation may vary as a function of the outcome variables. For example, concrete or behavioural outcomes, such as course grades or frequency of using university services, could be measured as an indicator adjustment and academic engagement. Using more objective outcome variables can also help controlling the effects social desirability.

A final limitation is that the level of inquiry of adjustment in this study was considerably high. Although students were asked how satisfied they were in general with their lives and with university, we do not know what happens to realistic or unrealistic students (i.e., positively oriented, negatively oriented and not-oriented group) when they are in a specific academic or social context, for example, taking a test, dealing with a midterm essay, or trying to deal with roommate problems or problems with close relationships. It is a question how different orientations to university play out in these specific contexts of university life. I consider this in Study III.

To further our understanding of the effects of realistic and positively biased orientations in challenging situations, we designed an experimental study using a specific situation often experienced by students. In Study II, it was found that both positively oriented and realistically oriented students report comparable levels of satisfaction with university despite the presence of unexpected difficulties. Positively oriented students, however, reported higher levels of social desirability than did realistically oriented students in Study I. Since self-report measures like satisfaction with university are affected by social desirability, an experimental setting can help us uncover some 
differences between realists and positively oriented students in coping with stress. More specifically, designing an experiment, I wanted to further explore the differences in how realists and positively oriented students would cognitively and emotionally engage in an unexpected academic challenge and how they would react to a disappointing outcome. 


\section{Chapter 8: Study III}

\section{Overview}

In Study I and Study II, presented some evidence that positively oriented students tend to protect their well-being despite the presence of unexpected difficulties. Although positively oriented students seemed less robust against difficulties than were realists, their scores on satisfaction measures were comparable with realists' scores. However, one major difference between realists and positively oriented students is the fact that, as shown in the Study I, positively oriented students tend to use defensive strategies such as impression management and self-deception. It is a question whether positively oriented students might be associated with defensive reactions to negative events or future possibilities. Hence, I wanted to explore differences in how realists and positively oriented subjects respond to a specific unexpected academic challenge.

To further our understanding of how realists and positively oriented students cope with stressful situations, we designed an experimental study ${ }^{7}$. To explore the possible differences in anticipatory coping strategies, we challenged realistic and positively oriented first year students with a difficult "IQ test". We wanted to determine (a) whether realists and positively oriented students differ in their performance expectancies, actual performance, and their perception of past performance, and (b) how realists and positively oriented students differ in the way they respond emotionally to an unexpected stressor. To achieve this, we not only compared groups based on their pre-existing differences in future orientation, but also manipulated their presumed preparatory coping

\footnotetext{
${ }^{7}$ Study 3 was conducted with Stephanie Blust who reported the data in her honours thesis.
} 
strategies. That is, half of the participants were instructed to prepare for the upcoming test by imagining success whereas the other half was instructed to imagine both success and failure. If realists differ from positively oriented students in their propensity to prepare by imagine failure, then the effect of preparatory instructions should mirror the effect of preexisting orientation.

The focus in this study is on students' expectancies of success just before the test, their test performance, and their perceived performance prior to feedback. To the extent that positively oriented subjects (and those instructed to prepare as such) do not consider the possibility of doing poorly, they may develop unrealistically positive performance expectancies. But how will they respond when the test is more difficult than they had anticipated? Cognitive Adaptation Theory (Taylor, 1983) suggests that they might engage in self-protective strategies to minimize the emotional impact of the subpar performance, including convincing themselves that they really did fairly well (i.e., interpreting any ambiguous evidence in a favourable light). Those who possess a realistic orientation, or are instructed to prepare by considering both success and failure, on the other hand should be less likely to use such self-protective strategies, and thus should be more likely to accurately interpret their performance. Thus, in the context of a difficult test, I have specifically hypothesized that:

1. Relative to positively oriented subjects, realistically oriented subjects will set lower, more realistic expectations, and will be more likely to acknowledge subpar performance by lowering their post performance self-assessment.

2. Instructing subjects to prepare by imagining only success, relative to instructions to prepare by imagining both success and failure, will lead 
subjects to make unrealistically positive performance expectancies and an unrealistically positive post performance self-assessment.

3. Subpar performance will decrease mood for those with a realistic orientation and those instructed to prepare by imagining success and failure, but not among those instructed to only imagine success as a preparatory strategy.

\section{Method}

\section{Participants}

Participants were 54 first year students from the mass testing pool. There were 13 male $(24 \%)$ and 41 female ( $76 \%)$ participants with the mean age of $20(S D=2.86)$. Given that this is a controlled experiment and we are interested in within subjects effects, $\mathrm{n}=12$ participants per condition were enough for power of .80 , according to Lenth (2009).

Participants were pre-selected based on their scores on the Orientation to University Scale in the mass testing. Realistic students were those who scored in the top $20 \%$ of the distribution on the positive and negative thoughts subscales. Positively oriented students were those who scored in the top $20 \%$ of the distribution on the positive thoughts and in the bottom $20 \%$ of the negative thoughts subscales. Thirty two participants (59\%) were deemed to be realistic in their orientation (4 males and 28 females) and $22(41 \%)$ were deemed to be positively oriented students (9 males and 13 females). The experimenter was blind to subjects' orientation. 


\section{Procedure}

We e-mailed and phoned participants to invite them to participate in an experiment on "Acing the IQ test" (from January to March 2008). At the beginning of the experiment, the experimenter told subjects that the purpose of the study was to assess whether Intelligence test scores can be influenced by different preparation strategies. After completing an initial demographic questionnaire, the experimenter told students that they would be given a test of intelligence in a few minutes, but before taking the test, they would be asked to prepare for the test in a particular way. Meanwhile, the experimenter randomly assigned students to either a "success focus" condition or a "success and failure focus" condition.

In the "success focus" condition, students were instructed to think exclusively about doing well. Specifically, they were told:

"I would like you to think positively and optimistically about the IQ test you are going to be taking. I want you to imagine that you are flying through all the questions very easily and without any effort at all. I want you to imagine that you will do very well on this test, and how this great score demonstrates that you are very intelligent. I want you to imagine how happy you will feel after completing the IQ test and the confidence you will have in your performance."

To facilitate their thought processes, they were asked to write down 10 thoughts about what a good test result would mean for them, and how it would make them feel.

In the "success and failure focus" condition, students were instructed to think about both positive and negative possibilities. Specifically, they were instructed: 
"I would like you to think of both positive and negative possible outcomes from the IQ test you are going to be taking. I want you to imagine the possibility of answering the questions where the answers come to you quite easily. I also want you to imagine the possibility where the questions are much more of a struggle and you are quite unsure of the answer. I want you to imagine the possibility of an IQ score which makes you happy, and also the possibility of an IQ score which you are not happy with. I want you to imagine the possibility of feeling happy with how you did after the IQ test, and also the possibility of feeling unhappy with how you did after the IQ test."

They were then asked to write down what it would mean to get a good test result, but also about what it might mean to do poorly on the test.

Students were then asked to rate how well they expected to do on the test using a 5 point scale ( $0=$ "Poor"; $4=$ "Really well"). They were then given 20 minutes to complete a challenging test of mental ability. After completing the test, a state mood measure, followed by a questionnaire asking about the strategies they used during the test, and an additional question regarding how well they thought they had done on the test were given. In the debriefing at the end of the experiment, students were told the true purpose of the experiment, and their actual score on the test. Students signed a second consent form presenting the true purpose of the experiment, and were given a written debriefing note. Those who participated in the experiment were either granted 1 percentage increase in their Psychology 1001/1002 grade or received $\$ 10$. The materials are provided in Appendix C. 
Description of Instruments

Positive and Negative Affect Schedule. The PANAS was used to assess students' current mood states (Watson, Clark, \& Tellegen, 1988). The PANAS has 10 positive and 10 negative mood adjectives (e.g. "Interested", "Distressed") using a Likert scale from 1 ("very slightly or not at all") to 5 ("extremely"). The reliability of the scale was good (before IQ test positive affect alpha $=0.89$, before IQ test negative affect alpha $=0.84$; after IQ test positive affect alpha $=0.93$, after IQ test negative affect alpha $=0.88$ ).

Expected and perceived performance. Immediately before doing the test, subjects were asked "How well do you expect to do on the IQ test?" using a scale from "poor" $(0)$ to "really well" (4). After the test, they were asked, using the same scale, "How well do you think you did on the IQ test?".

The test of mental ability. A 25 item test of mental ability was used to measure academic ability. The questions were derived from old Graduate Record Exams books. The test had a multiple choice format, with four or five choices per question. The test was difficult such that mean score was $11.6 / 25(S D=3.90)$.

\section{Results}

Before conducting the main analyses, I tested the differences between realists and positively oriented students (based on mass testing scores) on age, gender and selfreported GPA. Male students were more likely to be positively oriented (69.2\%), whereas females were more likely to be realistic in their orientation $\left(68.3 \% ; \chi^{2}(1,53)=5.76, p<\right.$ $.05)$. Positively oriented students were older $(M=21.5)$ than realistic students $(M=19.1)$. 
Because there were group differences in variances (Levene's $F=11.91, p<.01$ ), a quasi t-test was used to test group differences in age $(t(24.53)=-2.90, p<.01)$. Finally, positively oriented students reported higher GPA $(M=8.8$ graded as a $\mathrm{B} / \mathrm{B}+)$ than realists $(M=7.5$ graded as a $\mathrm{B}-; t(52)=-2.34, p<.05)$

Main analyses. To test the effect that prior orientation and preparation strategy had on estimated performance just before and just after the test, a 2 (Orientation: Realistic versus Positively Oriented) X 2 (Condition: "Success Focus" versus "Success and Failure Focus") X 2 (Time: Pretest versus Posttest) mixed model ANOVA was conducted on performance estimates. This analysis indicated (a) a main effect of Time, $F(1,49)=$ $97.91, p<.001$, such that posttest estimates of performance were lower than pretest assessments; (b) a main effect of the preparation strategy $(F(1,49)=8.05, p<.01)$, such that those imagining success only perceived better performance; (c) a marginally significant main effect of prior orientation, $(F(1,49)=3.20, p=.08)$, such that positively oriented participants perceived somewhat better performance than did realists; and (d) a significant 3-way interaction, $(F(1,49)=5.53, p<.05$, see Table 17 and Table 18 ) which qualified the main effects. The interaction, shown in Figure 13, indicates quite clearly that realists, regardless of preparation strategy, and positively oriented participants who used the "success and failure" preparation strategy significantly downgraded their perceived performance following the test, whereas the positively oriented who prepared by imagining only success did not significantly change their estimated performance from pretest to posttest. All other effects were not significant $\left(F^{\prime} \mathrm{s}<1.22\right.$, ns). Covarying participants' GPA, age and gender did not alter this pattern of results. Cohen's $d$ was relatively smaller for positively oriented group in the "success only" condition $(d=0.77)$ 
than for realists in the "success and failure" condition $(d=1.28)$, realists in the "success only" condition $(d=1.62)$ and than for positively oriented in the "success and failure" condition $(d=1.72)$.

Table 17. Within subjects effects on estimated performance scores

\begin{tabular}{|l|c|c|c|c|}
\hline \multicolumn{1}{|c|}{ Source } & $d f$ & $M S$ & $F$ & Sig. \\
\hline Time & 1 & 28.10 & 97.91 & 0.00 \\
Time * Orientation & 1 & 0.18 & 0.61 & 0.44 \\
Time * Condition & 1 & 0.35 & 1.22 & 0.27 \\
Time * & 1 & 1.59 & 5.53 & 0.02 \\
Orientation*Condition & 49 & 0.29 & & \\
Error(Time) & & & & \\
\hline
\end{tabular}

Table 18. Between subjects effects on estimated performance scores

\begin{tabular}{|l|c|c|c|c|}
\hline \multicolumn{1}{|c|}{ Source } & $d f$ & $M S$ & $F$ & Sig. \\
\hline Orientation & 1 & 2.71 & 3.20 & 0.08 \\
Condition & 1 & 6.82 & 8.05 & 0.01 \\
Orientation*Condition & 1 & 0.85 & 1.01 & 0.32 \\
Error & 49 & 0.85 & & \\
\hline
\end{tabular}


Estimated Performance Just Before and Just After Test

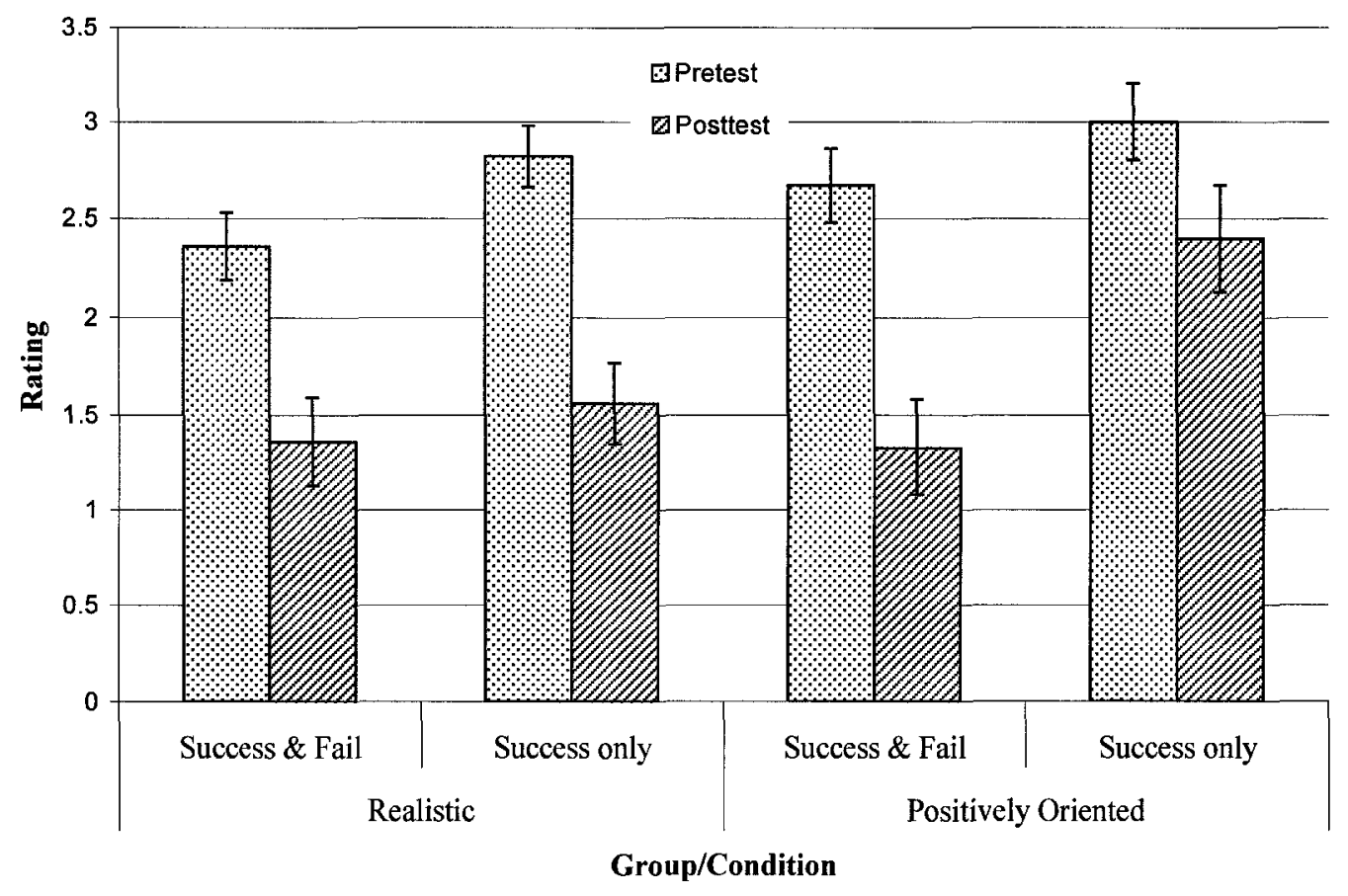

Figure 13. Estimated performance just before and just after the test.

To determine whether actual performance on the test was affected by the prior orientation or the preparation strategy, a 2 (prior orientation) X 2 (preparation strategy) ANOVA was conducted on test scores. No effects were significant $\left(F^{\prime} \mathrm{s}<1\right)$. Covarying age, gender, and GPA did not change these results.

Finally, a 2X2X2 mixed model ANOVA (Orientation: Realistic versus Positively Oriented) X (Condition: "Success Focus" versus "Success and Failure Focus") X (Time: Pretest versus Posttest) was conducted on pretest and posttest mood (NA subtracted from PA). This ANOVA indicated (a) a significant effect of time, $(F(1,50)=33.62, p<.001)$, such that mood declined from pretest to posttest; (b) a significant main effect of prior orientation, $(F(1,50)=8.18, p<.01)$, such that positively oriented students were happier than were realistically oriented participants; and (c) a significant prior orientation by time 
interaction, $(F(1,50)=4.22, p<.05)$, such that realistic participants' mood declined further than did positively oriented participants' mood (see Table 19 and Table 20). Although the three-way interaction term was not significant $(F<1.0)$, it was important to test whether mood changes followed the same pattern as test expectancies. Therefore, contrasts were computed comparing pretest mood to posttest mood for each of the four between group cells. These contrasts indicated that realistic participants (regardless of preparation strategy) and positively oriented participants who imagined both "success and failure" showed significant declines in mood $(p$ 's $<.01)$, whereas those who were positively oriented who prepared by imagining success only indicated no significant decline in mood ( $t<1.0$, see Figure 14). Cohen's $d$ was relatively smaller for positively oriented group in the "success only" condition $(d=0.17)$ than for realists in the "success and failure" condition $(d=1.15)$, realists in "success only" condition $(d=0.99)$ and than for positively oriented in the "success and failure" condition $(d=0.83)$. 
Table 19. Within subjects effects on mood scores (PA-NA)

\begin{tabular}{|l|c|c|c|c|}
\hline \multicolumn{1}{|c|}{ Source } & $d f$ & $M S$ & $F$ & Sig. \\
\hline Time & 1 & 13.99 & 33.62 & 0.00 \\
Time * Orientation & 1 & 1.76 & 4.22 & 0.05 \\
Time * Condition & 1 & 0.94 & 2.25 & 0.14 \\
Time * & 1 & 0.34 & 0.82 & 0.37 \\
Orientation*Condition & 50 & 0.42 & & \\
Error(Time) & & & \\
\hline
\end{tabular}

Table 20. Between subjects effects on mood scores (PA-NA)

\begin{tabular}{|l|c|c|c|c|}
\hline \multicolumn{1}{|c|}{ Source } & $d f$ & $M S$ & $F$ & Sig. \\
\hline Orientation & 1 & 11.19 & 8.18 & 0.01 \\
Condition & 1 & 0.24 & 0.18 & 0.68 \\
Orientation*Condition & 1 & 4.09 & 2.99 & 0.09 \\
Error & 50 & 1.37 & & \\
\hline
\end{tabular}


Pretest and Posttest Mood

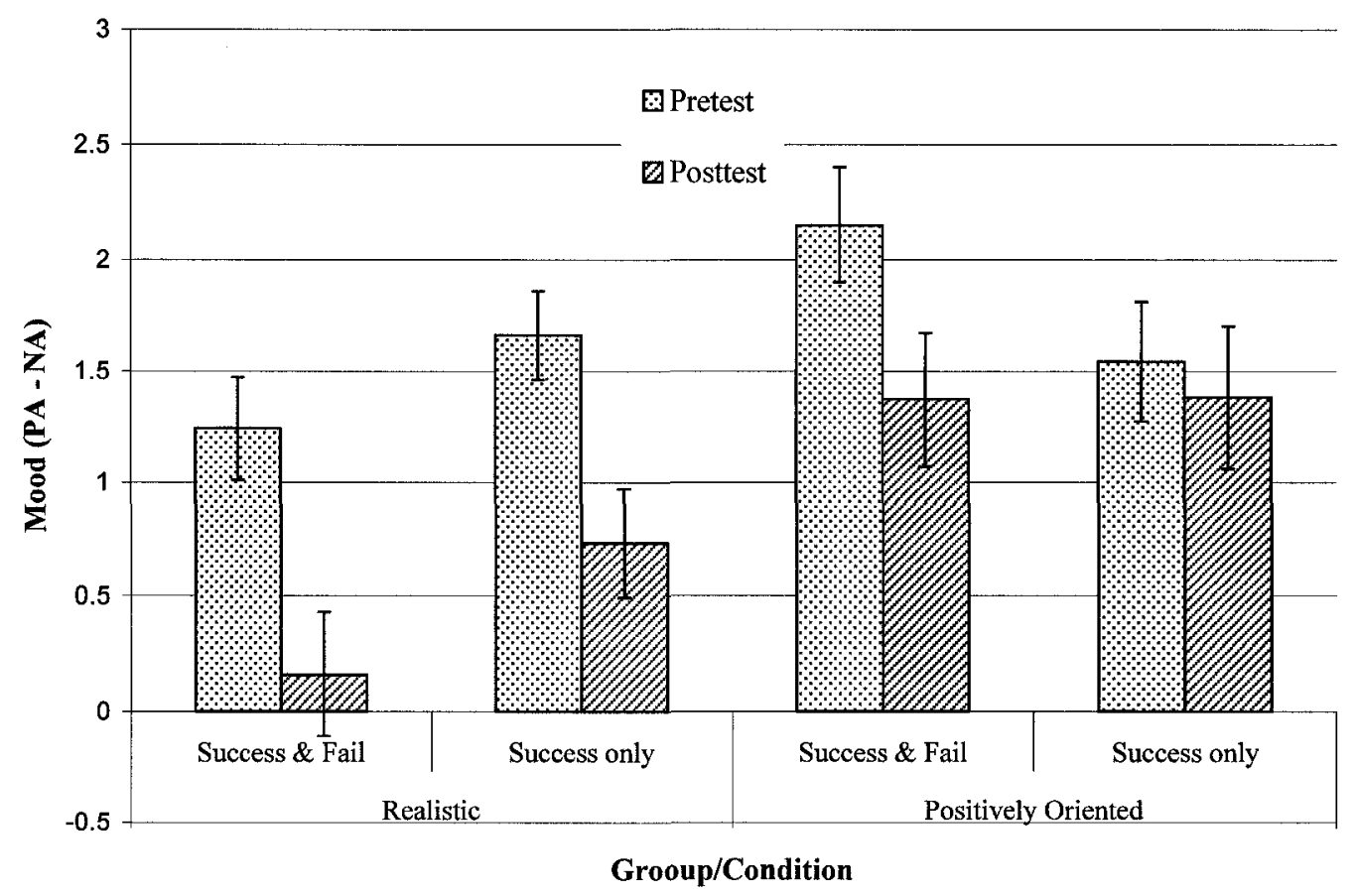

Figure 14. Pretest and Posttest mood levels of realists and positively oriented students in success and success-fail conditions

\section{Discussion}

In this study, I hypothesized that realistically oriented students, compared to positively oriented, would set more realistic expectations and would be more likely to acknowledge their subpar performance by lowering their post performance selfassessment. Second, it was hypothesized that instructing positively oriented students to prepare by imagining only success would lead them to make unrealistically positive performance expectancies and unrealistically positive post-performance assessments. Third, I expected that the mood of the realistically oriented students and those who were instructed to prepare by imagining success and failure would decrease after subpar 
performance, but not the mood of the positively oriented students who were instructed to imagine only success as a preparatory strategy. These hypotheses were confirmed.

When faced with a test that was more difficult than they had anticipated, realists and those positively oriented participants who were asked to prepare using a realistic strategy ("imagine success and failure" condition) downgraded their performance estimates from their pre-test expectancy. Positively oriented participants who imagined only "success" were less inclined to alter their post-test assessments. It is important to note that the positively oriented participants imagining only success did not perform any better than the other groups, despite their higher levels of performance estimates than other groups. Even after completing the test, they believed that they had done pretty well while all other groups (accurately) perceived that their performance was disappointing.

The mood data support this claim. Mood of the realists declined from pre-test to post-test, as did that of the positively oriented participants who imagined both "success and failure". Mood did not change, however, for those positively oriented participants who imagined "success" only. In effect, they appeared to be oblivious to their poor performance. Whereas realistically oriented subjects acknowledged that they did not do well, positively oriented subjects who did not consider the possibility of failure did not seem to have realized that they did poorly. Their mood did not decline significantly following the test, and their post-test self-assessments were out of line with their actual performance to a greater extent than other groups. This is consistent with earlier research indicating that self-enhancing students tend to report rising levels of positive affect when they are engaged in an experimental task (e.g., Robins \& Beer, 2001). 
This contrast between realistic thinking and positively biased thinking shows that these two groups use different strategies. A realistic orientation to future might be related to defensive pessimism, whereas, thinking exclusively about positive outcomes and expecting that good things will happen might be functional or motivating for optimist people, despite the strong possibility that actual outcomes would prove the reverse. The difference between expected and perceived scores of the positively oriented students in the "imagine success" condition is an example of unrealistic optimism and defensive denial of negative information. This might be related to a strong need for positive feelings and psychological denial of negative past experiences and negative future possibilities. Reporting an interesting example, Shelley Taylor and her colleagues found that HIVpositive men were significantly more optimistic about not acquiring AIDS than were HIV-negative men (Taylor et al. 1992; see also Hahn \& Renner, 1998). Although there might be short-term advantages of this belief system such as using positive emotions to increase a sense of control, the outcome-related consequences of this kind of unrealistically positive attitude can be negative. The unprocessed or denied negative future possibilities can be detrimental and overwhelming, especially when the repression of negative information is no longer possible or a viable strategy (Colvin, Block \& Funder, 1995; Robins \& Beer, 2001). It could be interesting to observe, for example, how realists and positively oriented students would react to their actual scores, especially to negative feedback. It might be also interesting to observe how these groups would perform in a subsequent difficult task after finishing a stressful and disappointing task. Current research shows that constructive realism can prepare one for difficult times by acknowledging the possible adversities, and can motivate someone to reach 
desired outcomes without denying future-related negative information and negative past experiences. The results of this experiment provided some evidence for the strategic architecture of constructive realism as compared to positively biased thinking. 
Chapter 9: General Discussion and Conclusion

In this dissertation, I have focused on three main hypotheses: First, I tested the constructivist assumption that psychological reactions to future events can be predicted by the nature of one's thought processes or anticipations. Based on Churchill's (2005) definition of constructive realism, it was specifically expected that those students who think about both positive and negative future possibilities would adjust to difficulties more easily than those who hold a positively or negatively biased view of university. This effect was expected to be seen especially when unexpected difficulties occur. Since constructive realists give thought to negative possibilities while maintaining positive motivations, they were expected to be more resilient than positively oriented students who do not give much thought to those negative possibilities. Second, from an attachment theory perspective, I tested the hypothesis that secure attachment is adaptive, and more importantly, that a change in one's attachment orientation could be predicted by the quality of one's orientation to university (i.e., realistic, positively biased, negatively biased). It was specifically expected that increased attachment insecurity would be a consequence of a biased view of future possibilities. Third, in terms of investigating the coping differences between constructive realists and positively oriented students, I expected that constructive realists would set more realistic expectations and would be more accurate in their performance appraisals than positively oriented students. Overall, there was mixed support for these hypotheses. 
Positively oriented students are doing well

Contrary to my expectations, the results of the second study indicate that positively oriented students are doing well, even when they experience unexpected difficulties. Positively oriented students reported high levels of academic and life satisfaction and high levels of attachment security. It might be the case that positively oriented students believe in their academic skills, they know why they are in university at this stage of their lives and they have supportive close relationships. Even under the most difficult circumstances, positively oriented students seemed to adjust better than any other group. This is consistent with the findings indicating that a positive orientation in life can lead to a successful coping with difficulties (Aspinwall \& Taylor, 1992; Taylor \& Brown, 1994; Scheier, Carver, \& Bridges, 2001).

The role of constructive realism in adjustment to university

Although I had hypothesized that realistic students would be better adjusted than other groups under stressful conditions, the results were not conclusive. In general, positively oriented students tended to report greater satisfaction with university than did realistically oriented students. In the absence of unexpected difficulties, positively oriented students reported greater satisfaction with university than did realistically oriented and negatively oriented students. When unexpected difficulties were reported, however, realistically oriented and positively oriented students did not differ in their satisfaction with university scores, but the negatively oriented students tended to report lower levels of satisfaction with university. This suggests that realistically oriented students, compared to negatively oriented ones, were protected from the negative effects 
of the unexpected difficulties. Furthermore, the protective power of realistic orientation was found to be significant over and above attachment variables.

This pattern of results was not replicated with the more general satisfaction with life measure. There was not an interaction effect of extra difficulties and thought variables. Overall, positively oriented students were more satisfied than negatively oriented students. In addition, the difference between realists and positively oriented students, and the difference between realists and negatively oriented students were not significant. In sum, protective effect of constructive realism that was based on futureoriented positive and negative academic thoughts was stronger when satisfaction with university was a concern, rather than satisfaction with life.

Although these findings do not suggest that realistically oriented students are better adjusted than positively oriented students, it is clear that both groups are better adjusted than negatively oriented students when the concern is satisfaction with university. The data, in this respect, are consistent with the view that not all future-related negative thinking is maladaptive. Rather, negative thinking that is balanced with motivating positive thinking can be adaptive, and can protect people from feelings of dissatisfaction (e.g., Norem, \& Chang, 2002; Oettingen \& Mayer, 2002). In the absence of positive thinking, students who were concerned about possible academic obstacles (negative orientation) reported significantly lower levels of satisfaction with university and satisfaction with life than did constructive realists, especially when there were unexpected difficulties. It is possible that the relative lack of positive anticipations among the negatively oriented individuals may be linked with external motivations to get a degree (e.g., parental expectations) or a low sense of academic self-efficacy. 
One reason why realists were not significantly better adjusted than positively oriented students (when academic and social difficulties occur) might be the nature of difficulties experienced in the first year of college. Although I expected that the index of difficulties would be uncorrelated with frequency of positive and negative thoughts, it was found that the difficulties were correlated positively with the frequency of negative thoughts. Those students who had thought a lot about negative possibilities (the realists and negatively oriented) were more likely subsequently to report that they experienced those difficulties. Hence, those difficulties did not have a surprising or unexpected quality as was hypothesised. Personal (i.e., extra) difficulties, on the other hand, are more surprising and seem to be less related with one's prior self-efficacy beliefs than academic and social difficulties. Hence, in the analyses conducted with the difficulties that are more surprising or unexpected in nature, I found some evidence that realistic students were less negatively affected by those difficulties than were negatively oriented students. This is consistent with the view that unexpected adversities or difficulties that are out of one's control (e.g., performance-irrelevant) may have a more adverse effect on individuals who hold a negatively biased view of future events than on individuals who have a balanced view of future events (Churchill, 2005; Oettingen \& Mayer, 2002; Peterson, 2000; Schneider, 2001; Tennen \& Affleck, 1987).

Although a positive orientation was consistently linked with greater satisfaction, it is important to note that there may be a significant downside to such an orientation. In Study 3,1 found that positively oriented students who prepared for their "IQ test" by imagining success not only overestimated how well they would do on the test, they also were less likely to recognize that their performance was subpar. These findings leave 
some doubt as to the adaptiveness of a positive orientation. Positively oriented students might think they are doing well, but in the absence of unambiguous feedback, their positively biased way of looking at the challenging situation may give a distorted assessment of how well they are actually doing. Consistent with this, those who scored in Study 1 as positively oriented tended to report high scores on a measure of both impression management and self-deception. This suggests that to some extent, the high levels of satisfaction reported by this group may be overstated in part because these students want to look good, but also in part because they may be failing to accurately read the signs that they might not be doing so well. To the extent that positively oriented students receive lower course grades than do their peers, their self-enhancing strategies may no longer protect them in the long run in the academic context. Consistent with this, Robins and Beer (2001) reported that self-enhancing first year university students tend to report decreasing self-esteem and well-being over four years of college life. In addition, they found that self-enhancing first year students were more likely to disengage from academic tasks (i.e., decreasing ego-involvement and increasing drop-out rate) and were slightly less likely to graduate in four years than were those first year students with selfdiminishing beliefs. Positively biased future orientation might be related with unrealistic self-enhancing beliefs in academic context that could become costly in the face of continual negative feedback, such as failure to achieve good grades. In sum, positively biased thinking might be associated with unrealistic optimism, and to the extent that outcomes do not work out as anticipated, people possessing this orientation may suffer in the long run (see also Colvin, Block \& Funder, 1995). 
Unlike the unrealistic optimism literature, which focuses on likelihood of various outcomes happening to others relative to oneself, I have focused on the future-related thoughts of university students and provided some tentative evidence that balancing positive thinking with consideration of possible negative challenges can buffer the transitional stress. This orientation would lead students to contrast an appealing positive future (i.e., desirability) with negative reality (i.e., feasibility), and can lead them to engage in proper actions to remove the obstacles and successfully accommodate surprising and stressful experiences (Churchill, 2005; Oettingen, Mayer, Thorpe, Janetzke \& Lorenz, 2005). Thinking exclusively about a desired future may prevent students from recognizing the real possibility of difficulties until it is too late. On the other hand, thinking too much about the possibility of bad outcomes may decrease the motivation of students to persevere with their academic goals in the face of challenges. A balanced view of future possibilities, however, can not only energize students to be realistically engaged in their first year tasks but also protect them from feeling of dissatisfaction in stressful times.

The effects of attachment (in) security and the way it changes

The results of the current research indicate that low levels of attachment anxiety and attachment avoidance are significant predictors of satisfaction with university and satisfaction with life. This is consistent with the previous literature indicating the benefits of attachment security during the transition to college (Bernier et al., 2004, 2005; Lapsey \& Edgerton, 2002; Larose, et al., 2005; Lopez \& Gormley, 2002). I have also found that increasing attachment security is associated with greater satisfaction with university and 
satisfaction with life. Transition to university probably causes an activation in attachment system and those students who report increasing levels of attachment security tend to be more satisfied than those who become more avoidant or anxious in their relationships (i.e., deactivation or hyperactivation of attachment system).

I had also hypothesized that attachment orientation can change during stressful life transitions and future orientation can explain the variance. In Study 2, realists and positively oriented students reported slightly decreasing levels of attachment anxiety and attachment avoidance, whereas negatively oriented students reported increasing levels of attachment avoidance. This is consistent with the view that attachment-related beliefs can change as a function of one's orientation. I argue that considering future obstacles can help positively motivated students to deal with the transitional problems in an active manner, and in turn, this realistic orientation can buffer the possible stress on attachment relationships. On the other hand, negatively biased future orientation may be related with ineffective coping during stressful times, and thus, it might have a negative effect on one's attachment orientation, such as increasing avoidance from close relationships as found in Study 2.

One could also expect that positively oriented students should report higher levels of attachment anxiety and attachment avoidance than realists during transition. However, there was no evidence indicating that positively oriented students were more negatively affected by the transitional challenges than were realists in terms of changing towards attachment insecurity. Current findings indicate that positive orientation is associated with attachment security and stability in attachment system. Although this is not what I 
hypothesized, it is understandable from an attachment theory perspective that securely attached individuals tend to stay secure during stressful times.

Research focusing on future anticipations of people can partly explain how attachment style changes in stressful transitions and who is more protected or vulnerable. I argue that attachment style is associated with and influenced by other psychological processes or experiences in one's life such as orientation to future and attachmentrelevant life transitions. Current research suggest that an unrealistic orientation to future, especially a negative one, may be associated with ineffective coping with stressful experiences during transitions, and thus, may have a destructive effect on one's close relationships.

\section{Implications and directions for the future research}

This research provides some evidence that a realistic orientation to future might be protective in the context of unexpected or very difficult negative events, especially as compared to a negative orientation. More specifically, Study 2 showed that negatively oriented students were negatively affected by the presence of unexpected difficulties, whereas those with a realistic orientation seemed robust against those difficulties. I argue that the concept of constructive realism can be an important concept in the relevant aspects of research in social and personality psychology. The dilemma of unrealistic optimism and questions about the adaptive value of positive illusions may be better investigated using a perspective focusing on the way people anticipate future events (Kelly, 1955), rather than a perspective using generalized expectations as the unit of analysis. Process oriented coping research might benefit from the constructivist 
perspectives on stress and coping (Gillies \& Neimeyer, 2006; Sewell, 2003) with a particular emphasis on the future anticipations of people.

The current research provides some limited evidence indicating that positive thinking might be associated with defensive tendencies, and these possibilities should be investigated more thoroughly. Past research indicates that other examples of positively biased thinking are associated with repression of negative thoughts and negative social information (e.g., Derakshan, Eysenck \& Myers, 2007; Myers \& Steed, 1999; Shedler, Mayman, \& Manis 1993). In a follow-up study, it would be interesting to further compare constructive realists and positively oriented students in terms of their short term cognitive processes, such as reaction to failure in an exam, and long term life outcomes such as course grades, drop-out or graduation rates, or switching one's academic major. This perspective can help us to further understand the important individual differences in the process of construing future events and accommodating (or assimilating) invalidating experiences. For example, the not-oriented group in this research reported comparable levels of well-being with realists and positively oriented students on the dependent variables (see Churchill, 2005 for similar results). However, we do not know much about this group, except that they are relatively high on optimism, impression management and self-deceptive enhancement. It is also a possibility that these individuals might have a relatively easy time in accepting difficult or challenging aspects of life. For example, recent research shows that some people do not frequently ask questions such as "why me" after a traumatic event and they can easily integrate or make sense of the negative experiences without being emotionally overwhelmed (e.g., Davis \& Morgan, 2008; Davis, Wohl, \& Verberg, 2007; Davis, Wortman, Lehman, \& Silver, 2000). One reason 
explaining the resiliency of these individuals in traumatic contexts would be their accommodative openness to the tragic aspects of life. It might be fruitful to investigate the mindset of those individuals who avoid thinking a lot about both positive and negative future possibilities, yet report doing well during life transitions.

Another important implication of the current research is the idea that attachment theory can benefit from the studies focusing on the anticipatory thoughts of people. While constructive realism was found to be a predictor of the stability of secure attachment style, negatively biased future-related thoughts seemed to be associated with attachment style instability. Given that the current data do not provide clear evidence for the latter, it might be fruitful from an attachment perspective to further investigate the impact of one's orientation on changes in one's attachment style. An alternative look at attachment styles suggests that quality of attachment relationships may be related to a larger class of psychological phenomena in which meaning of self, social world and the future are continuously reinterpreted or reconstructed as a whole. A realistic orientation to future may not only help secure individuals to protect the quality of their close relationships, but might also help insecure individuals build healthier relationships over time.

It is a question whether the extent to which people are realistic across different contexts changes, and whether their orientations change as they gain experience in those contexts. In Study 1, I showed some evidence that positively oriented students tend to change towards a more realistic orientation in a period as short as a few months. It is a question whether this trend of change is maintained or increased from first year to second. It is another question whether people who become more realistic in one domain of life after invalidating experiences also become more realistic in other domains too. If it 
is the case, future research may show that constructive realism is a general life skill that can be developed over time (Churchill, 2005).

Realistic orientation should be investigated in other challenging contexts, such as transition to immigration, marriage, parenthood, unemployment, starting a career, career change, working overseas, and retirement. Since the characteristics of each of these contexts differ from each other, the buffering effect of constructive realism may also differ from one domain to another. I think controllability in the context may be an important factor. The life outcomes in some contexts are less dependent on one's active efforts than in other contexts. Examples can be losing one's social support due to immigration, a forced marriage in the context of cultural pressure, a difficult childbirth in transition to motherhood, and losing one's job or being unemployed for a very long time in the context of global economic crisis. It is also possible that unexpected adversities might be more prevalent in some contexts (e.g., motherhood) than the others (e.g., transition to university). I think unexpected adversities (e.g., accidents) with the most uncontrollable consequences (e.g., spinal cord injury or losing a close relative) might provide the best ground to test the stress-buffering capacity of constructive realism as a life skill.

In terms of counselling and orienting new university students, current findings suggest that encouraging students to balance their positive thinking with a healthy dose of negative thinking can protect them from anticipatory failures. Given that negatively biased students were found to be the most vulnerable to stress, helping them to construct university life in a more balanced manner should be beneficial in the long run. A healthy orientation to future can be achieved not only with reference to possible obstacles, but 
also with reference to possible solutions to increase academic self-efficacy and possible ways to enjoy the academic and social environments of university.

\section{Limitations of the current research}

Although one can argue that personal constructs (e.g., good-bad, easy-difficult) are idiosyncratic and participants should define their own constructs, I argue that the method of elicitation of personal constructs as defined by Kelly may not be an appropriate tool to understand the way people anticipate future events. It should be remembered that different future events, such as academic, social and personal future possibilities, are not comparable in a matrix using bipolar dimensions. Rather these future possibilities are anticipated (Fransella, Bell \& Banister, 2004). I argue that frequency of future-related thoughts or fantasies reflects one's concerns or future anticipations about a transition (e.g., Oettingen \& Mayer, 2002), and the questionnaire that I developed resonates with the literature on adjustment of first year students. Nevertheless, there probably are context-specific constructs common among advanced university students to evaluate specific domains of university life. Future research can investigate these specific constructs (e.g., in the academic domain), and one can ask potential freshmen, for example, to generate the kind of academic tasks or issues they would be dealing with in university, and how they would evaluate them using those elicited constructs.

A further limitation of the current research is the lack of hard, tangible outcomes. It would have been helpful to be able to assess actual grades of students who participated, and to be able to follow these students over a longer period of time. It would be 
interesting to see, for example, if positively oriented students turn out to be more likely to change their major, take more years to graduate or drop out of university.

\section{Conclusion}

My interest in broad theories in social and personality psychology has led me to focus on two productive theoretical frameworks in order to understand general processes and individual differences among people in terms of coping with stress during a challenging life transition. These frameworks were constructivism (with an emphasis on Kellian postulates) and attachment theory (with an emphasis on adult attachment styles). Rather than measuring first year students' generalized expectations, I have focused on their future-related positive and negative thoughts.

From the perspective of constructivism, my firmest conclusion is that negative thinking that is balanced with positive thinking, as compared to a negatively biased orientation, can be adaptive when unexpected adversities strike, and can also protect individuals from attachment instability. Hence, not all negative thinking is bad. Rather it is a matter of balance in terms of anticipating future events or a matter of realistic construction of future events. Likewise, although tentative, a conclusion can be drawn from the data indicating the possibility that not all positive thinking is good: Positive thinking that is not balanced with a healthy dose of negative thinking might be associated with defensiveness, short term benefits, and long-term costs.

From the perspective of attachment theory, my firmest conclusion is that a secure attachment orientation and stability in attachment security are associated with greater adjustment during a difficult life transitions. Furthermore, while constructive realism 
seems to be associated with attachment security and protects students from attachment style instability, a negative orientation to future seems to be associated with increasing attachment insecurity (attachment avoidance). Connecting attachment theory with constructivist perspectives highlights the idea that an attachment style that is developed in the early stages of life might be associated with a particular construction of later stages of life (i.e., orientation to future). After validating or invalidating experiences, this orientation to future can be reconstructed in life and may be, in turn, a factor in predicting quality of one's close relationships.

Psychology has focused a lot on how people deal with challenging life events, but almost all of this research starts at some point after the event has occurred. The focus of this dissertation has been on trying to understand how people anticipate future events. We all go through challenging transitions in our lives: from high school to university, from university to career, and from career to retirement. Some transitions are well-planned and anticipated, but many of them are not. A constructivist perspective suggests that getting one to think about the various possible outcomes might make one a bit more anxious in the anticipatory period, but it can pay off when it helps one cope with the unexpected events. Having a balanced view of a future transition can help people navigate their way through difficult transitions and protect attachment relationships from stress. 
References

Ainsworth, M. D. S., Blehar, M. C., Waters, E., \& Wall, S. (1978). Patterns of attachment: Assessed in the strange situation and at home. Hillsdale, NJ: Erlbaum.

Armor, D. A., \& Taylor, S. E. (2002). When predictions fail: The dilemma of unrealistic optimism. In T. Gilovich, D. W. Griffin, \& D. Kahneman (Eds.), Heuristics and biases: The psychology of intuitive judgment. New York: Cambridge University Press.

Aspelmeier, J.E., \& Kerns, K.A. (2003). Love and school: Attachment/exploration dynamics in college. Journal of Social and Personal Relationships, 20, 5-30.

Aspinwall, L. G. (2005). The psychology of future-oriented thinking: From achievement to proactive coping, adaptation, and aging. Motivation \& Emotion, 29, 203-235.

Aspinwall, L. G., \& Brunhart, S. M. (1996). Distinguishing optimism from denial: Optimistic beliefs predict attention to health threats. Personality and Social Psychology Bulletin, 22, 993-1003.

Aspinwall, L.G., Sechrist, G.B., \& Jones, P. (2005). Expect the best and prepare for the worst: Anticipatory coping, proactivity, worry, and preparations for $\mathrm{Y} 2 \mathrm{~K}$. Motivation \& Emotion, 29, 353-384.

Aspinwall, L. G., \& Taylor, S. E. (1992). Modeling cognitive adaptation: A longitudinal investigation of the impact of individual differences and coping on college adjustment and performance. Journal of Personality and Social Psychology, 63, 989-1003. 
Aspinwall, L. G, \& Taylor, S. E. (1997). A stitch in time: Self-regulation and proactive coping. Psychological Bulletin, 121, 417-436.

Bartholomew, K., \& Horowitz, L. M. (1991). Attachment styles among young adults: A test of a four-category model. Journal of Personality and Social Psychology, 61, 226-244.

Bank, B., Biddle, B. \& Slavings, R. (1992). What Do Students Want? Expectations and Undergraduate Persistence. The Sociological Quarterly, 33, 321-335.

Benyamini. Y. (2005). Can high optimism and high pessimism co-exist? Findings from arthritis patients coping with pain. Personality and Individual Differences, 38, 1463-1473.

Bernier, A., Larose, S., Boivin, M., \& Soucy, N. (2004). Attachment state of mind: Implications for adjustment to college. Journal of Adolescent Research, 19, 783806.

Bernier, A., Larose, S., \& Whipple, N. (2005). Leaving home for college: A potentially stressful event for adolescents with preoccupied attachment patterns. Attachment \& Human Development, 7, 171-185.

Birnbaum, G. E., Orr, I., Mikulincer, M., \& Florian, V. (1997). When marriage breaks up - Does attachment style contribute to coping and mental health? Journal of Social and Personal Relationships, 14, 643-654.

Bowlby, J. (1969/1971). Attachment and loss: Vol. 1. Attachment (2nd ed.). Middlesex: Penguin Books.

Bowlby, J. (1973). Attachment and loss: Vol. 2. Separation: Anxiety and anger. NewYork: Basic Books. 
Bowlby, J. (1980). Attachment and loss: Vol. 3. Sadness and depression. New York: Basic Books.

Bowlby, J. (1988). A secure base: Clinical applications of attachment theory. London: Routledge.

Brennan, K. A., Clark, C. L., \& Shaver, P. R. (1998). Self-report measurement of adult romantic attachment: An integrative overview. In J. A. Simpson \& W. S. Rholes (Eds.), Attachment theory and close relationships (pp. 46-76). New York: Guilford Press.

Bretherton, I., \& Munholland, K. A. (1999). Internal working models in attachment relationships: A construct revisited. In J. Cassidy \& P. R. Shaver (Eds.), Handbook of attachment: Theory, research, and clinical application (pp.89-111). NewYork: Guilford Press.

Brown, K. W., Ryan, R. M., \& Creswell, J. D. (2007). Mindfulness: Theoretical Foundations and Evidence for its Salutary Effects. Psychological Inquiry, 18, 211-237.

Butt, T. W., \& Parton, N. (2005) Constructivist social work and personal construct theory. British Journal of Social Work, 35, 793-806.

Cannon, B. (1999). Sartre and existential psychoanalysis. The Humanistic Psychologist, $27,23-50$.

Carver, C. S., Pozo, C., Harris, S. D., Noriega, V. Scheier, M. F., \& Robinson, D. S. (1993). How coping mediates the effect of optimism on distress: A study of women with early stage breast cancer. Journal of Personality and Social Psychology, 65, 375-390. 
Caspi, A., Roberts, B. W., Shiner, R. (2005). Personality development. Annual Review of Psychology, 56, 453-484. 44

Chang, E. C. (1996). Evidence for the cultural specificity of pessimism in Asians and Caucasians: A test of the general negativity hypothesis. Personality and Individual Differences, 21, 819-822.

Chang, E. C. (2001). Cultural influences on optimism and pessimism: Differences in Western and Eastern conceptualizations of the self. In E. C. Chang (Ed.), Optimism and pessimism: Theory, research, and practice (pp. 257-280).

Washington: American Psychological Association.

Chang, E. C., \& Sanna, L. J. (2003). Optimism, accumulated life stress, and psychological and physical adjustment: Is it always adaptive to expect the best? Journal of Social and Clinical Psychology, 22, 97-114.

Chang, E.C., Maydeu-Olivares, A., \& D'Zurilla, T.J. (1997). Optimism and pessimism as partially independent constructs: Relations to positive and negative affectivity and psychological well-being. Personality and Individual Differences, 23, 433-440.

Churchill, A. (2005). Hoping for the best while preparing for the worst: Constructive realism. Personal projects and transition to parenthood. Unpublished PhD thesis. Carleton University: Ottawa, On.

Cohen, S., Kamarck, T. \& Mermelstein, R. (1983). A global measure of perceived stress. Journal of Health and Social Behavior, 24, 385-396.

Collins, N., \& Read, S. (1994). Cognitive representations of attachment: The structure and function of working models. In K. Bartholomew \& D. Perlman (Eds.), 
Attachment processes in adulthood: Advances in personal relationships (Vol. 5, pp. 53-90). London: Kingsley.

Colvin, C. R., \& Block, J. (1994). Do positive illusions foster mental health? An evaluation of the Taylor and Brown formulation. Psychological Bulletin, 116, 320.

Colvin, C.R., Block, J., \& Funder, D.C. (1995). Overly-positive self evaluations and personality: Negative implications for mental health. Journal of Personality and Social Psychology, 68, 1152-1162.

Cozzarelli, C. (1993). Personality and self-efficacy as predictors of coping with abortion. Journal of Personality and Social Psychology, 65, 1224-1236.

Cozzarelli, C., Karafa, J. A., Collins, N. L., \& Tagler, M. J. (2003). Stability and change in adult attachment styles: Associations with personal vulnerabilities, life events, and global construals of self and others. Journal of Social and Clinical Psychology, 22, 315-346.

Cozzarelli, C., Sumer, N., \& Major, B. (1998). Mental models of attachment and adjustment to abortion. Journal of Personality and Social Psychology, 74, 453467.

Davila, J., Burge, D., \& Hammen, C. (1997). Why does attachment style change? Journal of Personality and Social Psychology, 73, 826-838.

Davila, J., \& Cobb, R. (2003). Predicting change in self-reported and interviewerassessed adult attachment: Tests of the individual difference and life stress models of attachment change. Personality and Social Psychology Bulletin, 29, 859-870. 
Davila, J., \& Sargent, E. (2003). The meaning of life (events) predicts change in attachment security. Personality and Social Psychology Bulletin, 29, 1383-1395.

Davis, C. G., \& Morgan, M. S. (2008). Finding meaning, perceiving growth, and acceptance of tinnitus. Rehabilitation Psychology, 53, 128-138.

Davis, C. G., Wohl, M.J.A, \& Verberg, N. (2007). Profiles of posttraumatic growth following an unjust loss. Death Studies, 31, 693-712.

Davis, C. G., Wortman, C., Lehman, D., \& Silver, R. (2000). Searching for meaning in loss: Are clinical assumptions correct? Death Studies, 24, 497-540.

Davis, M. H., Morris, M., \& Kraus, L. A. (1998). Relationship-specific and global perceptions of social support: Associations with well-being and attachment. Journal of Personality and Social Psychology, 74, 468-481.

Debats, D. L. (1999). Sources of meaning: An investigation of significant commitments in life. Journal of Humanistic Psychology, 39, 30-57.

Derakshan, N., Eysenck, M. \& Myers, L.B (2007). Emotional information processing in repressors: A vigilance avoidance theory. Cognition and Emotion, 21, 1585-1614.

Diehl, M., Elnick, A. B., Bourbeau, L. S., \& Labouvie-Vief, G. (1998). Adult attachment styles: Their relations to family context and personality. Journal of Personality and Social Psychology, 74, 1656-1669.

Diener, E., Emmons, R. A., Larsen, R. J., \& Griffin, S. (1985). The Satisfaction With Life Scale. Journal of Personality Assessment, 49, 71-75.

Dixson, M., \& Duck, S. W. (1993). Understanding relationship processes: Uncovering the human search for meaning. In S. W. Duck (ed.) Understanding relationship processes 1: Individuals in relationships (pp. 175-206). Sage: Newbury Park. 
Duck, S. (1994). Attaching meaning to attachment. Psychological Inquiry, 5, 34-38.

Dyson, R., \& Renk, K. (2006). Freshmen adaptation to university life: depressive symptoms, stress and coping. Journal of Clinical Psycholog, 62, 1231-1244.

Epstein, S. (2003). Cognitive-experiential self-theory of personality. In. T. Millon, M.J. Lerner \& I.B. Weiner (Eds.), Handbook of Psychology: Personality and social psychology, Vol 5 (pp. 159-184). New Jersey, John Wiley \& Sons, Inc.

Epstein, S., \& Meier, P. (1989). Constructive thinking: A broad coping variable with specific components. Journal of Personality and Social Psychology, 57, 332-349.

Farwell, L., \& Wohlwend-Lloyd, R. (1998). Narcissistic processes: Optimistic expectations, favorable self-evaluations, and self-enhancing attributions. Journal of Personality, 66, 65-83.

Fisher, S., \& Hood, B. (1987). The stress of the transition to university: A longitudinal study of psychological disturbance, absentmindedness and vulnerability to homesickness. British Journal of Psychology, 78, 425-441.

Fisher, S., Murray, K., \& Frazer, N. A. (1985). Homesickness, health, and efficiency in first year students. Journal of Environmental Psychology, 5, 181-195.

Fitzgerald, T. E., Tennen, H., Affleck, G., \& Pransky, G. S. (1993). The relative importance of dispositional optimism and control appraisals in quality of life after coronary artery bypass surgery. Journal of Behavioral Medicine, 16, 25-43.

Fontaine, K., \& Jones, L. (1997). Self-esteem, optimism, and postpartum depression. Journal of Clinical Psychology, 53, 59-63.

Fraley, R. C. (2005). A Brief Overview of Adult Attachment Theory and Research. Retrieved 2005-12-13 from http://www.psych.uiuc.edu/ rcfraley/attachment.htm 
Fraley, R. C., Niedenthal, P. M., Marks, M. J., Brumbaugh, C. C., \& Vicary, A. (2006). Adult attachment and the perception of emotional expressions: Probing the hyperactivating strategies underlying anxious attachment. Journal of Personality, $74,1163-1190$

Fraley, C., \& Roberts, B. W. (2005). Patterns of Continuity: A Dynamic Model for Conceptualizing the Stability of Individual Differences in Psychological Constructs Across the Life Course. Psychological Review, 112, 60-74.

Fraley, R. C., Waller, N. G., \& Brennan, K. A. (2000). An item-response theory analysis of self-report measures of adult attachment. Journal of Personality and Social Psychology, 78, 350-365.

Franklin, K.M.; Janoff-Bulman, R.; Roberts, J.E. (1990) Long-Term Impact of Parental Divorce on Optimism and Trust: Changes in General Assumptions or Narrow Beliefs? Journal of Personality and Social Psychology, 59, 743-755.

Fransella, F., Bell, R., \& Bannister, D. (2004). A manual for repertory grid technique (2nd ed.). Hoboken, NJ: John Wiley \& Sons.

Frederickson, B. L. (2001). The role of positive emotions in positive psychology: The broaden-and-build theory of positive emotions. American Psychologist, 56, 218226.

Gillies, J. \& Neimeyer, R. A. (2006). Loss, grief, and the search for significance: Toward a model of meaning reconstruction in bereavement. Journal of Constructivist Psychology, 19, 31-67.

Given, C. W., Stommel, M., Given, B. A., Osuch, J., Kurtz, M. E., \& Kurtz, J. C. (1993). The influence of cancer patients' symptoms and functional states on patients' 
depression and family caregivers' reaction and depression. Health Psychology, 12, 277-285.

Gladis, M. M., Michela, J. L., Walter, J. L., \& Vaughan, R. D. (1992). High school students' perceptions of AIDS risk: Realistic appraisal or motivated denial. Health Psychology, 11, 307-316.

Goodman, E., Chesney, M. A., \& Tipton, A. C. (1995). Relationship of optimism, knowledge, attitudes, and beliefs to use of HIVantibody testing by at-risk female adolescents. Psychosomatic Medicine, 57, 541-546.

Greenglass, E. R., Schwarzer, R., \& Taubert, S. (1999). The Proactive Coping Inventory (PCI): A multidimensional research instrument. Retrieved from http://userpage.fuberlin.de/ health/greenpci.htm on August 2008.

Hahn, A. \& Renner, B. (1998). Health risk perception of smokers: How smoker status affects defensive optimism. Stress, Anxiety, and Coping: An International Journal, 11, 93-112.

Hazan, C., \& Shaver, P. (1987). Romantic love conceptualized as an attachment process. Journal of Personality and Social Psychology, 52, 511-524.

Heinonen, K., Räikkönen, K., Keltikangas-Järvinen, L., \& Strandberg, T. (2004). Adult attachment dimensions and recollections of childhood family context: associations with dispositional optimism and pessimism. European Journal of Personality, 18, 193-207.

Holmstrom, L., Karp, D., \& Gray, P. (2002). Why laundry, not Hegel? Social class, transition to college, and pathways to adulthood. Symbolic Interaction, 25, 437462. 
Jackson, L.M., Pancer, S.M., Pratt, M.W., \& Hunsberger, B. (2000). Great expectations: The relation between expectancies and adjustment during the transition to university. Journal of Applied Social Psychology, 30, 2100-2125.

Janoff-Bulman, R. (1992). Shattered Assumptions: Towards a New Psychology of Trauma. NY: Free Press.

Karp, D., Holmstrom, L., \& Gray, P. (1998). Leaving home for college: Expectations for selective reconstruction of self. Symbolic Interaction, 21, 253-276.

Kelly, G. A. (1955/1991). The Psychology of Personal Constructs. New York: Norton.

Kerr, S., Johnson, V. K., Gans, S. E., \& Krumrine, J. (2004). Predicting adjustment during the transition to college: Alexithymia, perceived stress, and psychological symptoms. Journal of College Student Development, 45, 593-611

Keup, J. R. (2007). Great Expectations and the Ultimate Reality Check: Voices of Students During the Transition from High School to College. NASPA Journal, 44, Retrieved on September 09, 2008, from http://publications.naspa.org/naspajournal/vol44/iss1/art3

Klion, R. E., \& Pfenninger, D. T. (1997). Personal construct psychotherapy of addictions. Journal of Substance Abuse Treatment, 14, 37-44.

Krallman, D. \& Holcomb, T. (1997). First-year student expectations: Pre- and postorientation. Paper presented at the Annual Meeting of the Association of Institutional Research, Buena Vista, FL.

Lapsley, D. K., \& Edgerton, J. (2002). Separation-individuation, adult attachment style, and college adjustment. Journal of Counselling and Development, 80, 484-492. 
Larose, S., Bernier, A. \& Tarabulsy, G.M. (2005). Attachment state of mind, students' learning dispositions, and academic performance during the college transition. Developmental Psychology, 41, 281-289.

Leak, G. K., \& Parsons, C. J. (2001). The susceptibility of three attachment style measures to socially desirable responding. Social Behavior and Personality, 29, 21-30.

Lenth, R. V. (2009). Java Applets for Power and Sample Size [Computer software]. Retrieved April 16, 2009, from http://www.stat.uiowa.edu/ rlenth/Power.

Lewis, M. (1997). Altering fate: Why the past does not predict the future. New York: Guilford Press.

Lewis, M. (2001). Issues in the study of personality development. Psychological Inquiry, $12,67-83$.

Lopez, F.G., \& Gormley, B. (2002). Stability and change in adult attachment style over the first-year college transition: Relations to self-confidence, coping, and distress patterns. Journal of Counseling Psychology, 49, 355-364.

Lopez, F. G., Mauricio, A. M., Gormley, B., Simko, T., \& Berger, E. (2001). Adult attachment orientations and college student distress: The mediating role of problem coping styles. Journal of Counseling and Development, 79, 459-464.

Luo, J., \& Isaacowitz, D.M. (2007). How optimists face skin cancer: Risk assessment, attention, memory, and behavior. Psychology \& Health, 22, 963-984.

MacCallum, R. C., Zhang, S., Preacher, K. J., \& Rucker, D. D. (2002). On the practice of dichotomization of quantitative variables. Psychological Methods, 7, 19-40. 
Maddi. S. R. (1998). Creating meaning through making decisions. In P. T. P Wong and P. Fry (Eds.). In P. T. P Wong \& P. Fry (Eds.). Handbook of personal meaning: Theory, research, and practice (pp. 3-26). Mahway, NJ: Lawrence Erlbaum.

Marshall, G. N., Wortman, C. B., Kusulas, J. W., Hervig, L. K. \& Vickers, R. R., Jr. (1992). Distinguishing optimism from pessimism: Relations to fundamental dimensions of mood and personality. Journal of Personality and Social Psychology, 62, 1067-1074.

Martin, J.S., \& Hanrahan, K. (2004). Criminology freshmen: Preparation, expectations, and college performance. Journal of Criminal Justice Education, 15, 251-269.

May, R. (1958). Contributions of Existential Psychotherapy. In R. May, E. Angel, \& H.F. Ellenberger (Eds.), Existence: A New Dimension in Psychology and Psychiatry (pp. 37-91). New York: Simon \& Schuster.

Mikulincer, M., \& Florian, V. (1998). The relationship between adult attachment styles and emotional and cognitive reactions to stressful events. In J. A. Simpson \& W. S. Rholes (Eds.), Attachment theory and close relationships (pp. 142-165). New York: Guilford Press.

Mikulincer, M., Horesh, N., Eilati, I., \& Kotler, M. (1999). The association between adult attachment style and mental health in extreme life-endangering conditions. Personality and Individual Differences, 27, 831-842.

Mikulincer, M, \& Shaver, P. R. (2003). The Attachment behavioral system in adulthood: activation, psychodynamics, and interpersonal processes. In M. P. Zanna (Ed.), Advances in Experimental Social Psychology (Vol. 35, pp. 53-152). New York: Academic Press. 
Mikulincer, M., \& Shaver, P.R. (2007). Attachment in adulthood: Structure, dynamics and change. New York: Guilford.

Mikulincer, M., Shaver, P. R., \& Pereg, D. (2003). Attachment Theory and Affect Regulation: The Dynamics, Development, and Cognitive Consequences of Attachment-Related Strategies. Motivation and Emotion, 27, 77-102.

Mroczek, D. K., Spiro, A., Aldwin, C. M., Ozer, D. J. \& Bosse, R. (1993). Construct validation of optimism and pessimism in older men: Findings from the Normative Aging Study. Health Psychology, 12, 406-409.

Myers, L.B. \& Steed, L. (1999). The relationship between dispositional optimism, dispositional pessimism and repressive coping and trait anxiety. Personality and Individual Differences, 27, 1261-1272.

Nauta, M. M. (2007). Assessing college students' satisfaction with their academic majors. Journal of Career Assessment, 15, 446-462.

Neimeyer, R. A. \& Baldwin, S. A. (2003). Personal construct psychotheraphy and the constructivist horizon. In Fransella, F. (Ed.), International Handbook of Personal Construct Psychology (pp 247-256). Chichester: Wiley.

Nolen-Hoeksema, S., Parker, L. E., \& Larson, J. (1994). Ruminative coping with depressed mood following loss. Journal of Personality and Social Psychology, $67,92-104$.

Norem, J. K. \& Cantor, N. (1986). Defensive pessimism: Harnessing anxiety as motivation. Journal of Personality and Social Psychology, 51, 1208-1217

Norem, J. K., \& Chang, E. C. (2001). A very full glass: Adding complexity to our thinking about the implications and applications of optimism and pessimism 
research. In E.C. Chang (Ed.), Optimism \& pessimism: Implications for theory, research, and practice (pp. 347-367). Washington, DC : American Psychological Association.

Norem, J. K, \& Chang, E. C (2002). The positive psychology of negative thinking. Journal of Clinical Psychology, 58, 993-1001.

Norem, J.K. \& Illingworth, K.S.S. (2004). Mood and performance among defensive pessimists and strategic optimists. Journal of Research in Personality, 38, 351366.

Oettingen, G., \& Mayer, D. (2002). The motivating function of thinking about the future: Expectations versus fantasies. Journal of Personality and Social Psychology, 83, $1198-1212$.

Oettingen, G., Mayer, D., Thorpe, J., Janetzke, H., \& Lorenz, S. (2005). Turning fantasies about positive and negative futures into self-improvement goals. Motivation and Emotion. 29, 237-267

Office of Institutional Research and Planning (2007a). 2007 Canadian Undergraduate Survey Consortium (CUSC): First-Year Undergraduate Students. Retrieved from http://oirp.carleton.ca/site/index.html in September, 2007.

Office of Institutional Research and Planning (2007b). Retention and Graduation of New First-time, Full-time Undergraduates - 1992 to 2006 at Carleton University, Retrieved from http://oirp.carleton.ca/site/index.html in September, 2007.

Pancer, S. M., Hunsberger, B., Pratt, M., \& Alisat, S. (2000). Cognitive complexity of expectations and adjustment to university in the first year. Journal of Adolescent Research, 15, 38-57. 
Park, C., Moore, P., Turner, R. A., \& Adler, N.E. (1997). The role of constructive thinking and optimism in psychological and behavioral adjustments during pregnancy. Journal of Personality and Social Psychology, 73, 584-592.

Paul, E. L., \& Brier, S. (2001). Friendsickness in the transition to college: Precollege predictors and college adjustment correlates. Journal of Counseling and Development, 79, 77-89.

Paulhus, D. L. (1991). Measurement and control of response bias. In J. P. Robinson, P.R. Shaver, \& L. S. Wrightsman (Eds.). Measures of personality and social psychological attitudes (pp. 17-60). San Diego: Academic Press.

Pavot, W. G., Diener, E., Colvin, C. R., \& Sandvik, E. (1991). Further validation of the Satisfaction with Life Scale: Evidence for the cross-method convergence of wellbeing measures. Journal of Personality Assessment, 57, 149-161.

Perkins, D. O., Leserman, J., Murphy, C., \& Evans, D. L. (1993). Psychosocial predictors of high-risk sexual behavior among HIV-negative homosexual men. AIDS Education and Prevention, 5, 141-152.

Peterson, C. (2000). The future of optimism. American Psychologist, 55, 44-55.

Pierce, G. R., Sarason, I. G., \& Sarason, B. R. (1991). General and relationship-based perceptions of social support: Are two constructs better than one? Journal of Personality and Social Psychology, 61, 1028-1039.

Pietromonaco, P. R., \& Barrett, L. F. (2000). The internal working models concept what do we really know about the self in relation to others? Review of General Psychology, 4, 155-175. 
Räikkönen, K., Matthews, K. A., Flory, J. D., Owens, J. F., \& Gump, B. B. (1999). Effects of optimism, pessimism, and trait anxiety on ambulatory blood pressure and mood during everyday life. Journal of Personality and Social Psychology, 76, 104-113.

Rholes, W. S., Simpson, J. A., Campbell, L. \& Grich, J. (2001). Adult attachment and the transition to parenthood. Journal of Personality and Social Psychology, 81, 421435.

Robins, R. W., \& Beer, J. S. (2001). Positive illusions about the self: Short-term benefits and long-term costs. Journal of Personality and Social Psychology, 80, 340-352.

Robinson-Whelen, S., Kim, C., MacCallum, R. C., \& Kiecolt-Glaser, J. K. (1997).

Distinguishing optimism from pessimism in older adults: Is it more important to be optimistic or not to be pessimistic? Journal of Personality and Social Psychology, 64, 324-332.

Ruitenbeek, H. M. (1962). Some Aspects of the Encounter of Psychoanalysis and Existential Philosophy. In H. M. Ruitenbeek (Ed.), Psychoanalysis and Existential Philosophy (pp. 11-26). New York: E. P. Dutton \& Co.

Ryan, R. M., Brown, K. W., \& Creswell, J. D. (2007). How integrative is attachment theory? Unpacking the meaning and significance of felt security. Psychological Inquiry, 18, 177-182.

Sadava, S. W., \& Park, A. W. (1993). Stress-related problem drinking and alcohol problems: A longitudinal study and extension of Marlatt's model. Canadian Journal of Behavioural Science, 25, 446-464. 
Scheier, M. F., \& Carver, C. S. (1992). Effects of optimism on psychological and physical well-being: Theoretical overview and empirical update. Cognitive Therapy and Research, 16, 201-228.

Scheier, M. F., Carver, C. S., \& Bridges, M. W. (2001). Optimism, pessimism, and psychological well-being. In E. C. Chang (Ed.), Optimism and pessimism: Implications for theory, research, and practice (pp. 189-216). Washington, DC: American Psychological Association.

Scheier, M. F., Carver, C. S., \& Bridges, M. W. (2001). Optimism, pessimism, and psychological well-being. In E. C. Chang (Ed.), Optimism and pessimism: Implications for theory, research, and practice (pp. 189-216). Washington, DC: American Psychological Association

Schneider, S.L. (2001). In search of realistic optimism: Meaning, knowledge, and warm fuzziness. American Psychologist, 56, 250-263

Schwarzer, R., \& Taubert, S. (2002). Tenacious Goal Pursuits and Striving Toward Personal Growth: Proactive Coping. In E. Fydenberg (Ed.), Beyond coping: Meeting goals, visions and challenges (pp. 19-35). London: Oxford University Press.

Schweizer, K., Beck-Seyffer, A., \& Schneider, R. (1999). Cognitive bias of optimism and its influence on psychological well-being. Psychological Reports, 84, 627-636.

Sedikides, C., Rudich, E. A., Gregg, A. P., Kumashiro, M., \& Rusbult, C. (2004). Are normal narcissists psychologically healthy? Self-esteem matters. Journal of Personality and Social Psychology, 87, 400-416. 
Sewell, K. W. (2003). An approach to posttraumatic stress. In Fransella, F. (Ed.), International Handbook of Personal Construct Psychology (pp 223-231). Chichester, Wiley.

Shaver, P. R., \& Mikulincer, M. (2005). Attachment theory and research: Resurrection of the psychodynamic approach to personality. Journal of Research in Personality, $39,22-45$.

Shedler, J., Mayman, M., \& Manis, M. (1993). The illusion of mental health. American Psychologist, 48, 1117-1131.

Schuerger, J. M., Zarella, K. L., \& Hotz, A. S. (1989). Factors that influence the temporal stability of personality by questionnaire. Journal of Personality and Social Psychology, 56, 777-783.

Simpson, J. A., Rholes, W. S., Campbell , L. , \& Wilson, C. (2003). Changes in attachment during the transition to parenthood . Journal of Experimental Social Psychology, 39, 317-331.

Smith, J. S., \& Wertlieb, E. C. (2005). Do first-year college students' expectations align with their first-year experiences? NASPA Journal, 42, 153- 174.

Stern, G. G. (1966). Myth and reality in the American college. American Association of University Professors Bulletin, 52, 408-414.

Taylor, S. E. (1983). Adjustment to threatening events: A theory of cognitive adaptation. American Psychologist, 38, 1161-1173.

Taylor, S. E. (1989). Positive illusions: Creative self-deception and the healthy mind. New York: Basic Books. 
Taylor, S. E., \& Armor, D. A. (1996). Positive illusions and coping with adversity. Journal of Personality, 64, 873-898.

Taylor, S.E., \& Brown, J. (1988). Illusion and well-being: A social psychological perspective on mental health. Psychological Bulletin, 103, 193-210.

Taylor, S. E. \& Brown, J. D. (1994). Positive illusions and wellbeing revisited: Separating fact from fiction. Psychological Bulletin, 116, 21-27.

Taylor, S. E., Kemeny, M. E., Aspinwall, L. G., Schneider, S. C., Rodriguez, R., \& Herbert, M. (1992). Optimism, coping, psychological distress, and high-risk sexual behaviors among men at risk for AIDS. Journal of Personality and Social Psychology, 63, 460-473.

Tennen, H., \& Affleck, G. (1987). The costs and benefits of optimistic explanations and dispositional optimism. Journal of Personality, 55, 377-393.

Trapnell, P. D., \& Campbell, J. D. (1999). Private self-consciousness and the five-factor model of personality: Distinguishing rumination from reflection. Journal of Personality and Social Psychology, 76, 284-304.

Waters, E., Hamilton, C., Weinfield, N. (2000). The stability of attachment security from infancy to adolescence and early adulthood: General introduction. Child Development. $71,678-683$.

Watson, D., L. A. Clark and A. Tellegen (1988). Development and validation of brief measures of positive and negative affect: The PANAS scales. Journal of Personality and Social Psychology, 54, 1063-1070.

Weger, H., Jr., \& Polcar, L. E. (2000). Attachment style and the cognitive representation of communication situations. Communication Studies, 51, 1-13. 
Weinberger, D. A. (1990). The construct validity of the repressive coping style. In J. L. Singer (Ed.). (1990). Repression and dissociation: Implications for personality theory, psychopathology, and health. Chicago: University of Chicago Press.

Wintre M. G., \& Bowers, C. D. (2007). Predictors of persistence to graduation: Extending a model and data on the transition to university model. Canadian Journal of Behavioural Science, 39, 220-234.

Wintre, M. G., \& Yaffe, M. (2000). First-year students' adjustment to university life as a function of relationships with parents. Journal of Adolescent Research, 15, 9-38.

Zhang, F., \& Labouvie-Vief, G. (2004). Stability and fluctuation in adult attachment style over a 6-year period. Attachment and Human Development, 6, 419-437.

Zimet, G.D., Dahlem, N.W., Zimet, S.G., \& Farley, G.K. (1988). The Multidimensional Scale of Perceived Social Support. Journal of Personality Assessment, 52, 3041. Zirkel, S., \& Cantor, N. (1990). Personal construal of a life task: Those who struggle for independence. Journal of Personality and Social Psychology, 58, 172-185.

Zuckerman, M. (2001). Optimism and pessimism: Biological foundations. In E. C. Chang (Ed.) Optimism and pessimism: Implications for theory, research, and practice (pp.169-188) Washington, DC: American Psychological Association. 


\section{Appendix A. Study I}

\section{Informed Consent}

The purpose of an informed consent is to ensure that you understand the purpose of the study and the nature of your involvement. The informed consent has to provide sufficient information such that you have the opportunity to determine whether you wish to participate in the study.

Study Title: First Year Students' Coping with the Transition to University

$\begin{array}{ll}\text { Study Personnel: } & \text { Colleen Rainey (tel.: (613) 520-2600 X 1448) } \\ & \text { Prof. Chris Davis (tel.: (613) 520-2600 X 2251) } \\ & \text { Ersin Asliturk (tel.: 520-2600 X 1448) }\end{array}$

Should you have any ethical or other concerns about this study then please contact Dr. Avi Parush, (Chair, Carleton University Ethics Committee for Psychological Research, 520-2600, ext. 6026) or Dr. Anne Bowker (Chair, Dept. of Psychology, 520-2600, ext. 2648).

Purpose and Task Requirements: The general purpose of this study is to investigate the how first year students' personality characteristics relate to their transition to university. We will be asking you to complete a series of questionnaires regarding personality, affect, feelings and behaviours.

Potential Risk and Discomfort: There is very minimal risk of discomfort; however, if any of the questions cause any upset, please speak with the experimenter or refer to the debriefing form for contact information of health, counselling, and distress centres and other sources of help.

Confidentiality: Participants' information will be kept anonymous and confidential within the confines of the study and researchers. No participants' information will be distributed to any persons outside of the direct purpose of the study.

Right to Withdraw: Your participation in this study is entirely voluntary. At any point during the study you have the right to not complete certain questions or to withdraw with no penalty whatsoever.

I have read the above description of the study concerning personality and transition to university. The data collected will be used in research publications and/or for teaching purposes. My endorsement indicates that I agree to participate in the study, and this in no way constitutes a waiver of my rights. I am at least 16 years of age.

\section{ACKNOWLEDGEMENT}

\section{ACKNOWLEDGE THAT I HAVE READ AND UNDERSTOOD THIS}

AGREEMENT, that I have executed this agreement voluntarily.

SIGNED THIS day of ,2007, at

Ottawa Ontario.

Signature of Participant

Printed Name of Participant:
Signature of Witness (Researcher) Printed Name of Witness: 


\section{Debriefing}

Thank you for participating in this study. The goal of this research was to examine realistic orientation, and how an individual's level of the trait may be related to their ability to cope during the transition to university.

As many as $30 \%$ of incoming university students will not finish their degrees. Although people leave for many reasons, one reason may be that some students have an inaccurate view of what university will be like when they begin, and are not prepared for the surprises along the way. We are interested in assessing the extent to which students new to the university are able to adapt themselves to their new environment.

In this study, we will be comparing your responses to a questionnaire administered at Mass Testing in September to the same questionnaire today. We are interested in the extent to which people stay the same or change over time, and whether people who had a good sense of what the university would be like back in September are doing well now. Our expectation is that people who were realistic then (i.e., they expected good and bad, fun and hard work) are more satisfied with their life and their studies now relative to those who were optimistic and those who were more pessimistic.

Please be assured that all responses will be kept completely anonymous and confidential. Participants' individual names and other identifying information will not be attached to their responses.

Thanks again for contributing to our research!

Contacts

The following people are involved in this research project and may be contacted at any time if you have any further questions about the project, what it means, or concerns about how it was conducted:

Colleen Rainey, crainey@connect.carleton.ca

Prof. Chris Davis, cdavis@ccs.carleton.ca

Ersin Asliturk, ersinasliturk@gmail.com

Should you have any ethical or other concerns about this study then please contact Dr. Avi Parush, (Chair, Carleton University Ethics Committee for Psychological Research, 520-2600, ext. 6026) or Dr. Anne Bowker (Chair, Dept. of Psychology, 520-2600, ext. 2648).

For further information regarding any health concerns you might have for yourself, or a loved one, please visit the Carleton University Health and Counselling Services, located on campus.

Carleton University Health and Counselling Services

http://www.carleton.ca/health/

Telephone: (613) 520-6674

Email: hcs@carleton.ca 


\section{BIDR Version 6 - Form 40A}

Using the scale below as a guide, write a number beside each statement to indicate how true it is.

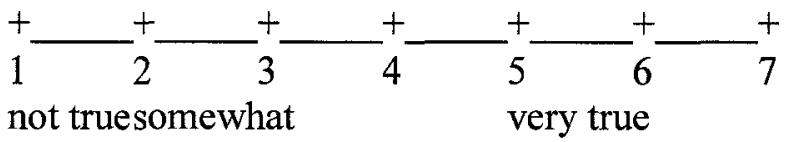

1. My first impressions of people usually turn out to be right.

2. It would be hard for me to break any of my bad habits.

3. I don't care to know what other people really think of.me.

4. I have not always been honest with myself.

5. I always know why I like things.

6. When my emotions are aroused, it biases my thinking.

7. Once I've made up my mind, other people can seldom change my opinion.

8. I am not a safe driver when I exceed the speed limit.

9. I am fully in control of my own fate.

10. It's hard for me to shut off a disturbing thought.

11. I never regret my decisions.

12. I sometimes lose out on things because I can't make up my mind soon enough.

13. The reason I vote is because my vote can make a difference.

14. My parents were not always fair when they punished me.

15. I am a completely rational person.

16. I rarely appreciate criticism.

17. I am very confident of my judgments

18. I have sometimes doubted my ability as a lover.

19. It's all right with me if some people happen to dislike me.

20. I don't always know the reasons why I do the things I do. 
Using the scale below as a guide, write a number beside each statement to indicate how true it is.

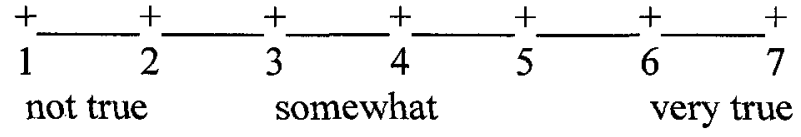

21. I sometimes tell lies if I have to.

22. I never cover up my mistakes.

23. There have been occasions when I have taken advantage of someone.

24. I never swear.

25. I sometimes try to get even rather than forgive and forget.

26. I always obey laws, even if I'm unlikely to get caught.

27. I have said something bad about a friend behind his/her back.

28. When I hear people talking privately, I avoid listening.

29. I have received too much change from a salesperson without telling him or her.

30. I always declare everything at customs.

31. When I was young I sometimes stole things.

32. I have never dropped litter on the street.

33. I sometimes drive faster than the speed limit.

34. I never read sexy books or magazines.

35. I have done things that I don't tell other people about.

36. I never take things that don't belong to me.

37. I have taken sick-leave from work or school even though I wasn't really sick.

38. I have never damaged a library book or store merchandise without reporting it.

39. I have some pretty awful habits.

40. I don't gossip about other people's business. 


\section{PCI}

Reactions to Daily Events Questionnaire

The following statements deal with reactions you many have to various situations.

Indicate how true each of these statements is for you by assigning each with a score from $1=$ "not true at all", 2= "barely true", 3= "somewhat true", 4= "completely true".

1. I am a "take charge" person.

2. I try to let things work themselves out on their own.

3. After attaining a goal, I look for another, more challenging one.

4. I like challenges and beating the odds.

5. I visualise my dreams and try to achieve them.

6. Despite numerous setbacks, I usually succeed in getting what I want.

7. I try to pinpoint what I need to succeed.

8. I always try to find a way to work around obstacles; nothing really stops me.

9. I often see myself failing so I don't get my hopes up too high.

10. When I apply for a position I imagine myself filling it.

11. I turn obstacles into positive experiences.

12. If someone tells me I can't do something, you can be sure I will do it.

13. When I experience a problem, I take the initiative in resolving it.

14. When I have a problem, I usually see myself in a no-win situation.

15. I imagine myself solving difficult problems.

problem.

16. Rather than acting impulsively, I usually think of various ways to solve a

17. In my mind I go through many different scenarios in order to prepare myself for different outcomes.

18. When I have a problem with my co-workers, friends, or family, I imagine beforehand how I will deal with them successfully.

19. Before tackling a difficult task I imagine success scenarios. 
20. I take action only after thinking carefully about a problem.

21. I imagine myself solving a difficult problem before I actually have to face it.

22. I address a problem from various angles until I fine the appropriate action.

23. When there are serious misunderstandings with co-workers, friends, or family members, I practice beforehand how I will deal with them.

24. I think about every possible outcome to a problem before tackling it.

25. When I have a problem I like to sleep on it. with it.

26. If I find a problem too difficult sometimes I put it aside until I'm ready to deal

27. When I have a problem I usually let it sit on the 'back burner' for a while. 


\section{Defensive Pessimism Questionnaire}

Think of a situation where you want to do your best. It may be related to work, to your social life, or to any of your goals. When you answer the following questions, please think about how you prepare for that kind of situation. Rate how true each statement is for you.

Not at all true of me 1---2---3---4---5---6---7 Very true of me

1. I I often start out expecting the worst, even though I will probably do OK.

2. I I worry about how things will turn out.

3. I carefully consider all possible outcomes.

4. I I I often worry that I won't be able to carry through my intentions.

5. I I spend lots of time imagining what could go wrong.

6. I I I imagine how I would feel if things went badly.

7. I I try to picture how I could fix things if something went wrong.

8. I' I'm careful not to become overconfident in these situations.

9. I I spend a lot of time planning when one of these situations is coming up.

10. I I I imagine how I would feel if things went well.

11. In these situations, sometimes I worry more about looking like a fool than doing really well.

12. Considering what can go wrong helps me to prepare. 


\section{Orientation to University Scale}

When you think about yourself as a new student at Carleton University, how frequently do you think about each of these issues?

\begin{tabular}{|l|l|l|l|l|l|l|}
\hline Not at all & & & Sometimes & & & $\begin{array}{l}\text { Very } \\
\text { frequently }\end{array}$ \\
\hline 1 & 2 & 3 & 4 & 5 & 6 & 7 \\
\hline
\end{tabular}

1.__ Getting good grades in my courses

2. Being separated from or missing the high school friends or loved ones I have left behind

3. Being prepared for classes

4. Increasing my knowledge and skills

5.__ Being respected as an individual

6. Developing positive contacts with instructors

7. Having help and support from study groups

8. Making a big mistake (like getting pregnant/ getting someone pregnant)

9. Fulfilling a major academic goal in my life

10.__ Going to parties

11. Not keeping up with readings and assignments

12. Thinking, "Am I disciplined enough to do well"

13. Being independent

14. Making intimate friendships

15. How difficult it will be to concentrate on various academic issues

16. Meeting the goals I have set for myself

17. How I will handle working to make money and studying at the same time

18. Thinking "What if I cannot live up to my parents" academic expectations of me"

19._ Making and being with new friends

20. Thinking, "What if I do worse than expected"

21._Being overwhelmed by the workload

22. Learning interesting stuff

23. How I will handle being alone or possibility of being isolated

24. Having sex

25. Being an enthusiastic student

26. The difficulties of getting along with my roommate(s) or family members.

27. The challenges of not having or making enough money

28. Thinking, "Am I smart enough to do well"

29. Enjoying the clubs and social organizations

30. Using too much alcohol or drugs at parties 


\section{LOT-R}

Please be as honest and accurate as you can throughout. Try not to let your response to one statement influence your responses to other statements. There are no "correct" or "incorrect" answers. Answer according to your own feelings, rather than how you think "most people" would answer.

\begin{tabular}{|l|l|l|l|l|}
\hline $\mathbf{1}$ & $\mathbf{2}$ & $\mathbf{3}$ & $\mathbf{4}$ & $\mathbf{5}$ \\
\hline $\begin{array}{l}\text { I strongly } \\
\text { disagree }\end{array}$ & $\begin{array}{l}\text { I disagree a } \\
\text { little }\end{array}$ & $\begin{array}{l}\text { I neither agree } \\
\text { nor disagree }\end{array}$ & I agree a little & $\begin{array}{l}\text { I strongly } \\
\text { agree }\end{array}$ \\
\hline
\end{tabular}

1. In In uncertain times, I usually expect the best.

2. It_s easy for me to relax.

3. If__ If something can go wrong for me, it will.

4. I'm always optimistic about my future.

5. I I enjoy my friends a lot.

6. I _ It's important for me to keep busy.

7. I _ I hardly ever expect things to go my way.

8. I I I don't get upset too easily.

9. I rarely count on good things happening to me.

10._ Overall, I expect more good things to happen to me than bad. 
Table 21. Correlations

Appendix B. Study II

\begin{tabular}{|c|c|c|c|c|c|c|c|c|}
\hline & $\begin{array}{l}\text { Positive } \\
\text { Thinking }\end{array}$ & $\begin{array}{l}\text { Negative } \\
\text { Thinking }\end{array}$ & $\begin{array}{c}\text { Attachment } \\
\text { Avoidance } \\
\text { Time2 }\end{array}$ & $\begin{array}{c}\text { Attachment } \\
\text { Anxiety } \\
\text { Time2 }\end{array}$ & $\begin{array}{c}\text { Difficult } \\
\text { Ratings }\end{array}$ & $\begin{array}{l}\text { Satisfaction } \\
\text { with } \\
\text { University }\end{array}$ & $\begin{array}{l}\text { Satisfaction } \\
\text { with } \\
\text { Life }\end{array}$ & $\begin{array}{l}\text { Perceived } \\
\text { Stress }\end{array}$ \\
\hline Positive Thinking & 1.00 & & & & & & & \\
\hline $\begin{array}{l}\text { Negative } \\
\text { Thinking }\end{array}$ & $.29 * *$ & 1.00 & & & & & & \\
\hline $\begin{array}{l}\text { Attachment } \\
\text { Avoidance } \\
\text { Time2 }\end{array}$ & $-.25 * *$ & -.02 & 1.00 & & & & & \\
\hline $\begin{array}{l}\text { Attachment Anxiety } \\
\text { Time2 }\end{array}$ & -.09 & $.13^{*}$ & $.43 * *$ & 1.00 & & & & \\
\hline $\begin{array}{c}\text { Difficulty } \\
\text { Ratings }\end{array}$ & -.05 & $.23 * *$ & .07 & $.13^{*}$ & 1.00 & & & \\
\hline $\begin{array}{c}\text { Satisfaction } \\
\text { With University }\end{array}$ & $.18^{* *}$ & $-.13^{*}$ & $-.21 * *$ & $-.21 * *$ & $-.25 * *$ & 1.00 & & \\
\hline Satisfaction with Life & .08 & $-.25 * *$ & $-.29 * *$ & $-.31 * *$ & $-.37 * *$ & $.27 * *$ & 1.00 & \\
\hline $\begin{array}{c}\text { Perceived } \\
\text { Stress }\end{array}$ & -.04 & $.38^{* *}$ & $.14 * *$ & $.34 * *$ & $.41^{* *}$ & $-.25 * *$ & $-.52 * *$ & 1.00 \\
\hline $\begin{array}{c}\text { Social } \\
\text { Support }\end{array}$ & $.21^{* *}$ & .05 & $-.69 * *$ & $-.39 * *$ & -.10 & $.20 * *$ & $.37^{* *}$ & $-.21 * *$ \\
\hline
\end{tabular}




\title{
Informed Consent
}

The purpose of an informed consent is to ensure that you understand the purpose of the study and the nature of your involvement. The informed consent has to provide sufficient information such that you have the opportunity to determine whether you wish to participate in the study.

Study Title: First Year Students' Coping with the Transition to University

\author{
Study Personnel: $\quad$ Ersin Asliturk (tel.: 520-2600 X 1448) \\ Colleen Rainey (tel.: (613) 520-2600 X 1448)
}

Prof. Chris Davis (tel.: (613) 520-2600 X 2251)

Should you have any ethical or other concerns about this study then please contact Dr. Avi Parush, (Chair, Carleton University Ethics Committee for Psychological Research, 520-2600, ext. 6026) or Dr. Anne Bowker (Chair, Dept. of Psychology, 520-2600, ext. 2648).

Purpose and Task Requirements: The general purpose of this study is to investigate the how new students experience the first year of the university. We will be asking you to complete a series of questionnaires regarding personality, affect, feelings and behaviours.

Potential Risk and Discomfort: There is very minimal risk of discomfort; however, if any of the questions cause any upset, please speak with the experimenter or refer to the debriefing form for contact information of health, counselling, and distress centres and other sources of help.

Confidentiality: Participants' information will be kept anonymous and confidential within the confines of the study and researchers. No participants' information will be distributed to any persons outside of the direct purpose of the study.

Right to Withdraw: Your participation in this study is entirely voluntary. At any point during the study you have the right to not complete certain questions or to withdraw with no penalty whatsoever.

I have read the above description of the study concerning personality and transition to university. The data collected will be used in research publications and/or for teaching purposes. My endorsement indicates that I agree to participate in the study, and this in no way constitutes a waiver of my rights. I am at least 16 years of age. 


\section{Debriefing}

Understanding Transition to University

\section{Dear Participant,}

Thank you for agreeing to participate this study. By taking part, you have provided us with valuable information on the expectations and experiences of first year students. The information from this study will be used to help us uncover sources of stress and better coping strategies of new students. We wish to understand why this significant transition is more difficult for some students than for others and what factors increase or decrease the level of stress experienced.

The relevant research indicates that most of the first year students are very optimistic for their future life in university. However, they experience a number of difficulties during transition. Some of them include academic difficulties such as getting good grades, being overwhelmed by the workload and keeping up with assignments. Some of them include social-personal difficulties such as getting along with friends, feeling isolated, not having enough money to support oneself, and working and studying at the same time. As you might remember from mass testing we asked you how frequently you were thinking these aspects of first year university experiences.

In this research, those students who thought about both negative and positive future possibilities are seen as 'realists' and they are expected to cope better with those difficulties, since they are psychologically more prepared than the other students who only consider, for example, positive possibilities ('optimists') at the beginning of the fall term. Hence, when optimist students start to experience difficulties, some of them might feel overwhelmed, usually because they have not considered the negative possibilities before they are experienced. A possible change towards a more realistic future thinking, acknowledging both positive and negative aspects of first year university life, would be helpful for potential new students. You can also apply this view to the other aspects of your life.

A study conducted under the supervision of Dr. Chris Davis confirmed these expectations. You can visit our web-site and read the results of Dr. AnnMarie Churchill's research on Realism and the Transition to Motherhood. In the results of that study, you can see that thinking realistically about future issues is very adaptive in the context of transition to motherhood.

The following people are involved in this research project and may be contacted at any time if you have any further questions about the project, what it means, or concerns about how it was conducted:

Ersin Asliturk, ersinasliturk@gmail.com

Prof. Chris Davis, cdavis@ccs.carleton.ca

Colleen Rainey, crainey@connect.carleton.ca

Should you have any ethical or other concerns about this study then please contact Dr. Avi Parush, (Chair, Carleton University Ethics Committee for Psychological Research, 520-2600, ext. 6026) or Dr. Anne Bowker (Chair, Dept. of Psychology, 520-2600, ext. 2648).

For further information regarding any health concerns you might have for yourself, or a loved one, please visit the Carleton University Health and Counselling Services, located on campus: Carleton University Health and Counseling Services http://www.carleton.ca/health/ Telephone: (613) 520-6674 Email: hcs@carleton.ca 


\section{Demographics}

These first questions are about your background. Your answers to these questions help us understand your current situation.

-Gender:

Male

Female

Age:

-Relationship status: Please check one or more of them.

Single

Married

Common Law

Separated, divorced or widowed

- Do you have prior university or college experience: Yes

No

- If yes, how long did you attend? 


\section{Difficulties in Transition to University Scale}

Below questions are about your experiences in transition to university. Please indicate if you had the difficulty in each aspects of your experience as a first year student. Notice that items are the completion of:

"I have had difficulties in....................."

1. getting good grades in my courses Yes_ No _

IF YES: HOW DIFFICULT HAS THIS BEEN FOR YOU?

Not at all A little Somewhat $\quad$ Very

2. being prepared for classes Yes__ No

IF YES: HOW DIFFICULT HAS THIS BEEN FOR YOU?

Not at all A little Somewhat Very

3. Developing positive contacts with instructors Yes__ No

IF YES: HOW DIFFICULT HAS THIS BEEN FOR YOU?

Not at all A little Somewhat Very

4. getting help and support from study groups Yes _ No

IF YES: HOW DIFFICULT HAS THIS BEEN FOR YOU?

Not at all A little Somewhat $\quad$ Very

5. keeping up with readings and assignments Yes_No

IF YES: HOW DIFFICULT HAS THIS BEEN FOR YOU?

Not at all A little Somewhat $\quad$ Very

6. getting disciplined enough to do well Yes__ No

IF YES: HOW DIFFICULT HAS THIS BEEN FOR YOU?

Not at all A little Somewhat $\quad$ Very

7. living up to my parents' academic expectations of me Yes__ No

IF YES: HOW DIFFICULT HAS THIS BEEN FOR YOU?

Not at all A little Somewhat $\quad$ Very 
8. managing the workload Yes_ No

IF YES: HOW DIFFICULT HAS THIS BEEN FOR YOU?

Not at all A little Somewhat $\quad$ Very

9. making and being with new friends Yes No

IF YES: HOW DIFFICULT HAS THIS BEEN FOR YOU?

$\begin{array}{llll}\text { Not at all } & \text { A little } & \text { Somewhat } & \text { Very }\end{array}$

10. being respected as an individual Yes_ No _

IF YES: HOW DIFFICULT HAS THIS BEEN FOR YOU?

Not at all A little Somewhat $\quad$ Very

11. having fun or enjoying fun activities Yes _ No

IF YES: HOW DIFFICULT HAS THIS BEEN FOR YOU?

Not at all A little Somewhat Very

12. making intimate friendships

Yes__ No

IF YES: HOW DIFFICULT HAS THIS BEEN FOR YOU?

Not at all A little Somewhat $\quad$ Very

13. having enough money Yes_No

IF YES: HOW DIFFICULT HAS THIS BEEN FOR YOU?

$\begin{array}{llll}\text { Not at all } & \text { A little } & \text { Somewhat } & \text { Very }\end{array}$

14. working and studying at the same time Yes__ No _

IF YES: HOW DIFFICULT HAS THIS BEEN FOR YOU?

$\begin{array}{llll}\text { Not at all } & \text { A little } & \text { Somewhat } & \text { Very }\end{array}$

15. Managing loneliness Yes__ No

IF YES: HOW DIFFICULT HAS THIS BEEN FOR YOU?

Not at all A little Somewhat Very 
Below you might want to add other aspects of the experience that have been difficult for you.

16.

HOW DIFFICULT HAS THIS BEEN FOR YOU? Not at all

A little Somewhat Very

17.

HOW DIFFICULT HAS THIS BEEN FOR YOU? Not at all

A little Somewhat Very

18.

HOW DIFFICULT HAS THIS BEEN FOR YOU? Not at all

A little Somewhat Very

19.

HOW DIFFICULT HAS THIS BEEN FOR YOU? Not at all

A little Somewhat Very

20.

HOW DIFFICULT HAS THIS BEEN FOR YOU? Not at all

A little Somewhat Very 


\section{Relationships Structures (RS) Questionnaire}

Please answer the following 10 questions with respect to someone you feel closest (e.g., your dating or marital partner, your mother or father, or your best friend).

\begin{tabular}{|c|c|c|c|c|c|c|}
\hline $\begin{array}{c}\text { Strongly } \\
\text { Disagree }\end{array}$ & $\begin{array}{c}\text { Moderately } \\
\text { Disagree }\end{array}$ & $\begin{array}{c}\text { Slightly } \\
\text { Disagree }\end{array}$ & Neutral & $\begin{array}{c}\text { Slightly } \\
\text { Agree }\end{array}$ & $\begin{array}{c}\text { Moderately } \\
\text { Agree }\end{array}$ & $\begin{array}{c}\text { Strongly } \\
\text { Agree }\end{array}$ \\
\hline 1 & 2 & 3 & 4 & 5 & 6 & 7 \\
\hline
\end{tabular}

1. It helps to turn to this person in times of need.

2. I I usually discuss my problems and concerns with this person.

3. I I talk things over with this person.

4. I I find it easy to depend on this person.

5. I I I don't feel comfortable opening up to this person.

6. I I prefer not to show this person how I feel deep down.

7. I I I often worry that this person doesn't really care for me.

8. I'm afraid that this person may abandon me.

9. I w worry that this person won't care about me as much as I care about him or her.

10. I I don't fully trust this person 


\section{Perceived Stress Scale}

\begin{tabular}{|c|c|c|c|c|}
\hline 0 & 1 & 2 & 3 & 4 \\
\hline never & $\begin{array}{c}\text { almost } \\
\text { never }\end{array}$ & sometimes & $\begin{array}{c}\text { fairly } \\
\text { often }\end{array}$ & very often \\
\hline
\end{tabular}

1. In the last month, how often have you been upset because of something that happened unexpectedly?

2. In the last month, how often have you felt that you were unable to control the important things in your life?

3. In the last month, how often have you felt nervous and "stressed"?

4. In the last month, how often have you felt confident about your ability to handle your personal problems?

5.__ In the last month, how often have you felt that things were going your way?

6. In the last month, how often have you found that you could not cope with all the things that you had to do?

7. In the last month, how often have you been able to control irritations in your life?

8. In the last month, how often have you felt that you were on top of things?

9. In the last month, how often have you been angered because of things that were outside of your control?

10. In the last month, how often have you felt difficulties were piling up so high that you could not overcome them? 


\section{Multidimensional Scale of Perceived Social Support}

\begin{tabular}{|c|c|c|c|c|c|c|}
\hline $\begin{array}{c}\text { Strongly } \\
\text { Disagree }\end{array}$ & $\begin{array}{c}\text { Moderately } \\
\text { Disagree }\end{array}$ & $\begin{array}{c}\text { Slightly } \\
\text { Disagree }\end{array}$ & Neutral & $\begin{array}{c}\text { Slightly } \\
\text { Agree }\end{array}$ & $\begin{array}{c}\text { Moderately } \\
\text { Agree }\end{array}$ & $\begin{array}{c}\text { Strongly } \\
\text { Agree }\end{array}$ \\
\hline 1 & 2 & 3 & 4 & 5 & 6 & 7 \\
\hline
\end{tabular}

1. There is a special person who is around when I am in need.

2. There is a special person with whom I can share my joys and sorrows.

3. My family really tries to help me.

4. I I get the emotional help and support I need from my family.

5. I I have a special person who is a real source of comfort to me.

6. My friends really try to help me.

7.__ I can count on my friends when things go wrong.

8. I I can talk about my problems with my family.

9._I I have friends with whom I can share my joys and sorrows.

10. There is a special person in my life who cares about my feelings.

11._ My family is willing to help me make decisions.

12. I can talk about my problems with my friends. 


\section{Satisfaction with University Scale}

Please be as honest and accurate as you can throughout. Try not to let your response to one statement influence your responses to other statements. There are no "correct" or "incorrect" answers. Answer according to your own feelings, rather than how you think "most people" would answer.

\begin{tabular}{|c|c|c|c|c|}
\hline $\mathbf{1}$ & $\mathbf{2}$ & $\mathbf{3}$ & $\mathbf{4}$ & $\mathbf{5}$ \\
\hline $\begin{array}{c}\text { I strongly } \\
\text { disagree }\end{array}$ & $\begin{array}{c}\text { I disagree } \\
\text { little }\end{array}$ & $\begin{array}{c}\text { I neither agree } \\
\text { nor disagree }\end{array}$ & I agree a little & I strongly agree \\
\hline
\end{tabular}

1. I often wish I hadn't gone to this university.

2. I wish I were happier with my choice of university.

3. I am strongly considering changing to another university.

4. Overall, I am happy with the university I've chosen.

5. I feel good about the university I've selected.

6. I would like to talk to someone about changing universities. 


\section{Satisfaction with Life Scale}

Below are five statements about how you perceive your life at this time. To what extent do you agree or disagree with the following statements.

\begin{tabular}{|c|c|c|c|c|c|c|}
\hline $\begin{array}{l}\text { Strongly } \\
\text { Disagree }\end{array}$ & Disagree & $\begin{array}{l}\text { Slightly } \\
\text { Disagree }\end{array}$ & $\begin{array}{l}\text { Neither } \\
\text { agree nor } \\
\text { disagree }\end{array}$ & $\begin{array}{c}\text { Slightly } \\
\text { agree }\end{array}$ & Agree & $\begin{array}{l}\text { Strongly } \\
\text { agree }\end{array}$ \\
\hline 1 & 2 & 3 & 4 & 5 & 6 & 7 \\
\hline
\end{tabular}

1. __ In most ways my life is close to my ideal.

2. The conditions of my life are excellent.

3. I I I am satisfied with my life.

4. So far I have gotten the important things I want in life.

5. ___ If I could live my life over, I would change almost nothing. 


\section{Appendix C. Study III \\ Informed Consent}

The purpose of an informed consent is to ensure that you understand the purpose of the study and the nature of your involvement. The informed consent is intended to provide sufficient information, such that you have the opportunity to determine whether you wish to participate in the study.

Study Title: Acing the IQ test

Study Personnel: Stephanie Blust (613-520-2600 ext. 1448)

Professor Chris Davis (613-520-2600 ext. 2251)

Colleen Rainy (613-520-2600 ext. 1448)

Ersin Asliturk (613-520-2600 ext. 1448)

Should you have any ethical or other concerns about this study, then please contact Dr. Avi Parush, (Chair, Carleton University Ethics Committee for Psychological Research, 520-2600, ext. 6026) or Dr. Anne Bowker (Chair, Dept. of Psychology, 520-2600, ext. 2648).

Purpose and Task Requirements: The general purpose of this study is to assess whether IQ test scores may be influenced by preparation strategies. We will be asking you to complete a series of questionnaires, to participate in a short thinking task and in a short IQ test.

Potential Risk and Discomfort: Some people get anxious when they have to take a test. If the test is too difficult or you find it too stressful, you may quit the study.

Credit: You will receive 1\% in credits towards PSYC1001/1002 for your participation in the study.

Confidentiality: The data collected in this study will be confidential and anonymous. We will not disclose any information on individual participants.

Right to Withdraw: Your participation in this study is entirely voluntary. At any point during the study you have the right to not complete certain questions or to withdraw with no penalty whatsoever.

I have read the above description of the study concerning IQ test taking strategies. The data collected will be used in research publications and/or for teaching purposes. My endorsement indicates that I agree to participate in the study, and this in no way constitutes a waiver of my rights. I am at least 16 years of age.

\section{ACKNOWLEDGEMENT}

I ACKNOWLEDGE THAT I HAVE READ AND UNDERSTOOD THIS AGREEMENT, that I have executed this agreement voluntarily.

SIGNED THIS day of ,2008, at Ottawa Ontario.

Signature of Participant

\section{Printed Name of Participant}

B552 Loeb Bldg.

$\underline{520-2600}$
Signature of Witness (Researcher)

Printed Name of Witness

Carleton University, $P$ sychology Dept.

$1125 \mathrm{Col} . \mathrm{By} \mathrm{Dr}$, , Ottawa, K1S 5B6, 613-

Witness Address \& Phone No. 


\section{Background Information}

Please fill in the following demographic information. This information is collected for the purpose of describing general information about our sample of participants.

Gender: $\quad$ Male $\quad$ Female

Age:

Current average at Carleton University: Please circle one of the below grades

$\mathrm{A}+\mathrm{A}$ A- $\mathrm{B}+\mathrm{B}$ B- C+ C C- D+ D D- 


\section{PANAS}

\section{Directions}

This scale consists of a number of words that describe different feelings and emotions. Read each item and then circle the appropriate answer next to that word. Indicate to what extent you have felt this way right now.

Use the following scale to record your answers.
(1) $=$ Very slightly or
(2) $=$ A little
(3) $=$ Moderately
(4) = Quite a bit
(5) = Extremely

\begin{tabular}{|c|c|c|c|c|c|}
\hline & $\begin{array}{l}\text { Very slightly or } \\
\text { not at all }\end{array}$ & A little & Moderately & Quite a bit & Extremely \\
\hline Interested & 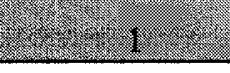 & 2 & 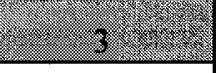 & $2-4$ & 5. \\
\hline Distressed & 1 & 2 & 3 & 4 & 5 \\
\hline Excited & 18 & 202 & 3 & 4 & S. \\
\hline Upset & 1 & 2 & 3 & 4 & 5 \\
\hline Strong: & 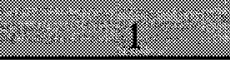 & 2. & 3 & 4.20 & 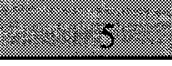 \\
\hline Guilty & 1 & 2 & 3 & 4 & 5 \\
\hline Scared & 1 & 2. & 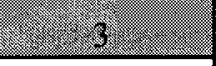 & 4. & 5 \\
\hline Hostile & 1 & 2 & 3 & 4 & 5 \\
\hline Enthusiastic & $y^{2}=2-1$ & 2 & 3. & 82 & $5=2$ \\
\hline Proud & 1 & 2 & 3 & 4 & 5 \\
\hline Initable & 8. & 28 & $3=2 x=0$ & $4=0$ & 5 \\
\hline Alert & 1 & 2 & 3 & 4 & 5 \\
\hline Ashamed & 1 & 2 & 3 & 4. & S: \\
\hline Inspired & 1 & 2 & 3 & 4 & 5 \\
\hline Nerrous $=8$ & 1. & 2 & 3. & $4^{2}$ & 5 \\
\hline Determined & 1 & 2 & 3 & 4 & 5 \\
\hline Attentive & 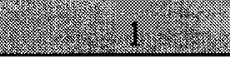 & 2 & 3 & 4 & 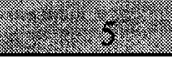 \\
\hline Jittery & 1 & 2 & 3 & 4 & 5 \\
\hline Active & 1 & 2 & 3. & 4 & 5 \\
\hline Afraid & 1 & 2 & 3 & 4 & 5 \\
\hline
\end{tabular}




\section{Script}

\section{Information about test:}

In a few minutes we are going to ask you to complete an IQ test to assess your mental aptitude. This test has been used by several psychologists to assess mental ability and has been shown to predict academic success and future earning potential. 


\section{Script \\ Thinking task explained:}

\section{Optimistic Thinking Group:}

Before I get you to complete the IQ test, I would like you to participate in a short thinking activity.

I would like you to think positively and optimistically about the IQ test you are going to be taking. I want you to imagine that you are flying through all the questions very easily and without any effort at all. I want you to imagine that you will do very well on this test, and how this great score demonstrates that you are very intelligent. I want you to imagine how happy you will feel after completing the IQ test and the confidence you will have in your performance.

I'm going to pass out some sheets, on them I would like you to write out ten positive expectations relating to the IQ test that you will be completing. There is also one question on the bottom of this page I would like you to answer. Just raise your hand when you are done and I will collect the sheet from you.

\section{Realistic Thinking Group:}

Before I get you to complete the IQ test, I would like you to participate in a short thinking activity.

I would like you to think of both positive and negative possible outcomes from the IQ test you are going to be taking. I want you to imagine the possibility of answering the questions where the answers come to you quite easily. I also want you to imagine the possibility where the questions are much more of a struggle and you are quite unsure of the answer. I want you to imagine the possibility of an IQ score which makes you happy, and also the possibility of an IQ score which you are not happy with. I want you to imagine the possibility of feeling happy with how you did after the IQ test, and also the possibility of feeling unhappy with how you did after the IQ test.

I'm going to pass out some sheets, on them I would like you to write out 5 positive expectations and 5 negative expectations relating to the IQ test that you will be completing. There is also one question on the bottom of this page I would like you to answer. Just raise your hand when you are done and I will collect the sheet from you. 
("Imagine success and failure" condition)

\section{Positive Expectations}

1.

2.

3.

4.

5.

\section{Negative Expectations}

1.

2.

3.

4.

5.

Please circle the option which applies

1. How well do you expect to do on the IQ test?

$\begin{array}{llll}\text { Really well } & \text { Pretty well } & \text { Average } & \text { Below Average }\end{array}$




\section{("Imagine only success" condition)}

\section{Positive Expectations}

1.

2.

3.

4.

5.

6.

7.

8.

9.

10.

Please circle the option which applies

1. How well do you expect to do on the IQ test?

$\begin{array}{llll}\text { Really well Pretty well } & \text { Average } & \text { Below Average }\end{array}$


Name:

Sex: $\square$ Male $\quad \square$ Female

Age:

yrs, months

Education Completed:

$\square$ High School

Undergraduate degree

$\square$ Graduate degree

\section{Smith - Anderson Test of Mental Abilities}

\section{Version: Adult Short Form}

(C) 2005, Intelligence Testing Service, Berkeley, CA

Directions: $\quad$ Each sentence below has one or two blanks, each blank indicating that something has been omitted. Beneath the sentence are five lettered words or sets of words. Circle the letter corresponding to the word or set of words for each blank that bes $t$ fits the meaning of the sentence as a whole. Do not begin this test until instructed to do so. 
1. The author of this book

Time permitted: 15 minutes overlooks or minimizes some of the problems and shortcomings in otherwise highly successful foreign industries in order to the points on which they excel and on which we might try to emulate them.
(A) accidentally. .exaggerate
(B) purposely. .emphasize
(C) occasionally. .counterbalance
(D) intentionally. .confuse
(E) cleverly. .compound

2. Some customs travel well; often, however, behaviour that is considered the epitome of at home is perceived as impossibly rude or, at least, harmlessly bizarre abroad.
(A) novelty
(B) eccentricity
(C) urbanity
(D) coarseness
(E) tolerance

3. Although specific concerns may determine the intent of a research project, its results are often
(A) unanticipated
(B) beneficial
(C) expensive
(D) spectacular
(E) specialized

4. People frequently denigrate books about recent catastrophes as morally attempts to profit from misfortune, but in my view our desire for such books, together with the venerable tradition to which they belong, them.

(A) inopportune. . encourages

(B) fortuitous. fosters

(C) treacherous. .safeguards

(D) despicable. .legitimizes

(E) corrupt. .generates

5. The availability of oxygen is an essential for plant life for animal life, while carbon dioxide is equally

(A) choice. optional

(B) duplication. .selective

(C) conversion. .exchangeable

(D) condition. .necessary

(E) luxury. .harmful

6. Compared mathematically to smoking and driving, almost everything else seems relatively risk-free, almost nothing seems worth regulating.
(A) yet
(B) since
(C) so
(D) even though
(E) as long as 
Directions: In each of the following questions, a related pair of words or phrases is followed by five lettered pairs of words or phrases. Circle the lettered pairs that best expresses a relationship similar to that expressed in the original pair.

\section{ESCAPE : CAPTURE ::}
(A) warn : danger
(B) immerse : dampness
(C) feint : thrust
(D) dodge : blow
(E) invest : bankruptcy

8. CURATOR : ART ::
(A) functionary : administration
(B) archivist : documents
(C) referee : laws
(D) physician : research
(E) raconteur : stories

9. DISABUSE : ERROR ::
(A) rehabilitate : addiction
(B) persevere : dereliction
(C) belittle : imperfection
(D) discredit : reputation
(E) discern : discrimination

10. BUTTER : MARGERINE ::
(A) sugar : saccharin
(B) porcelain : tile
(C) photograph : painting
(D) music : tape
(E) signal : whistle

\section{COGENT: CONVINCE}
(A) irrational : disturb
(B) repugnant : repel
(C) dangerous: avoid
(D) eloquent : refine
(E) generous : appreciate

\section{MERCURIAL : MOOD}
(A) energetic : delirium
(B) jovial : conviviality
(C) fickle : affection
(D) martial : anarchy
(E) paranoid : suspicion 
Directions: Each question below consists of a word printed in capital letters, followed by five lettered words or phrase. Choose the lettered word or phrase that is most nearly opposite in meaning to the word in capital letters.

Since some of the questions require you to distinguish fine shades of meaning, be sure to consider all the choices before deciding which one is best.

\section{DOMINANT:}
(A) defective
(B) multiple
(C) inferred
(D) shifting
(E) recessive

\section{PERJURY}
(A) truthful deposition
(B) vivid recollection
(C) voluntary testimony
(D) inadvertent disclosure
(E) inexplicable fabrication

\section{DORMACY:}
(A) momentum
(B) hysteria
(C) availability
(D) activity
(E) cultivation

16. FACILITATE:
(A) evict
(B) thwart
(C) define
(D) make excuses for
(E) call attention to

17. EULOGY
(A) defamation
(B) fluctuation
(C) characterization
(D) hallucination
(E) deprivation

\section{NASCENT}
(A) widely displaced
(B) completely clear
(C) totally natural
(D) strongly contrary
(E) fully established 
Directions: Each of the following has five answer choices. For each of these questions, select the best of the answer choices given.

Questions 19-23 refer to the following floor plan.

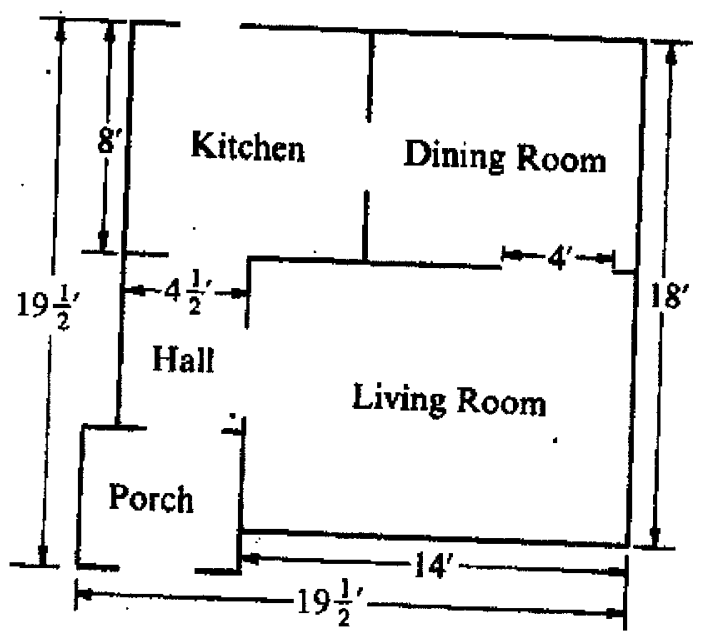

19. How many more feet does the porch extend in front of the house than it does beyond the side of the house?
(A) $1 / 2$
(B) 1
(C) $1 \frac{1 / 2}{2}$
(D) 2
(E) It cannot be determined from the information given.

20. If the hall is $6 \frac{1}{2}$ feet long, what is the perimeter, in feet, of the porch area?
(A) 18
(B) 19
(C) 20
(D) 21
(E) 22

21. If the ceilings and walls of the living room, dining room, kitchen, and hall are to be painted, how many square feet must be painted?
(A) $231 \frac{1 / 4}{4}$
(B) 324
(C) 333
(D) $3801 / 4$
(E) It cannot be determined from the information given. 
22. What is the area, in square feet, of the living room?
(A) 161
(B) 140
(C) 133
(D) 126
(E) 115

If the kitchen is square, what is the ratio of the area of the kitchen to the area of the dining room?
(A) $16 / 37$
(B) $3 / 7$
(C) $4 / 7$
(D) $8 / 11$
(E) 115

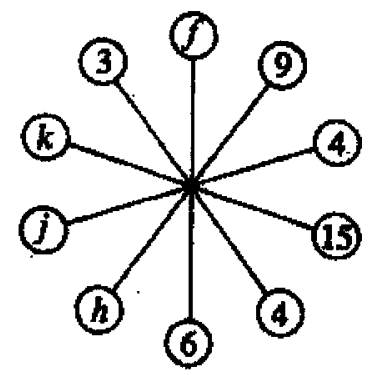

24. In the figure above, the product of any two numbers in adjacent circles is equal to the product of the two numbers that are opposite those circles. For example, $3 \cdot f=4 \cdot 6$. What is the value of $j$ ?
(A) 3
(B) 4
(C) 6
(D) 12
(E) 20

25 . If a certain company purchased its computer terminals for a total of $\$ 540,400$ and each of the terminals was purchased for $\$ 350$, how many terminals did the company purchase?
(A) 1,624
(B) 1,544
(C) 1,434
(D) 1,384
(E) 1,264 
Please Circle the option which applies

1. How well do you think you did on the IQ test?
Really well
Pretty well
Average
Below Average
Poor 


\section{Verbal Debriefing}

The study is now complete. I want to go over with you now the details of what we were trying to do with this experiment. Thinking back over the study, can you tell me what you think the study was about? [NOTE S's OBSERVATIONS]

What I told you at the beginning of the study wasn't the whole story, and I want to fill you in on what we are trying to do with this study and why we are doing it.

Studies have shown that individuals who consider both the negative and the positive outcomes in future challenging events demonstrate significantly better coping than those who use an optimistic strategy. When people consider a wide variety of outcomes - some positive and some negative, they are more likely to be prepared for these outcomes. People who just focus on the positive may be quite unprepared for failure.

This positive and negative type of thinking is considered to be a realistic orientation. We were trying to understand whether different thinking patterns would affect an individuals coping. We wanted to find out whether optimists and realists would benefit or be disadvantage by using alternative ways of preparing for a difficult test.

The test you took was not a real IQ test. The test was in fact made up of items drawn from real tests used by some universities to help select students who will do well in graduate school. We called it an IQ test as a way of motivating you to try your hardest.

Of the $\mathrm{XX}$ questions, you got $\mathrm{XX}$ correct. Given that you are not a graduate student, this score is [not bad/ quite good/ excellent].

We will not know whether the preparation strategy you were asked to use was effective (helped you do well) until we have analyzed all of the results. If you provide your email, I will send you a summary of our general findings when the study is complete in April.

Lastly, I want to ask that you do not tell other students who may be participating in this research about the fake IQ test that we have used today. If they knew about it beforehand, we would not be able to use their results as they could be biased.

If you have any further questions about the experiment, please let me know or contact any of the people who are listed on the debriefing sheet you have been given. 


\section{Written Debriefing}

Studies have shown that individuals who consider both the negative and the positive outcomes in future challenging events demonstrate significantly better coping than those who use an optimistic strategy. When people consider a wide variety of outcomes - some positive and some negative, they are more likely to be prepared for these outcomes. This balanced way of thinking is considered to be a Realistic Orientation, and can be contrasted to people who have an Optimistic or Pessimistic Orientation. In this study, we want to see whether the coping strategies that optimistic and realistic people use can lead people to perform better on a difficult test.

The following people are involved in this research project and may be contacted at any time if you have any further questions about the project, what it means, or concerns about how it was conducted:

Dr. Chris Davis, Dept of Psychology, Carleton University, 613-520-2600 ext. 2251

Stephanie Blust, Honours Student, Carleton University, 613-520-2600 ext.1448 Colleen Rainey, Honours Student, Carleton University, 613-520-2600 ext.1448 Ersin Asliturk, PhD Student, Carleton University, 613-520-2600 ext. 1448

If you have any ethical concerns about how this study was conducted, please contact Dr. Avi Parush, chair of the Carleton University Ethics Committee for Psychological Research, at 520-2600 ext. 6026 or Dr. Anne Bowker, Chair of the Dept of Psychology, 520-2600 ext 2648.

If you are feeling anxious or distressed, you can contact Carleton's Health and Counseling Services at 613-520-6674 or the Ottawa Distress Centre at 613-238-3311. 